\title{
Supporting the library and information needs of UWE health and social care students on placement: final report.
}

$\underline{\text { Research by: }}$

Pauline Shaw - Assistant Librarian, Glenside Library Jon Lloyd - Senior Library Assistant, Glenside Library

Project Manager:

Caroline Plaice - Faculty Librarian, Health and Life Sciences, Glenside Campus

Date: July 2013 


\section{EXECUTIVE SUMMARY}

Clinical placements for health and social care students now account for around $50 \%$ of their course time and are increasingly taking place in diverse and non-traditional locations. Alongside this, there has been a revolution in the means of access to, and development and availability of electronic resources and support services, which have lessened the importance of access to a physical library while on placement.

Changes in the UWE academic curriculum for health and social care students are beginning to change the nature of information resources required, and increasingly the library's role is to support a range of needs (both clinical and social, as well as academic) that impact on the overall placement experience of the student.

All this is happening against the backdrop of massive changes in the nature and potential modes of study for our students, where reliable access to the Internet means the ability to study where and when they choose, and has certainly seen a huge growth in students studying and accessing information at home.

Our findings and subsequent recommendations are based around:

- The importance of the holistic student experience on placement

- Students devoting more placement time to own study and clinical work, rather than for assignment completion or other academic work

- New technologies making access to the Internet and a range of electronic resources more widely available than ever, and making more study from home the norm rather than the exception for students on placement.

Our aim is that students on placement should consider themselves to be "out of sight, but not out of mind". 


\section{ACKNOWLEDGEMENTS}

We would like to thank the project manager Caroline Plaice for her unfailing support, advice and encouragement throughout the research. We also want to thank Geoff Glover at the HEA for funding the research project as well as for his support and enthusiasm. We are grateful to Professor Pam Moule for kindly reading through the report and offering her expertise.

We wholeheartedly appreciate the help shown by UWE library colleagues especially Fay for reading through the report and offering valuable advice; Hannah for her sterling work compiling and formatting the figures for the finished report; Phil for answering our very many questions about his current role; Emily for proof-reading the whole report, and Jason for providing us with the relevant background information.

We would like to thank NHS librarians in the South West for responding to our questions and supporting our students whilst on placement.

We could not have completed this without the help given by other UWE colleagues particularly Maggie Hehir for promoting our research among her students; numerous other members of UWE academic staff who also helped promote the questionnaire among their students; Louise Ford for agreeing to be interviewed; Dave Rogers for updating the PS Net so promptly; Liz Robinson and Tatiana Nurse (PPO) for adding our library questions to the placement evaluation questionnaire.

Finally, we would like to thank the students who participated in this research and all the other people who responded to our various requests for information. 


\section{TABLE OF CONTENTS}

Executive Summary 2

Acknowledgements 3

1. INTRODUCTION AND CONTEXT 10

1.1 Research title 10

1.2 Aims of study 10

1.3 Context and introduction 10

1.4 Background 11

1.5 Educating the NHS workforce and NHS libraries 12

1.6 Government policy and legislation $\quad 14$

$\begin{array}{ll}1.7 \text { Evidence-based practice } & 17\end{array}$

1.8 UWE strategic direction and new phase of partnership 19 working with NHS

1.9 UWE curriculum changes 20

1.10 UWE Library developments 20

1.11 Social and technological developments 21

1.12 Recent research 23

1.13 The future 23

2. LITERATURE REVIEW UPDATE 24

2.1 Brief summary of existing literature 24

2.1.1 Professional organisation and government policy $\quad 25$

2.1.2 Access to resources on placement 25

2.1.3 Other issues regarding placement experiences $\quad 25$

2.1.4 Support mechanisms 25

2.1.5 Community and non-NHS placement issues 26

2.2 Updated literature review 26

2.3 Desk research 28

3. RESEARCH DESIGN 31

3.1 Ethics 31

3.2 Research methods 31 
3.3 Focus groups 32

3.3.1 Recruitment 32

3.4 Online questionnaire 33

3.5 Semi-structured interview 34

3.6 Written survey questions 35

4. FINDINGS 36

4.1 What programme are you studying? 36

4.2 What is your current year of study? 37

4.3 Where was your last placement? 38

4.4 During your placement how frequently did you use the 39 following libraries?

4.5 At your placement venue, which of the following facilities 41 were available for your use?

4.5.1 Community 41

4.5.2 Hospital 42

4.5.3 Combined community and hospital $\quad 42$

4.6 Which of these facilities was most important to you? 44

4.6.1 Community 44

4.6.2 Hospital $\quad 45$

4.6.3 Combined community and hospital 45

4.7 How important was it for you to access library resources 46 while on placement

4.8 What was your main reason for using the library 47 resources?

4.9 Where did you do most of your studying? 49

4.9.1 Community 49

4.9.2 Hospital 50

4.9.3 Combined community and hospital 50

4.10 During your placement, from which location did you 52

access the following library resources?

4.10.1 Community 52

4.10.2 Hospital 53 
4.11 Do you have access to any of the following at home? 55

4.12 Before going on placement, do you feel you received 57

enough information about how to access library resources from off campus?

4.13 During your placement, how often did you contact any of 60 the following for support in using library resources or facilities?

4.14 Qualitative response analysis 61

4.14.1 Circulations / books 61

4.14.2 E-resources 64

4.14.3 Referencing 64

4.14.4 Mobile technologies 65

4.14.5 Library support 67

4.14.6 Time 68

4.14.7 NHS libraries

5. DISCUSSION 70

$\begin{array}{ll}5.1 \text { Summary } & 70\end{array}$

5.2 During your placement how frequently did you use the $\quad 71$ following libraries?

5.3 At your placement venue, which of the following facilities were available for your use?

5.4 Which of these facilities was most important to you? 72

5.5 How important was it for you to access library resources $\quad 72$ whilst on placement?

5.6 What was your main reason for using library resources? $\quad 73$

5.7 Where did you do most of your studying? 73

5.8 During your placement, from which location did you access $\quad 74$ the following library resources?

5.9 Do you have access to any of the following at home? 74

5.10 Before going on placement, do you feel you received $\quad 75$ enough information about how to access library resources 
off campus?

5.11 During your placement, how often did you contact any of the following for support in using library resources?

6. RECOMMENDATIONS 77

6.1 To have a named UWE NHS liaison and placement 77 librarian

6.2 UWE and NHS liaison and communication 77

6.3 Technological solutions $\quad 78$

6.4 Training and support $\quad 79$

6.5 E-resources $\quad 80$

6.6 Website improvements $\quad 80$

6.7 Next Steps $\quad 81$

$\begin{array}{ll}\text { 7.REFERENCES } & 82\end{array}$

$\begin{array}{ll}\text { 8.APPENDICES } & 91\end{array}$

APPENDIX 1 - Detailed breakdown of the Literature review search 91 strategy

APPENDIX 2 - Chart showing home, like home etc from 2010 Adult Nursing curriculum

APPENDIX 3 - Research questionnaire $\quad 94$

APPENDIX 4 - Janet 3G price list $\quad 97$

APPENDIX 5 - Academic in practice interview questions 99

APPENDIX 6 - Transcript of academic in practice interview 100

APPENDIX 7 - List of abbreviations 104

APPENDIX 8 - Practice Support Net page and individual documents 106 from this page

APPENDIX 9 - Details of the UWE Xternal Access (XA) System 113

APPENDIX 10 - How to access resources at a distance or on 116 placement

APPENDIX 11 - NHS Athens FAQs from UWE library webpages $\quad 119$

APPENDIX 12 - UWE staff guide to using Microsoft Lync 121 
APPENDIX 14 - List of NHS placement locations from Surveymonkey 123

APPENDIX 15 - Qualitative and quantitative outputs from Surveymonkey

APPENDIX 16 - NHS librarian responses

APPENDIX 17 - Visiting and using other libraries while at UWE

APPENDIX 18- Tweets to advertise Survey

APPENDIX 19 - JISC Mail posting

\section{LIST OF FIGURES}

FIGURE 1 - Respondents' current year of study

FIGURE 2 - Map showing potential placement locations

FIGURE 3 - How frequently respondents used the following libraries

FIGURE 4 - The facilities available on community placements

FIGURE 5 - The facilities available on hospital placements

FIGURE 6 - The facilities available on both hospital and community placement locations combined

FIGURE 7 - The importance of facilities to respondents on a community placement

FIGURE 8 - The importance of facilities to respondents on a hospital placement

FIGURE 9 - The importance of facilities to respondents on both a hospital and community placement combined

FIGURE 10 - The importance of accessing library resources whilst on placement

FIGURE 11 - The main reasons respondents used library resources

FIGURE 12 - Where respondents on community placements do most of their studying

FIGURE 13 - Where respondents on hospital placements do most of their studying.

FIGURE 14 - Where respondents on both hospital and community placements do most of their studying combined

FIGURE 15 - Where respondents on community placements 
accessed resources from

FIGURE 16 - Where respondents on hospital placements accessed resources from

FIGURE 17 - Where respondents on both hospital and community placements accessed resources from

FIGURE 18 - Which devices respondents were able to access from home

FIGURE 19 - The number of devices respondents had access to

FIGURE 20 - Did respondents feel they received enough information from the library about how to access resources off campus?

FIGURE 21 - How frequently respondents contacted us for support in using various library resources or facilities 


\section{INTRODUCTION AND CONTEXT}

\subsection{Research Title}

\section{Supporting the library and information needs of UWE health and social care students on placement.}

Research questions as follows:

i. What are the experiences of library and information resource support for health and social care students on placement?

ii. Does experience vary based on type of placement?

iii. In what ways could library and information resource support be developed and improved?

\subsection{Aims of Study}

This research seeks both to inform the development of a new service to support Health and Social Care students on placement, and to evaluate the first six months of that new provision in the second phase.

\subsection{Context and Introduction}

In the light of the changing landscape for health and social care students, the variety of placement locations and the development of electronic support services and resources, the University of the West of England, Bristol (UWE), is reviewing and developing Library Services support for students on placement. The Higher Education Academy (HEA) kindly agreed to fund this research project, and this is perhaps indicative of a growing and wider interest in the subject of support for students on placement.

The research was carried out at the Glenside Campus Library, which is the Health and Social Care Library of the University of the West of England. 


\subsection{Background}

Currently, there are service level agreements (SLAs) with three NHS trust library services. These were established at a time (in 2003) when students were predominantly on placement within acute (hospital) locations and the support of physical libraries, providing a range of print resources, was of particular value, and available to support the vast majority of students. In the light of changes in the education and healthcare landscape, and the new technology available to access resources, it was agreed, in conjunction with the HLS Dean, to terminate the current NHS Library SLAs with Bath, Swindon and Weston at the end of September 2013 when the current students based at Swindon complete their programmes.

NHS Libraries are directed through their organisations and the Learning and Development Agreement (Health Education South West, 2013) to support students in pre-registration healthcare education as part of the "NHS family" with entitlement to make use of NHS Library services and resources, particularly when they are out on placement.

According to the National Institute for Health and Clinical Excellence (NICE) Evidence Service website, Athens resources are available to eligible users within the "NHS Family" which includes:

Healthcare students, from the date of commencement of an NHS-commissioned education programme which involves practice and placement within NHS provider services, for the duration of their programme. (NICE, 2013)

Over recent years there have been massive changes in both UK higher education library expenditure on electronic resources and students' usage of electronic resources as reported by the Research Information Network (2011, all p.25) with particular reference to the period $2003 / 4$ to $2007 / 8$ 
Libraries shifted their spending patterns on resources to favour electronic content (journals, books and databases) over print. Spending on e-resources rose very significantly over the period (165.7[\%])

Spending on electronic (e-only and e+print) journals rose (141.7[\%]) while spending on print journals declined (80.9[\%]).

There was spectacular growth in the numbers of full-text article downloads (262.1[\%]). Usage at the new universities doubled (208.7[\%]) and more than tripled (356.7[\%]) at Russell Group institutions.

This shift has continued to such an extent that figures from 2010-2011 show "68\% of information provision expenditure now goes on the various electronic resources available". (Sconul, 2012, p2). This is in a climate where total library spending is actually lower than in previous years (Sconul, 2012).

Therefore, a "tipping point" may have been reached, where the nature of the partnership between university and NHS libraries may need to be reviewed, as access to academic resources electronically may be breaking down some of the traditional barriers (opening hours, location, stock levels) to accessing physical resources on placement. (Brettle and Urquhart, 2012)

\subsection{Educating the NHS workforce and NHS libraries}

The new proposal arising from Liberating the NHS: Developing the Healthcare Workforce, provides local education and training boards (LETBs) with the power to 'ensure that funding in the new system follows the student/trainee...' (Great Britain. Department of Health, 2012). There is at present no clarity on the way in which this funding source could benefit NHS libraries.

All NHS organisations in the NHS South West and six voluntary sector organisations currently receive funding from Health Education South West; 
the Local Education and Training Board for the South West. The Learning and Development Agreement sets out the obligations regarding education and training for the organisations who receive funding through this allocation. (Health Education South West, 2013)

The NHS Library Quality Assurance Framework (LQAF) (2012) was created to underpin the quality assessment and improvement of NHS Library Services. Its purpose is explained thus:

The underpinning aim of NHS library/knowledge services is to put knowledge to work, which in turn will transform patient care and public health. This aim will be supported by implementing the NHS Library Quality Assurance Framework (LQAF) England.... The Framework enables a robust quality assessment of library/knowledge services so that an organisation can assess its level of compliance to national standards and demonstrate the fitness for purpose that our 21st century health system demands. It provides a clear focus for action planning across all NHS organisations, driving forward a quality improvement plan, offering clarity of direction for service managers and transparency of development to meet business and client need.

(NHS Strategic Health Authority Library Leads, 2012)

The Standards cover five Domains of NHS Library Services provision for:

1) Strategic Management of NHS Library Services

2) Finance and Service Level Agreements

3) Human Resources and Staff Management

4) Infrastructure and Facilities

5) Library and Knowledge Services Service Delivery and Development

The domains covered by points 4) and 5) above would clearly have a considerable impact on the expected quality for library services for both health professionals and students accessing NHS library resources while on placement. 
At a recent South West NHS Library Managers meeting held in June 2013, a minimum specification for library services for students on placement was discussed and agreed, that students on placement can expect from NHS library services to have:

1. Access to collections;

2. Professional expertise;

3. Sign-posting to resources;

4. Study space;

5. NHS Athens, i.e. Open Athens;

6. IT access, but this will be subject to the policies of the Trust hosting the library;

This will be developed in detail through future meetings

\subsection{Government policy and legislation}

Ultimately, central Government policy, and professional body regulations and directives impact greatly on all aspects of the health and social care sector, with practice placements no exception. Plaice, in Walton and Booth (2004, p.39) says that the

ability to access and appraise information in order to improve decision making lies at the heart of government health strategy.

Nurse education made a seismic change in 1989 with the implementation of Project 2000, which began the process of transferring nurse education from hospital-based nursing schools to the Higher Education (HE) sector. Nursing is now an all graduate profession, with courses generally split between $50 \%$ theory in the HE setting, and $50 \%$ practical delivered on placement in clinical areas. With half of the course being delivered away from the host university and all the physical information resources and support it offers, a fresh approach to satisfying the information needs of students on placement should be considered and implemented. 
Health and social policy of at least the last two Governments has led to a greater emphasis on care being delivered in the community and voluntary sectors, and this shift has been echoed by educators seeking to increase the exposure to settings outside of the acute hospital environment for practice placement.

The NHS Next Stage Review documents which followed Liberating the NHS $(\mathrm{DoH}, 2010)$ confirmed a commitment to the increased prominence of the community, primary and voluntary sectors (including private and social enterprise providers) via some form of clinical commissioning consortia.

The Department of Health's own guidance notes Placements in Focus as far back as 2001 reinforced this message by calling for an increase in the "variety, extent and location of placement opportunities" through improved collaboration between "HEls and those who manage health and social care services, independent health care services and voluntary organisations" $(\mathrm{DoH}, 2001, \mathrm{p.15})$

The implications for information providers in trying to follow this shift in placement location and the consequent potential change to ease and method of access to resources are clear, and need an innovative and robust solution.

This was endorsed more recently in 2012 by the Council of Deans' response to the RCN Commission on nurse education, where they confirmed that

....as population needs and service models change it will become increasingly important that student nurses are educated to work across hospital, primary care and community settings ( $p$ 4)

Similarly, the Nursing and Midwifery Council (NMC) in 2010 stated that

Learning may take place in diverse environments in a range of settings In the NHS and elsewhere in the public, independent and voluntary sectors (NMC, 2010, p8) 
It is worth noting here, that the specific nature of being on placement in the community setting may cause different issues and stresses to that of a hospital placement. The existing literature suggests that this may impact on a number of factors that would affect the placement experience:

- The potential isolation of the role and the possibility of lone working can make it more stressful and can make the student/mentor relationship more difficult to maintain.

- The more specialised clinical nature of the community placement can lead to different stresses and problems.

- Possible lack of time and opportunity to select information resources for their practice (compared to nurses in the acute hospital sector) although lack of time for study while on placement is not an issue exclusive to students on a community placement.

Issues pertaining to students on community placements were explored by Baglin and Rugg (2010, p144) who stated that

the need for increased community nursing capacity must be balanced with adequate support for student nurses' learning needs during community-based placements.

The host university's own responsibilities are clearly mapped out by the Quality Assurance Agency who issued its Code of Practice (2007) for the assurance of academic quality and standards in higher education. Section 9 relates directly to work-based and placement learning. This required awarding institutions to

provide students with appropriate and timely information, support and guidance prior to, throughout and following their work-based and placement learning. (QAA, 2007,p.17). 
The most recent government intervention in healthcare comes in the shape of the recommendations from the Francis Report (Mid Staffordshire NHS Foundation Trust Public, 2013) that will impact upon pre-registration nurse training. The report suggests that people should gain three months' experience in patient care before enrolment to ensure that student nurses have the requisite attributes. Another recommendation states that

There should be an increased focus in nurse training, education and professional development on the practical requirements of delivering compassionate care in addition to the theory. (Mid Staffordshire NHS Foundation Trust Public, 2013, pp76)

This may have an effect on the type of practical training student nurses receive on placement.

\subsection{Evidence-based practice}

One of the main reasons for the more academic focus, is the evolution of a strong evidence base to the health profession, where educators now have to

prepare students to critically assess real world situations and then base their professional practice on the evidence available to them.

(Brettle and Urquhart, 2012, p21)

This is further endorsed by Emerson and Records (2008, p359) who argue that

the ultimate imperative facing nursing today is the creation of a culture that values the practice of nursing education and expands evidence-based education through the design, testing, and refinement of education strategies from nursing and other disciplines.

The centrality of the evidence-based curriculum within UWE is demonstrated by the refreshed nursing curriculum, where there is a new module in level 1 , 
Appreciating Evidence for Practice. This is developed in year 2 with the Evidence-Based Practice for Nursing and Midwifery module.

At a recent NMC validation, the modules were described as

an integral part of the nursing and midwifery curriculum

that promotes the importance of students' understanding the

need for health service improvement through the

implementation of evidence-based practices. (UWE, 2013)

The application of an evidence base to practice is confirmed by the NMC (2010) who stipulate that

All nurses must appreciate the value of evidence in practice, be able to understand and appraise research, apply relevant theory and research findings to their work, and identify areas for further investigation"

(NMC, 2010, p14).

and this is enshrined in the NMC regulatory code (Standards of conduct, performance and ethics for nurses and midwives, 2008).

The importance of the information needs of both students and qualified staff was evidenced in 2008 by two high-profile reports by Hill and Lord Darzi, with Darzi's High Quality Care for All (DoH, 2008) and its recommendation for the NHS Evidence (now NICE Evidence) service, being particularly indicative of the profile of health libraries and information access in policymaker thinking.

The continued relevance of the evidence-based practice curricula is demonstrated by two current initiatives. One is the opening up of access to NICE Evidence through NHS Athens logins for all eligible students from the start of their HE course, instead of placement-only access . 
The other is the Royal College of Nursing's (RCN) "How trustworthy is your information?", which is an information resource available to nursing students, and aims to

encourage learners to think about why trustworthy information

is essential to their practice, and what they can do to get the right information at the right time $(R C N, 2011, p .2)$

The RCN also set out in their "Helping students get the best from their practice placements" toolkit that effective practice placements should help students to

Reflect contemporary thinking within modern health care to evaluate the effectiveness of care provided, based on research evidence $(R C N, 2006, p 2)$

The central importance of understanding the principles of evidence-based practice for students on placements is again emphasised by Lea and Callaghan (2011, p 136) who maintain that it is

crucial that students are able to access appropriate resources whilst on placement in order that their practice is supported by current evidence.

\subsection{UWE strategic direction and new phase of partnership working with NHS}

As part of UWE strategic direction to maximise student experience and redirect resources:

- The UWE campus at Bath closed in March 2010

- UWE opened a campus in Gloucester (Alexandra Warehouse) September 2011

- UWE campus at Swindon closed April 2013 


\subsection{UWE Curriculum changes}

In the new 2010 curriculum, nursing students spend placements in 'Home', 'Like Home' or 'Near to Home' locations, often far removed from NHS libraries. This reflects the NHS strategies to both maximize the variety of locations and providers offering health and social care placements, and the patient choice imperative (see Appendix 2).

There has also been a recent attempt in the UWE Nursing curriculum to shift the emphasis of work for placement students away from theory concerns towards the essentially practice based. Time pressure is clearly a major issue for students on placement and this has been recognised by UWE with an aspiration for a smaller academic component on placement. A senior UWE academic with a remit for curriculum development advises that

All Nursing and Midwifery programmes are $50 \%$ theory and $50 \%$ practice, whilst every endeavour is made not to have submission dates whilst in clinical practice, due to the nature of the programme there will be times when a student will be writing an assignment when in practice but submit when they come back to the University. (Cox, 2013)

It is worth noting however, that some students may need to re-submit assignments or other academic work, and they may need to work on this (and access library resources) even if there is no formal assignment work due during the placement.

\subsection{UWE Library developments}

UWE Library's response to the enormous changes in the information provision landscape include:

- UWE Library Services are committed to spending half of its book budget on electronic books (in excess of $£ 50,000$ per year), and Health and Social 
Care now (figure at May 2013) have approximately 3,000 electronic books. This includes the very popular Royal Marsden Hospital Manual of Clinical Nursing Procedures.

- These e-books can currently be accessed on a wide range of mobile devices. Librarians are working with publishers/suppliers with regard to developing new models of access, in particular the extension of offline mobile access.

- UWE Library Services have continued to grow electronic journals provision and figures from the latest SCONUL annual return (figure at October 2011) indicates that approximately 50,000 e-journals are known to be available.

- We are making sure that the library website, and our other core online services such as Library Search (Summon), have websites that are mobile-friendly and have been designed "responsively" ensuring accessibility across all devices. (Wyatt, 2013)

- 24/7 Chat service has been available at UWE since August 2011. Chat is a 24/7 and 365 days a year real-time messaging service for UWE staff, students and members of the public to use. Between $10 \mathrm{am}-5 \mathrm{pm}$, queries are usually answered by a UWE librarian and outside these times, queries are answered by mainly US reference librarians (who have extensive access to UWE library policies and procedures) as part of the global cooperative. Similar systems are also used by the NHS and the Open University.

\subsection{Social and technological developments}

- There has been a revolution in the ways in which households access the internet and adults' use of computers in the last few years. This can be clearly illuminated by recent statistics from the Office for National Statistics (ONS):

- In 2012, 21 million households in GB (80\%) had Internet access, compared with 19 million (77\%) in 2011 (ONS, 2012) 
- In 2012, 33 million adults accessed the Internet every day, more than double the 2006 figure of 16 million, when directly comparable records began (ONS, 2013)

- The number of households with Internet access has increased by 7.1 million (23\%) since 2006, when directly comparable records began (ONS, 2012)

Internet access is not only from home desktop computers and laptops, but also via mobile phones, demonstrating the remarkable cultural shift that has taken place. This is mainly due to the dramatic increase in smartphone ownership which has risen from 28\% in December 2010 to 65\% in January 2013 according to Mintel's Digital Trends series of quarterly reports (Mintel, 2012 and 2013).

- Access to the Internet using a mobile phone more than doubled between 2010 and 2012 , from $24 \%$ to $51 \%$ (ONS, 2013)

- In $2012,58 \%$ of adults accessed the Internet 'on the go' either via Wi-Fi or mobile phones networks (ONS, 2013)

- Pertinently for this study, $80 \%$ of people aged between $16-34$ used a mobile phone to access the Internet (ONS, 2013)

- More recent figures from Mintel (2013) show that $27 \%$ of Internet users aged 16 and over now connect using a tablet device, which is an increase of 10 percentage points since September 2012.

Regarding the student population, the latest EDUCAUSE Center for Applied Research (ECAR) survey found that a remarkable $67 \%$ of students reported using their smartphone for academic purposes (Dahlstrom, 2012, p14). This figure shows substantial growth from 2011 when it was $37 \%$.

The composite of the statistics presented above shows that students are increasingly likely to consider accessing library resources from technologies other than fixed IT or desktops, especially via mobile devices. This has clear implications for the role of the physical library and the ways in which we 
deliver library services in a world where students expect to be able to access e-resources 24/7 anytime, anywhere.

\subsection{Recent research}

A recent $\mathrm{MSc}$ in Information and Library Management dissertation (Lloyd, 2012) suggested that the following trends were beginning to exhibit themselves with regards to the use and needs of information for students on placement:

- Access to information resources on placement is still seen as important.

- In terms of physical library, UWE libraries used more than NHS.

- Trend toward accessing e-resources from home or host university library.

- Access to computer/Internet on placement is very high.

\subsection{The future}

In 2012, Caroline Plaice articulated the Faculty vision for UWE placement support in the future:

the Faculty are committed to providing on-going Library support for students, who spend $50 \%$ of their programmes on placement. We have the opportunity now to rework and develop our offering from next year to provide a modern, student focussed liaison and support service. This has synergies with the wider Library Service in terms of its support as a whole for UWE as a 'Partnership University' and the continued growth of local, national and international partnerships, with an emphasis on support for students learning and working at a distance and equity in the provision available. 


\section{LITERATURE REVIEW UPDATE}

\subsection{Brief summary of existing literature}

A full summary of the existing literature relating to the experience of library support for nursing students on hospital and community-based placements can be found in Lloyd (2012). While this focussed specifically on comparing the differences in experience of library support for the two types of placement location (and looked exclusively at nursing students), it is still the most recent major survey of this sort and it is felt that the subject area and research sample of this dissertation is sufficiently relevant to be the starting point for this research.

Lloyd agreed with Riddington (2008, p.5) that there was a "dearth of literature concerning healthcare students' use of library and learning resources during clinical placement", with Raynor (2009) and Lloyd (2012) being the only two recent major surveys, and in general there being

little concerning the differing nature of the community and acute placement experience, and library solutions to their specific information requirements.

(Lloyd, 2012, p.13)

Broadly, the existing literature could be categorised in five ways:

1) Professional organisation and Government policy

2) Access to resources on placement

3) Other issues regarding placement experiences

4) Support mechanisms

5) Community and non-NHS placement issues 


\subsubsection{Professional organisation and Government policy}

Literature in this area looks at the impact of initiatives such as Project 2000 and Making a Difference and how they have impacted on nurse education and the prominence of practical training within that education. It also covers the current trends and impacts of legislation such as the reports by Hill (2008) and Darzi (2008), and how the growth of lifelong learning and evidence-based practice is shaping the information needs of students both pre-and postqualification. Lloyd also looked at the literature relating to the growth of the community and primary care sectors for placement provision.

\subsubsection{Access to resources on placement}

The existing literature is quite thorough in this regard and has been the subject of several major surveys such as Walton (2004), HENSAL (2002) and THESAL (2005). It covers access to resources by detailing the importance of accessibility, the issue of equality of access, and how the use of ICT and technology can facilitate this access.

\subsubsection{Other issues regarding placement experiences}

Within this section, the literature looks at a wide range of other issues that impact on a student's experience of their placement. These other issues cover topics such as lack of time outside clinical demands to engage with library resources, and the concept of a "ward ethos" (Koh, 2002,p.40) where the cultural environment of the clinical area can have a greater impact on the placement experience than any physical aspects.

\subsubsection{Support mechanisms}

Physical support in practice (placement mentors or link tutors), university support and communication options (including those supplemented by NHS library colleagues), and the importance and effectiveness of any pre- 
placement preparation are looked at in existing literature on support mechanisms.

\subsubsection{Community and non-NHS placement issues}

This section of the literature looks at issues which are particularly acute for community and non-NHS placements. There is little written with this as a specific focus (perhaps as this sort of placement location is still relatively new to the field as it maps the underlying political and social trends), and that which does

tends to look more at clinical and social issues such as lone working and isolation, rather than any learning resource issues that are peculiar to community placements. (Lloyd, 2012, p.24)

What is of interest however, is that many of the main historical surveys (Walton, 2004, Baird et al, 2005, Ward and Moule, 2006, Mailer, 2006) do seem to form a consensus that students on community and non-NHS placements can encounter additional difficulties accessing physical library resources and ICT provision due to their potential remoteness from a university or NHS library base. This view was not endorsed by more recent surveys (Raynor, 2009 and Lloyd, 2012) and may reflect the ways that Internet access and the huge recent growth in various forms of mobile technology have lessened this isolation and the pre-existing barriers to access of information resources.

\subsection{Updated literature review}

It was decided to use a similar search strategy to that employed by Lloyd (2012) (see appendix 1). A literature search was conducted using a broad range of both healthcare and information science databases to find any new research published since the previous review. 
Very few directly relevant journal articles about support for students on placement were found, but there is certainly much discussion and debate happening in the wider field of the use of mobile technologies, m-learning, Web 2.0 and social media both in education and the NHS.

Lea and Callaghan (2011) looked into mobile technology and the potential of mobile devices to meet students' information needs whilst on placement. This involved loaning iPods, PDAs, camcorders and WAP mobile phones on a trial basis for m-learning. The students identified some of the benefits of mobile devices such as their portability, ease of transportation and use. However, some students also found it difficult to read on the small screens.

Pacheco, Kuhn and Grant (2010) investigated the use of Web 2.0 among medical school librarians. Whilst a potentially relevant study, no specific uses relating to students on placement emerged from this article. Finally, a book chapter by Callaghan et al (2008) (in Needham and Ally) discusses the use of a guide for students to facilitate access to e-resources whilst on placement. The authors found that there was also a need for personal support for library resource issues alongside the guide.

Other useful reports were found either by snowballing other references or general Internet searching. These included two cases where technology has helped to improve the student placement experience. The University of Leeds (2010) developed an innovative loan scheme of smartphones to medical students. The iphones are preloaded with dedicated apps and copies of key medical texts which saves carrying heavy textbooks around during placements. The University of Plymouth (2012) has also implemented a unique digital book project. Initially, first-year psychology students got their reading list issued as 23 free e-books which they were able to access on their smartphones. This scheme has proved so successful that it has now been extended to include students from five other degree programmes. 
One of the students said

The e-book scheme is fabulous! Aside from the huge amount of money it saved me, the e-books are so much more accessible than the hard copies.

I can now carry twelve textbooks round with me on my phone and iPad... I can read during the commute to uni and even whilst I'm queuing to pay for my groceries. Similarly the search facilities are so much more effective and book marking and highlighting are especially useful. I've never used ebooks before and in all honesty I typically find reading a bit of a chore, but having the e-books really has made a world of difference (University of Plymouth, 2012).

\subsection{Desk research}

As part of the desk research, we sent various email requests for information. We emailed a librarian at the University of Suffolk with regards to her previous JISCmail posting in March 2012 about ways of improving support for nursing students on placement. The replies she received largely centred on placement or extended loans, special return arrangements or postal loans, and training around NHS Athens resources.

We also posted a similar question on both the UHMLG and LIS-Medical JISCmail lists (see Appendix 20). We only received three replies from UHMLG members and none from LIS-Medical. One particularly informative response was from the Brighton and Sussex Medical School (BSMS) detailing their Mobile Medical Education (MoMED) initiative, which includes providing a suite of key texts (DrCompanion app) to all year 3, 4 and 5 medical students for use on their smartphones. This has proved very successful and "feedback from students repeatedly reveals high levels of satisfaction with the software, which enables them to access up-to-date information when and where they need it, and learn more efficiently" (BSMS, 2012). 
Another interesting point made by our colleagues in Sussex was that they have

a once a year get together, where we look back at all the feedback from the 3 placements for Year 5 and respond to that. We have ensured that the evaluation of the placement survey which students complete on leaving their placement includes a question relating to how good or bad the library was.

We also used the Glenside library Twitter account to ask whether anyone was using technology or social media to support students on placement (see Appendix 19), but this did not yield any responses.

Aware of the benefits that Wi-Fi enabled technology could bring to students with their own mobile devices, we decided to find out more about the Wi-Fi provision in the NHS in the South West. A leading NHS knowledge manager advised that

Wi-Fi is available within many Trusts, but largely in the postgraduate centres. It is not always available in the NHS libraries and unlikely to be available on the wards. The latest statistics we have are for Sept 2011 which explained that of the 36 service points in the South West we had 11 with Wi-Fi access. It is very likely that this figure will have increased in 2012 and again in the first half of 2013. Community settings are unlikely to provide access to Wi-Fi.

We also contacted the NHS-HE Co-ordinator at Janet and facilitator of the NHS-HE Forum who explained that it is possible for University Eduroam Wi-Fi networks to be extended to the NHS for visitors and the Bristol Royal Infirmary is one example where this has happened. Weston Area Health NHS Trust has also recently used the N3 Janet gateway for the authentication of traffic via Bristol University, so this seems to be happening on a site-by-site basis.

This is supported by research from the Epic / NHS South of England (Central) in 2012 which also reported that "individual Trusts are starting to upgrade Wi-Fi access" (p32). 
We understand that the current N3 infrastructure is being reviewed in the next few years by the Health and Social Care Information Centre, and it is hoped that this will increase the availability of secure wireless networks in hospitals. The potential implications of this will be discussed further in the recommendations. 


\section{RESEARCH DESIGN}

\subsection{Ethics}

Prior to any research being carried out, an application was made to the University of the West of England's Faculty of Health and Life Sciences Research Ethics Subcommittee for ethical approval of the research, and this was granted.

The interests of participants should be protected by the researcher by ensuring that any information disclosed during the research is treated as confidential and that their anonymity is guaranteed (unless explicit consent to identify responses is gained). Questionnaires and consent forms were stored separately and no personal or identifiable data was collected on the questionnaire. Interview transcripts, taped recordings and analyses were stored separately from consent forms and again confidentiality was assured.

\subsection{Research methods}

It was considered that elements of both a qualitative and quantitative approach would complement the research, and consequently a mixed approach was decided upon.

The research methods chosen were:

1. Focus groups for students.

2. Online questionnaire using SurveyMonkey for students.

3. Semi structured interview with UWE academic in practice and UWE nursing student on placement.

4. Written survey questions for four NHS libraries taking UWE students on placement, and the NHS Liaison and placement librarian at UWE.

Looking at each of these areas in more detail: 


\subsection{Focus groups}

The research strategy included using focus groups and questionnaires to a sample of year 2 and year 3 students across health and social care programmes.

We targeted these students for similar reasons to Mailer (2006):

it was thought that second and third/final year students would provide the most valuable information as their placements were longer) and the students were more experienced in using learning resources. (p112)

The purpose of the focus groups was to obtain high quality feedback and gain real insight into the students' experience of placements. It was hoped that we would be able to discover what the main issues and problems were in terms of accessing library resources and that these would generate a rich source of data which we would then be able to explore further in the follow-up survey.

\section{$\underline{\text { 3.3.1 Recruitment }}$}

A focus group (with lunch included) was planned for each school i.e. Nursing and Midwifery (N\&M), Allied Health Professions (AHP) and Health and Applied Social Sciences (HASS). By opening up our research to a wide range of programmes, we extended the potential research sample over and above what other recent surveys of this sort have done.

Despite extensive promotion from both the researchers and academic tutors, we were unable to recruit any students for a focus group. This may reflect the fact that time is very precious to students when on placement and the main focus of their attention and energies are directed towards the specific experience of the clinical placement rather than on any library-related issues. 
The decision was taken on February $13^{\text {th }} 2013$ not to run any focus groups due to the lack of responses. Since then anecdotal evidence within the University has shown that it is notoriously difficult to run focus groups with students, no matter what the incentives. The absence of focus groups has however hampered the design of the research and subsequent analysis of the results, as several subsequent lines of enquiry would have proved more effective had focus groups been in place to inform the questions asked, and to find out first-hand information from students about their placement experiences. It is a recommendation that in the second part of the research (the evaluation phase) we work more closely with the Faculty to get participants for focus groups.

\subsection{Online questionnaire}

An online questionnaire using the SurveyMonkey (see Appendix 3) software package was employed as this is frequently used by UWE for information gathering. Previous studies (Lloyd, Riddington, HENSAL, THESAL, Raynor) had used a similar method (although not always an online survey) successfully, which allowed both an element of confidence in it as a tested method, and the opportunity for comparison and contrast with these earlier studies.

To utilise previous successful experiences, questionnaires used by similar studies were identified and their format and questions helped inform this research. A combination of open and closed questions were used. The closed questions would, as described by Olsen (2012, p.119) tend to encourage completion by making the "questionnaire work much more quickly", and the open questions allow for greater richness and personal insight into a participant's responses. It was recognised that open questions can discourage completion by requiring greater effort from the participant, and can be time-consuming to analyse (Denscombe, 2010, p.166). Another advantage of closed questions is that they encourage consistency of 
responses which improves reliability and efficiency of analysis (Burns, 2000 \& Denscombe, 2010).

We offered a $£ 30$ book token prize, the recipient of which was chosen at random, as an incentive for completion. The survey was promoted quite heavily at Glenside Library, by email from the researchers, via the Library website by means of an attractive advert on our subject pages, on Twitter and on BlackBoard by some academic tutors. We also used bookmarks (Appendix 16) with information and the web address, and these were placed in reserved books for collection in the library, given out by librarians in teaching sessions, and sent to selected NHS libraries within our region.

The online survey was open from Jan $22^{\text {nd }}$ to March $4^{\text {th }} 2013$.

In total 326 questionnaires were started, of which 252 were completed. $45 \%$ were considered to be related to a community-based placement and $55 \%$ a hospital-based placement (although this allocation was based on the names of places participants had stated as their most recent placement location, so is open perhaps to question or interpretation). This resulted in a $10 \%$ response rate of the students within three of the five Departments that make up the Faculty, and was felt to be a sufficient sample for the purposes of the report.

\subsection{Semi-structured interview}

It was felt that another data collection method would be beneficial to the research aims, in order to provide what Denscombe (2010, p.346) describes as "methodological triangulation", to allow for corroboration or questioning of the findings. It was decided that a semi-structured interview with an appropriate party would provide this opportunity through their ability to: explore topics in depth and detail; provide a flexible approach allowing for potential new lines of enquiry to be opened up as the interview progressed; 
and produce quality data based on "informants' priorities, opinions and ideas". (Denscombe, 2010, p.192)

The participant was identified due to the nature of their role in placement support at UWE. A semi-structured interview (see Appendix 4) was designed where a pre-set list of questions and issues were provided to the interviewee in advance for consideration, essentially to provide a basic structure, where topics could be expanded on and issues raised, subject to some flexibility. This approach was explained to the interviewee prior to the interview, so they knew that points of particular interest could be elaborated on as necessary.

\subsection{Written survey questions}

Information was also required from some parties who we were unable to meet for face-to-face interviews, or for whom time meant we could not do this. We identified the UWE NHS liaison and placement librarian along with some NHS librarians as suitable candidates. A written survey with a series of questions was provided for the individuals/groups in question, and they were asked to complete the form and return by email. The written questions allowed for a follow up by e-mail or telephone if any clarification was required or further information needed. 


\section{FINDINGS}

\subsection{Question 1 - What programme are you studying?}

The research gained responses from 252 students on a wide range of courses within Health and Social Care. This spread of courses is fairly unique in terms of the breadth of its scope, as many other similar surveys have focussed on a particular area or speciality. This has enabled the researchers to access the experiences of a wide range of students and scenarios.

\begin{tabular}{|l|l|}
\hline Programme & $\begin{array}{l}\text { No of } \\
\text { respondents }\end{array}$ \\
\hline Adult nursing & 102 \\
\hline Mental health nursing & 26 \\
\hline Children's nursing & 24 \\
\hline Midwifery & 15 \\
\hline Occupational therapy & 14 \\
\hline Social work & 13 \\
\hline $\begin{array}{l}\text { Specialist community public health } \\
\text { nursing (SCPHN) }\end{array}$ & 13 \\
\hline Radiotherapy & 8 \\
\hline Learning disabilities nursing & 7 \\
\hline Physiotherapy & 4 \\
\hline Diagnostic imaging & 3 \\
\hline Sports therapy and rehabilitation & 1 \\
\hline Other & 22 \\
\hline Total & $\mathbf{2 5 2}$ \\
\hline
\end{tabular}




\subsection{Question 2 - What is your current year of study?}

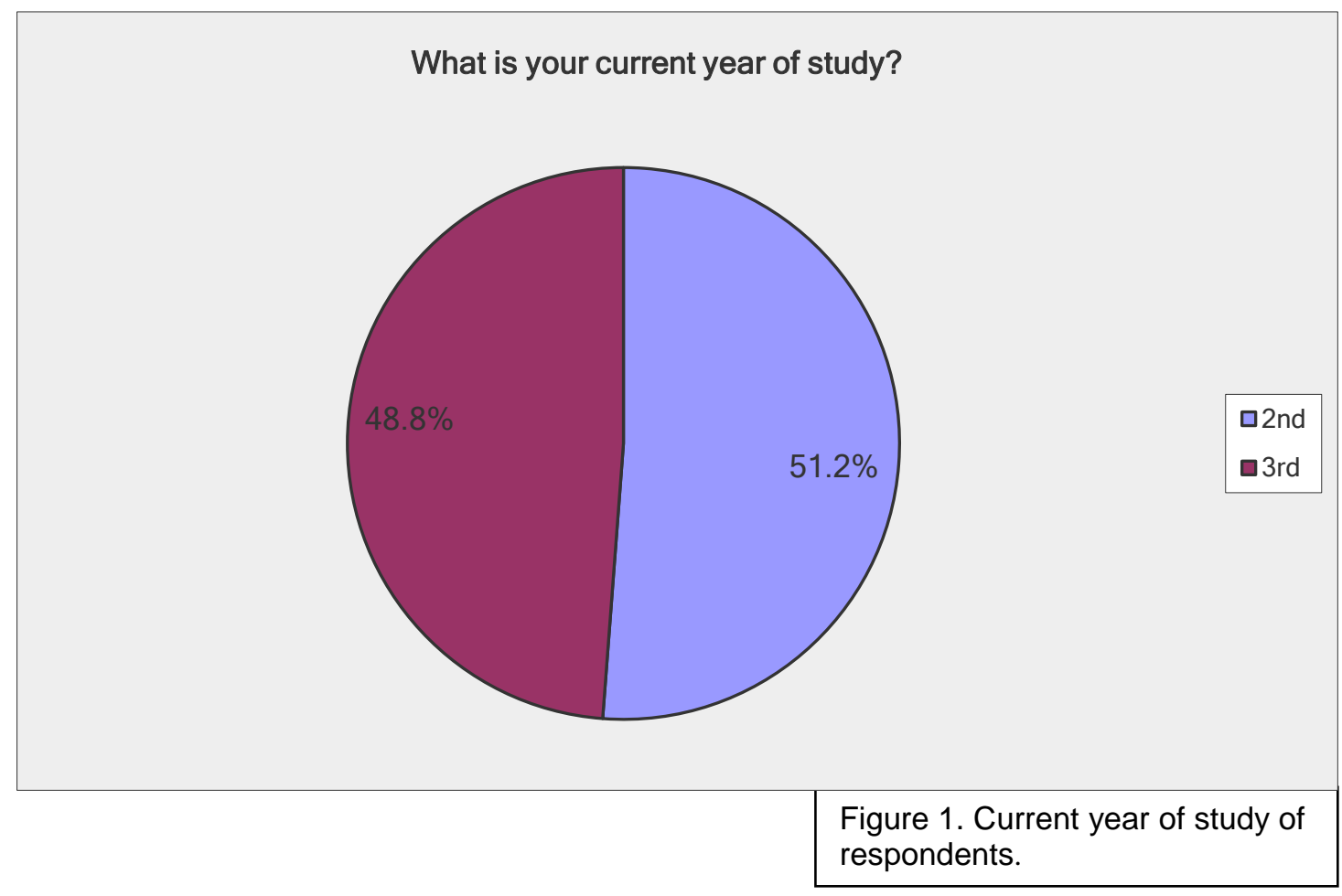

It is interesting to note that we got an almost equal response from both level 2 and level 3 students, which gives a good range of potential placement experiences. It was felt to be useful to the research that a good proportion of returns came from level 3 students who we would expect to be accessing a range of library and information resources in preparation for completing their dissertation. 


\subsection{Question 3 - Where was your last placement?}

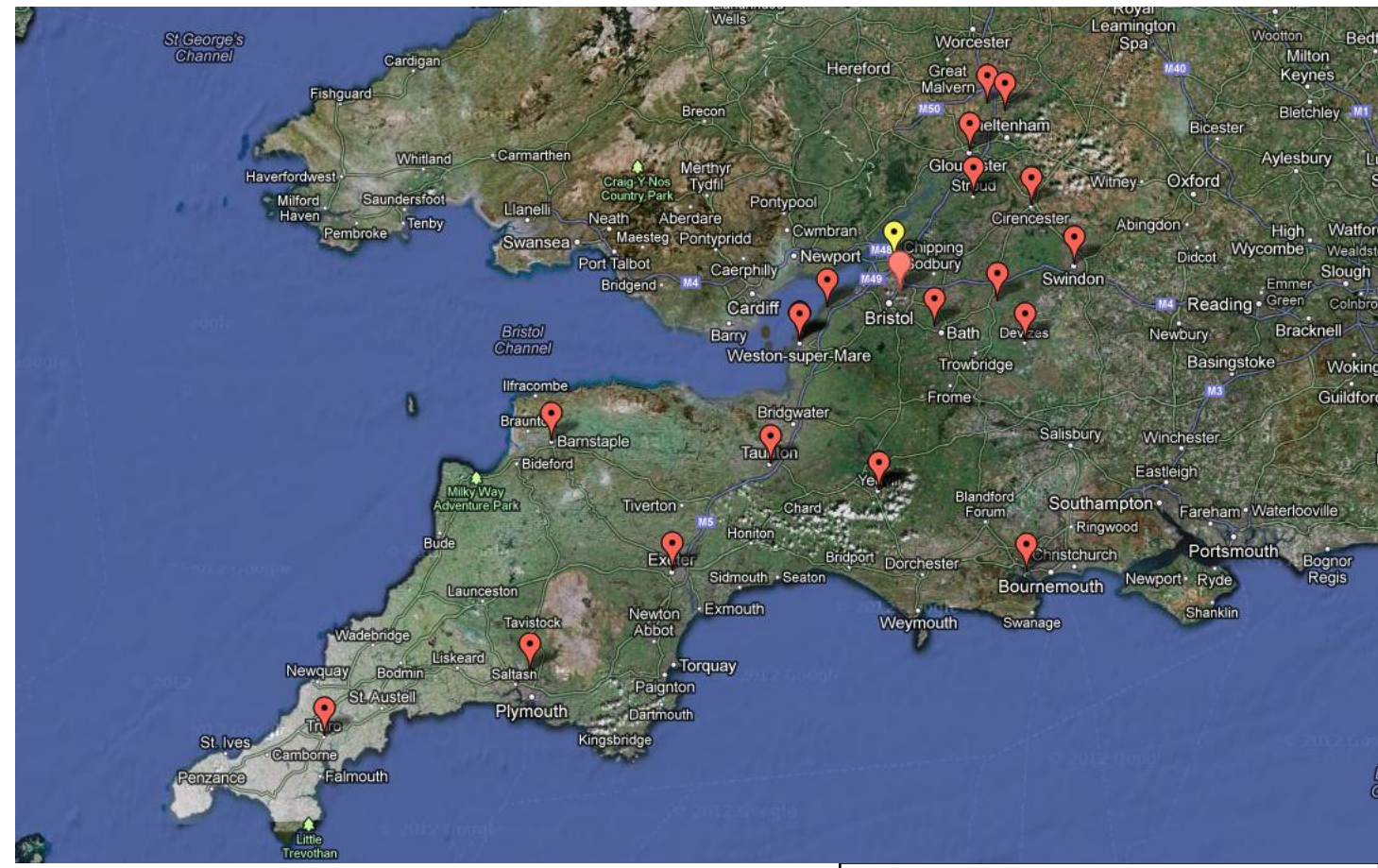

Figure 2. A map showing potential placement locations.

The map clearly indicates the wide range of placement locations in terms of geography and also shows the potential isolation and distance from the host university library in Bristol (Appendix 17). This sense of distance from the base university library was touched upon by some respondents:

\section{Too far to drive to actually come to library}

Living and being on placement so far away, returning resources within the time restrictions is not always easy

When analysing the results for subsequent questions, we divided the responses up in terms of where their placement location was - either community or hospital, based on our understanding of where these sites were. 


\subsection{Question 4 - During your placement how frequently did you use the following libraries?}

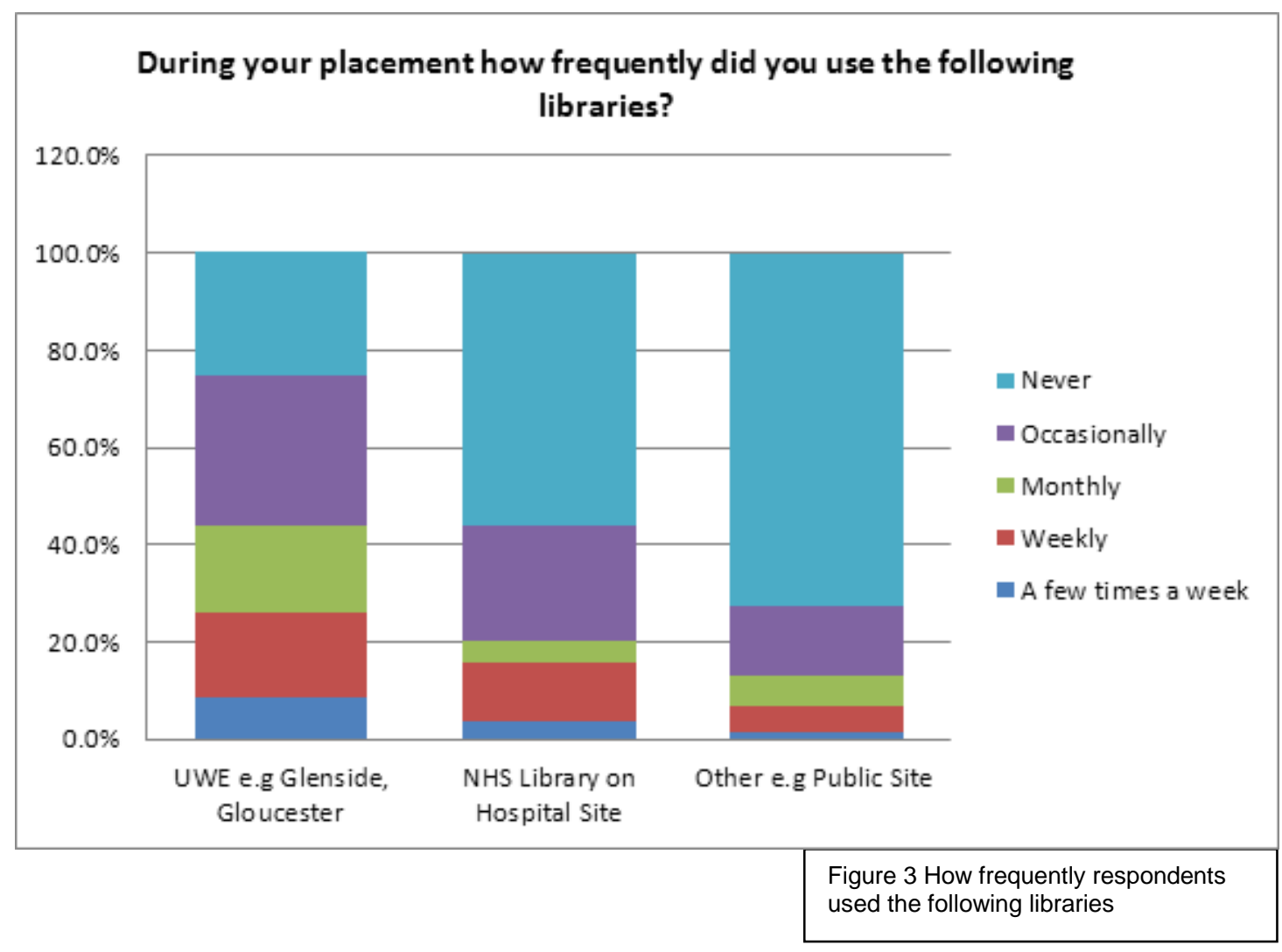

The research suggests that students' use of NHS libraries on hospital sites is low. There is in fact a significant percentage of students who never use NHS libraries. This is reinforced by qualitative responses from NHS library colleagues. To the question "How many queries a week do you get from UWE students?" the replies were:

We don't record this information but would estimate it to be around 5-10 queries per week.

Very few 10

Although it was suggested that it is not always easy to identify visitors as UWE students unless they are in uniform or identify themselves as such. 
When asked "Please estimate how much time (hours/mins) that you spend dealing with queries from UWE students per week?" the NHS library responses were:

\begin{abstract}
Most enquiries are answered within a couple of minutes but if we help someone with a literature search/critical appraisal then we may spend up to an hour with them
\end{abstract}

\title{
Less than 30 mins
}

\section{5 hours}

UWE libraries are used more, but still largely only weekly, monthly or occasionally, although only a small proportion never use this library option when on placement. A student commented that

No facility near my placement (community in Clevedon) only access to UWE library during days at UWE (once a fortnight).

There were also a significant number of students who stated that they simply did not have the time to use the library whilst on placement:

I have never had the chance to use the library during placement time, neither at UWE or an NHS library.

The time is not given to go off and do this

I don't feel there is a need to access library during placement as we are all far too busy and e-books are more convenient

A small number of comments about the suitability and extent of opening hours in the qualitative responses suggest that there are still some perceived problems with these issues, however this may be largely due to lack of awareness. 
4.5 Question 5 - At your placement venue, which of the following facilities were available for your use?

\subsubsection{Community}

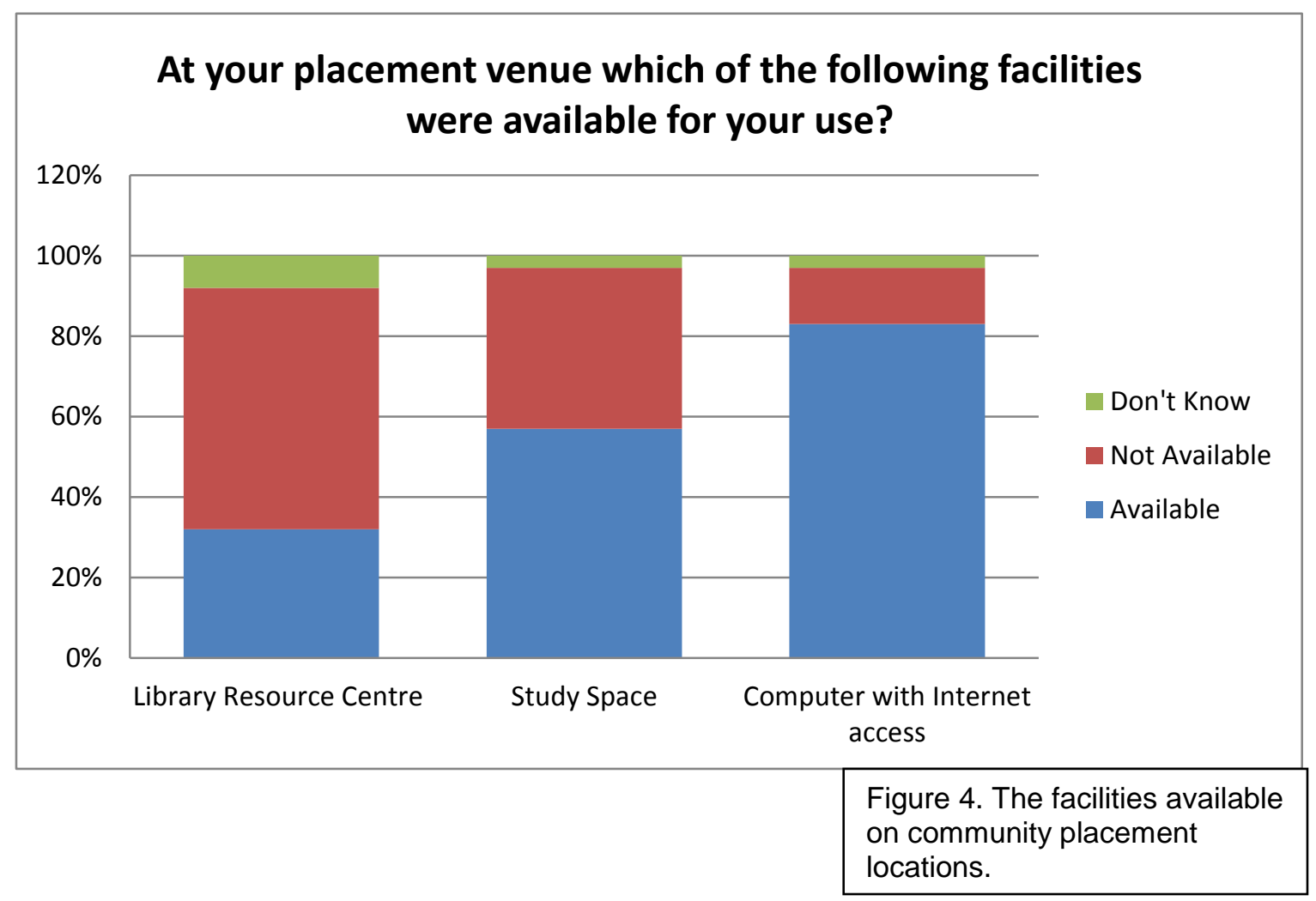




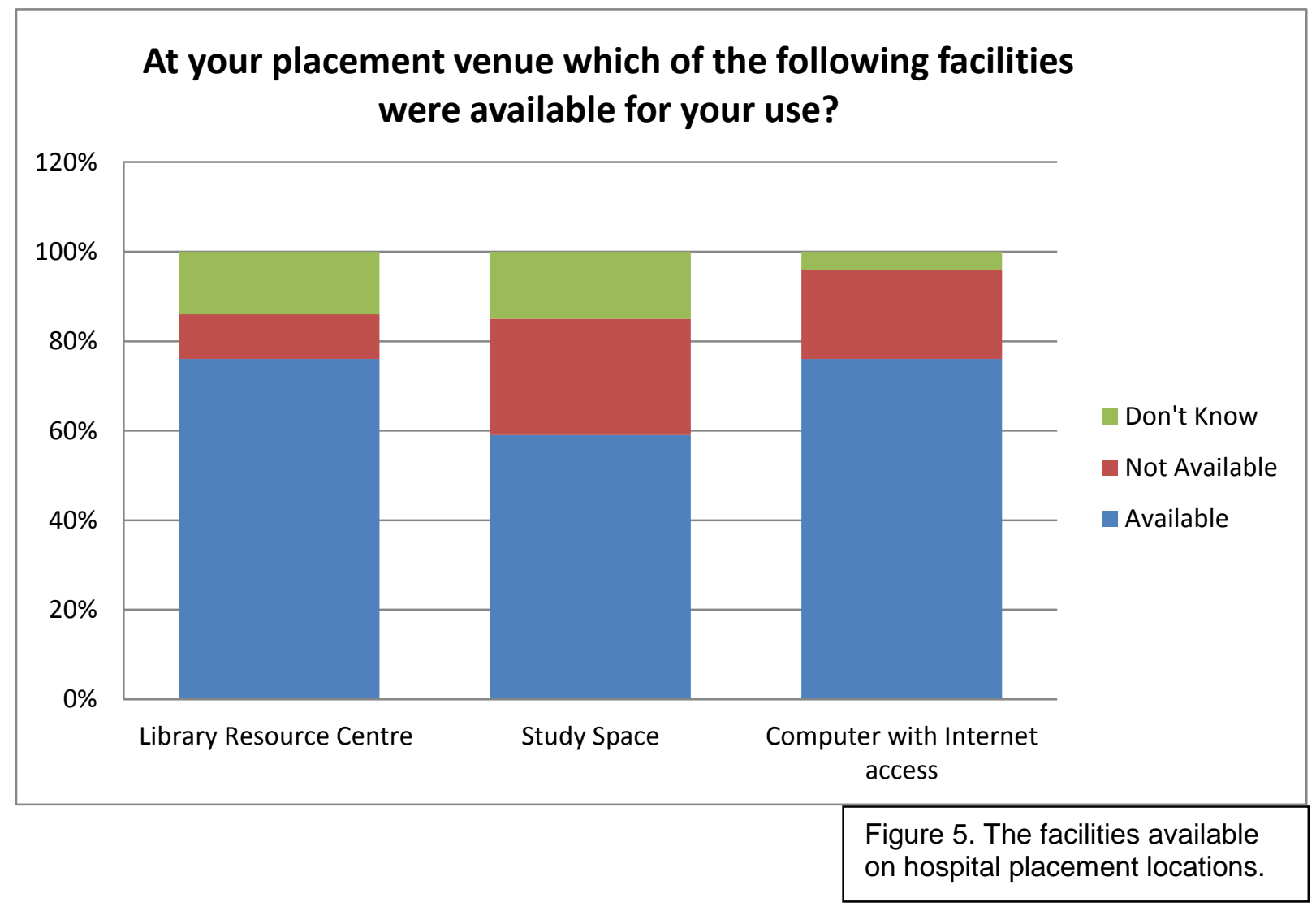

4.5.3. Combined community and hospital

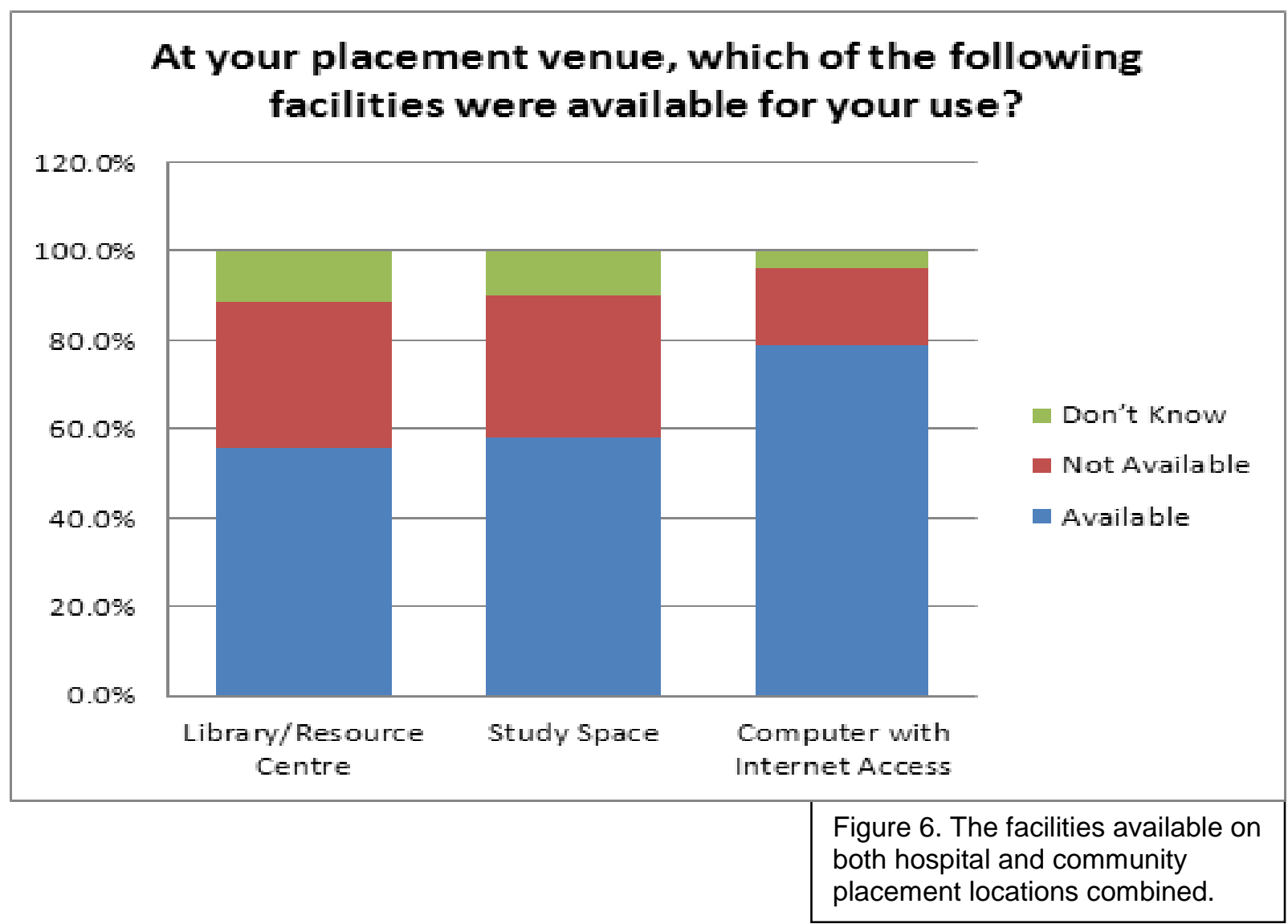


The vast majority of students (78\%) report that they have access to a computer with Internet regardless of site. Overall there is

- Parity of access to computer with Internet between hospital and community

- Parity of study space between hospital and community (slightly lower in community)

- Access to a library / resource centre in the community setting is lower than hospital as expected, and may increase the sense of isolation for these students

Echoing Lloyd (2012), some students continued to report a frustration with access to computers both on hospital wards and in the library

Have to ask the registered nurse for a password to get onto the internet at work

Problems logging on at start

Frustrating not being able to access internet from $R U H$ computers because don't have an RUH log-in.

and there would also seem to be variations in ease and reliability of access depending on where the students work.

Figure 6 shows that some students either don't have access or don't know about these facilities

I only found out about NHS library through another student and not placement mentor or other staff

I live in Exeter so it would be good to know how to access local NHS libraries when on days off 
A flaw in these statistics may be that we are unsure how many students with their own device have not known how to interpret the question as the wording could be seen as ambiguous.

\subsection{Question 6 - Which of these facilities was most important to} you?

4.6.1 Community

\section{Which one of these facilites was most important to you?}

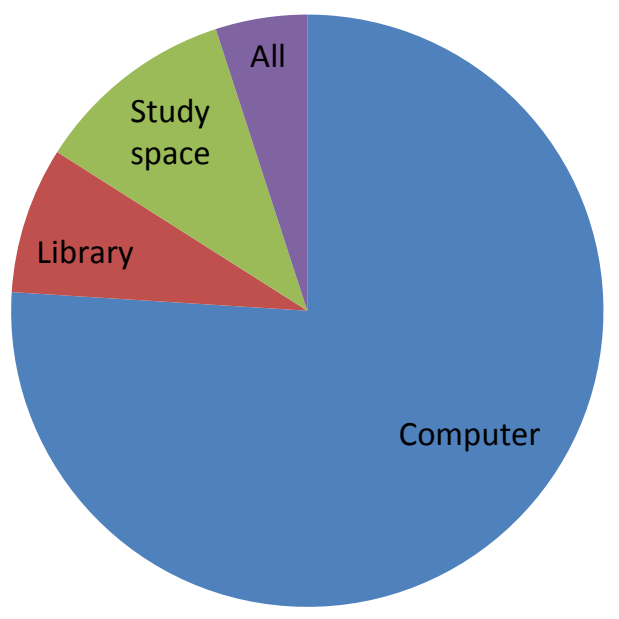




\section{Which of these facilities was most important to you?}

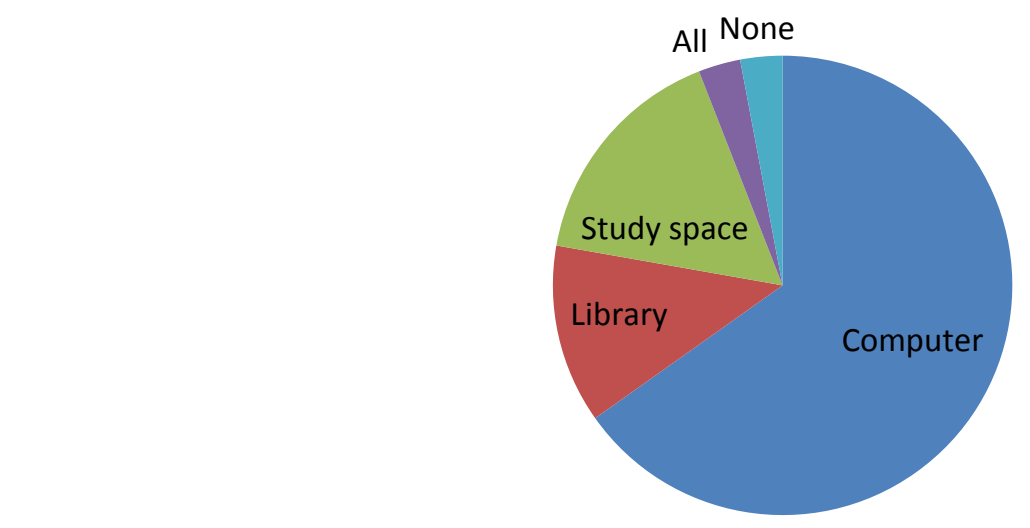

Figure 8. The importance of facilities to respondents on a hospital placement.

4.6.3 Combined Community and Hospital

Which of these facilities was most important to you?

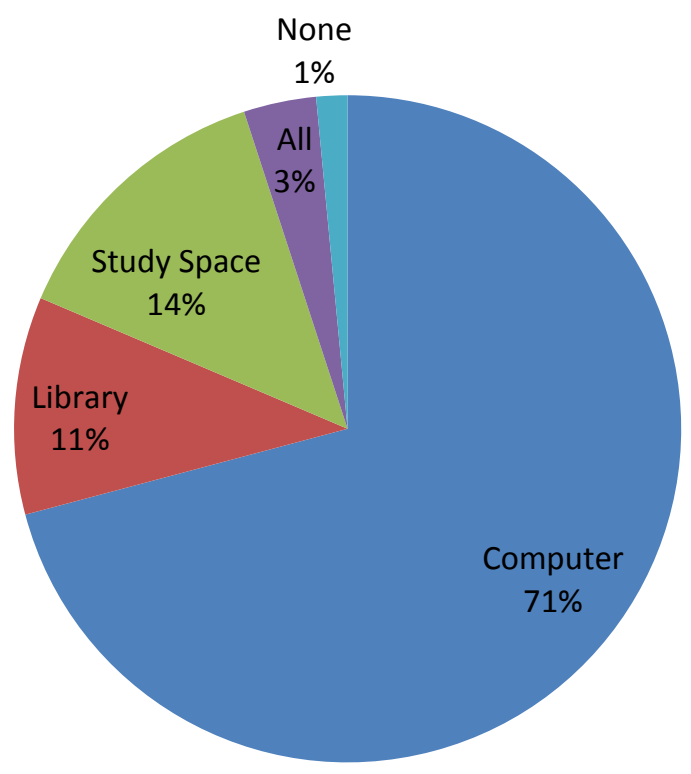

Figure 9. The importance of facilities to respondents on both a hospital and community placement combined. 
Access to a computer is clearly the most important facility that students want from their placement location

I feel there should be a dedicated computer(s) resource area for students to have access to whilst on placement 24/7

What we are unable to ascertain from our question is the actual importance of a library or study space to students on placement and had we been able to carry out focus groups, we would have been able to ask more pertinent questions and gain more insight regarding student experiences. i.e. what information they were accessing or using.

\subsection{Question 7 - How important was it for you to access library resources whilst on placement?}

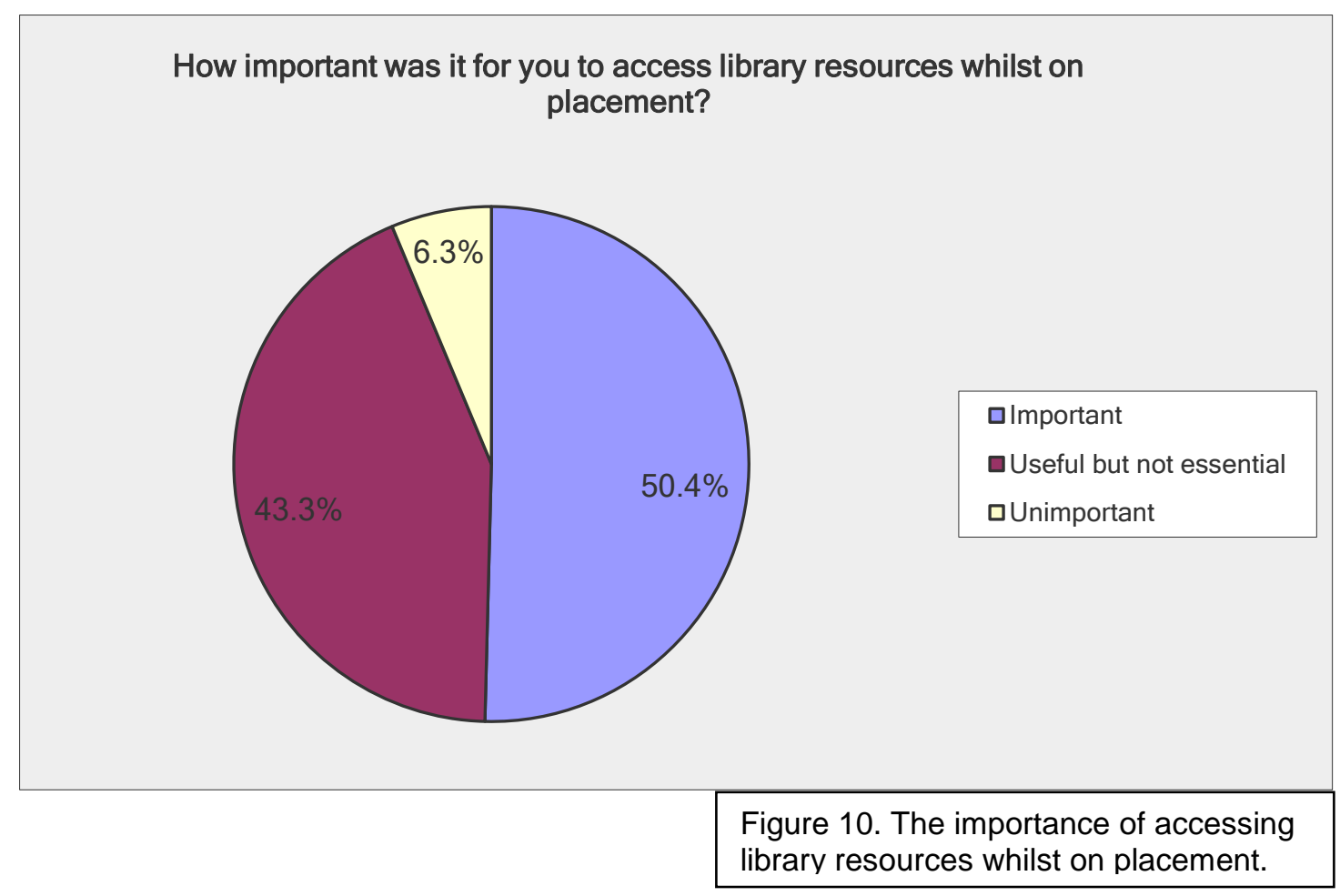

The research indicates that over $90 \%$ of students think that accessing library resources is important or useful, but only $50 \%$ think it is important. Riddington's (2008) research revealed that UWE nursing students viewed access to library resources when on placement as very valuable, and this is 
endorsed by the findings of Walton (2004), HENSAL (2002) THESAL (2005) and Lloyd (2012). This new research is broadly consistent with the past studies, although previous studies tended to have consistently higher figures for "important" (THESAL reports $98 \%$ as important or very important) and no respondents saying that access was unimportant.

Interpretation of what constitutes "library resources" may account for some confusion and interpretation problems. This may relate to some people saying it is unimportant.

\subsection{Question 8 - What was your main reason for using library resources?}

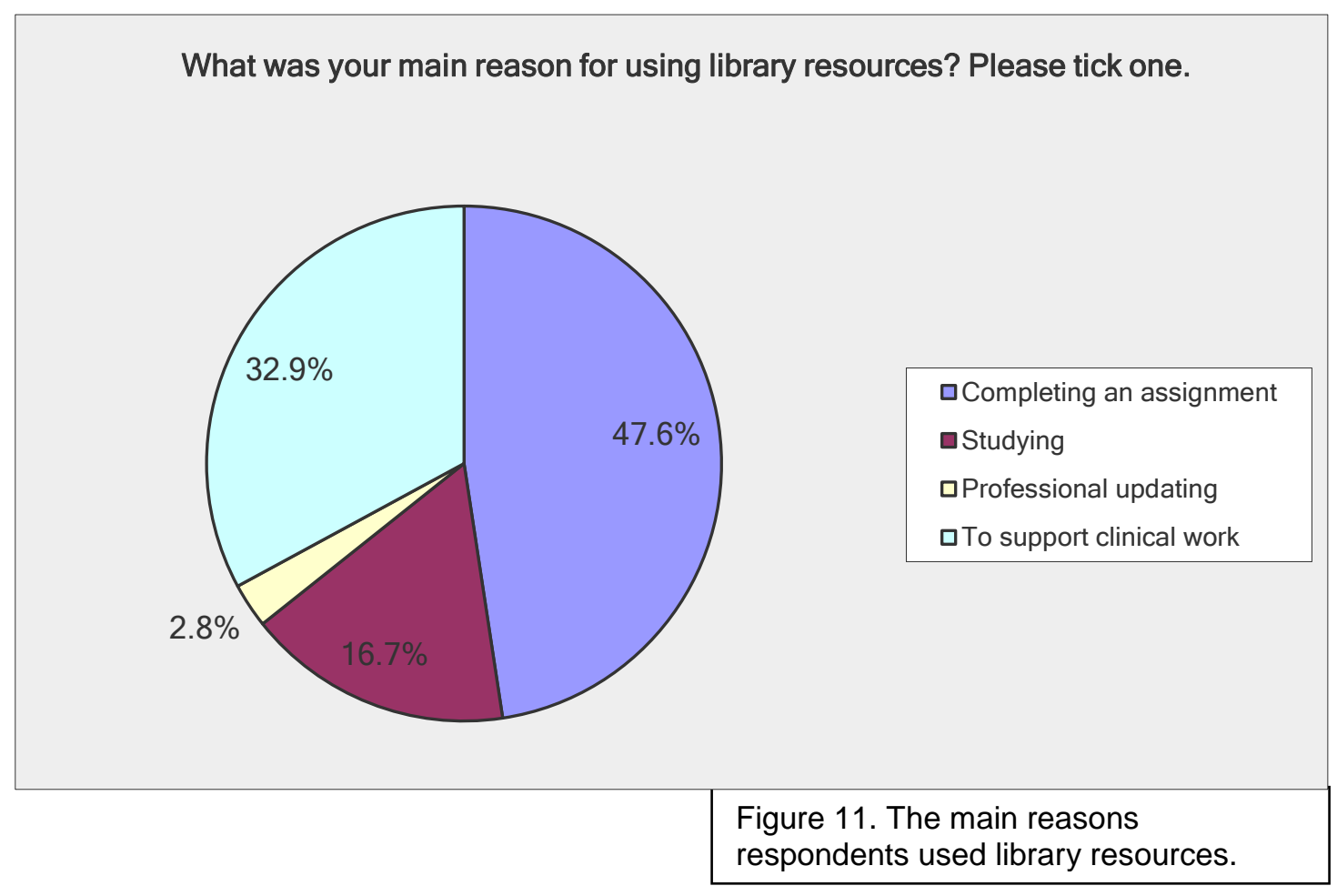

The research shows that $47 \%$ mainly used library resources on placement to assist with completing an academic assignment, and 33\% to support their clinical work. A significant percentage (17\%) also said they used library resources for general studying purposes. Previous studies found much higher percentages of students used library resources for completing assignments (Riddington, 2008, p30), although our question only allowed for one answer, so this is possibly not a directly comparable statistic. However, it would 
appear that completing an assignment is becoming less important whilst on placement.

This is an area where the opportunity to ask more detailed questions at a focus group would have given us much richer data on exactly what students use library resources for on placement.

A wider question that could have been asked would be what students use Internet access for on their placement? We have had the opportunity to discuss this with one member of academic staff who deals with students on placement, as well as another who asked students on our behalf on a Supervision of Learning (SOL) day.

The students who were canvassed during their SOL day gave us some interesting feedback on their use of the Internet for UWE academic work and for clinical placement work (they made the distinction).

Some students reported that they do not have time to do UWE work when on placement as

there are no assignments set so no need to read

which suggests a real division between theory and practice in the mind of the student.

Some said they do the clinical work (look up clinical conditions and so on, that they need to understand) when they get home, but would use Google in preference to the UWE library

because it is quicker and easier to access than UWE library.

Most of the students agreed that they

only use UWE library for references otherwise Google is used. 
Some students said when they have used the UWE library search facility it comes up with random stuff in a way that Google does not

and that they

like the quickness of Google.

A strong theme that also came out from both respondents was that students appreciate Internet access on placement for a range of issues that are both of academic use and of personal or leisure use and this will be discussed further in the discussion and recommendations.

\subsection{Question 9 - Where did you do most of your studying?}

\subsubsection{Community}

\section{Where did you do most of your studying?}

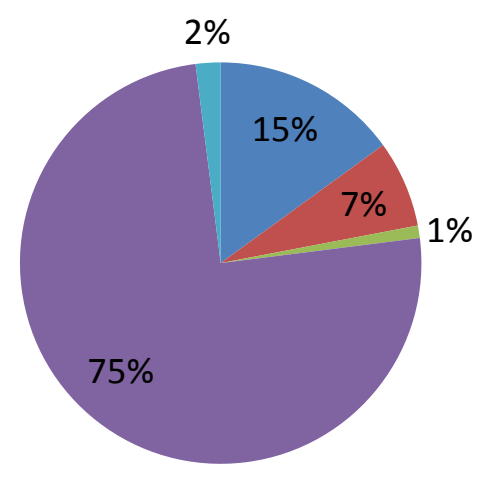

UWE Library

NHS Library

Other Library

Home

Other studying. 


\section{Where did you do most of your studying?}

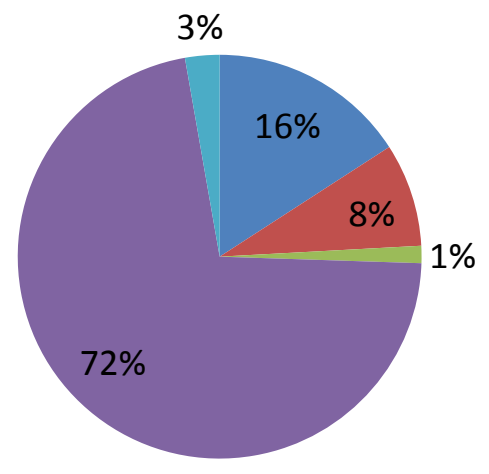

- UWE Library

NHS Libray

Other Library

Home

Other

Figure 13. Where respondents on hospital placements do most of their

4.9.3 Combined community and hospital

\section{Where did you do most of your studying}

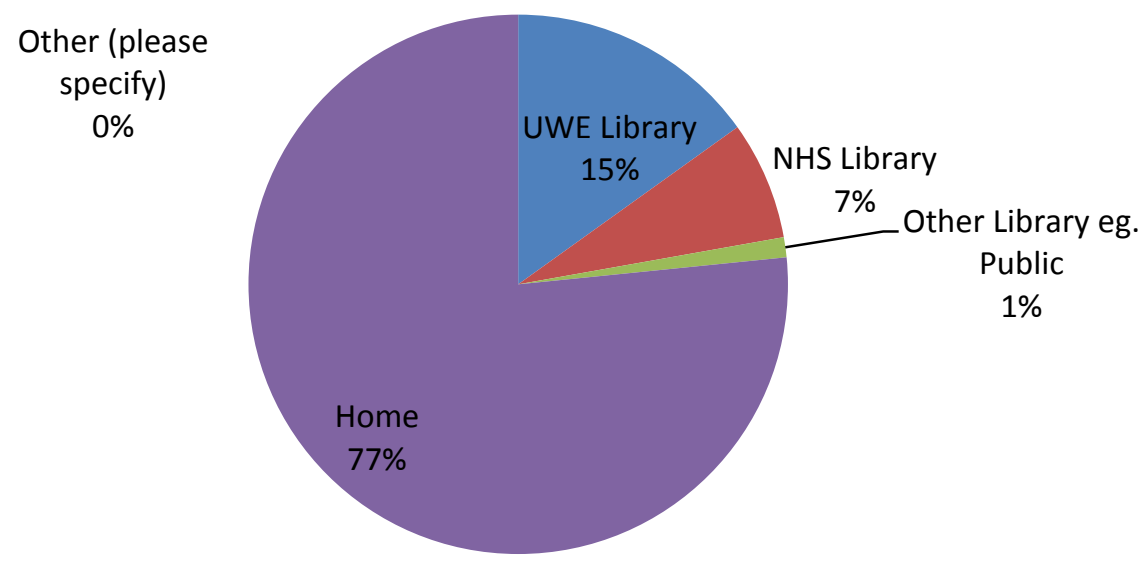

Figure 14. Where respondents on both hospital and community placements do most of their studying combined. 
Over three-quarters of students on placement did most of their studying from home, with this figure consistent across both acute hospital and community placement locations. This figure is also broadly in line with other previous major surveys, and continues to map a trend toward high levels of Internetbased electronic access to resources facilitating the "study anywhere" philosophy in students, where they can study wherever is most convenient to them at that time.

when you are working full time hours on a busy ward I don't understand how you are supposed to have time to access library resources except in your free time at home

$$
\begin{aligned}
& \text { library online resources are very useful } \\
& \text { meaning work can be completed at home }
\end{aligned}
$$

I rarely visit the library when on placement due to time constraints, but find that I can access what I need from home.

UWE libraries are the second most popular placement study location, but a long way behind studying from home, and there are very low figures for NHS libraries, where only 12 people studied in an NHS library (out of 108 who had access) and this seems to be supported by the answers to questions 4, 5 and 6.

A recent visit to an NHS library by one of the researchers supported the view (as suggested by Fig. 3) that there were relatively low levels of visits from UWE placement students for study purposes, although that may relate to the particular location of that individual library. 
4.10 Question 10 - During your placement, from which locations did you access the following resources?

4.10.1 Community

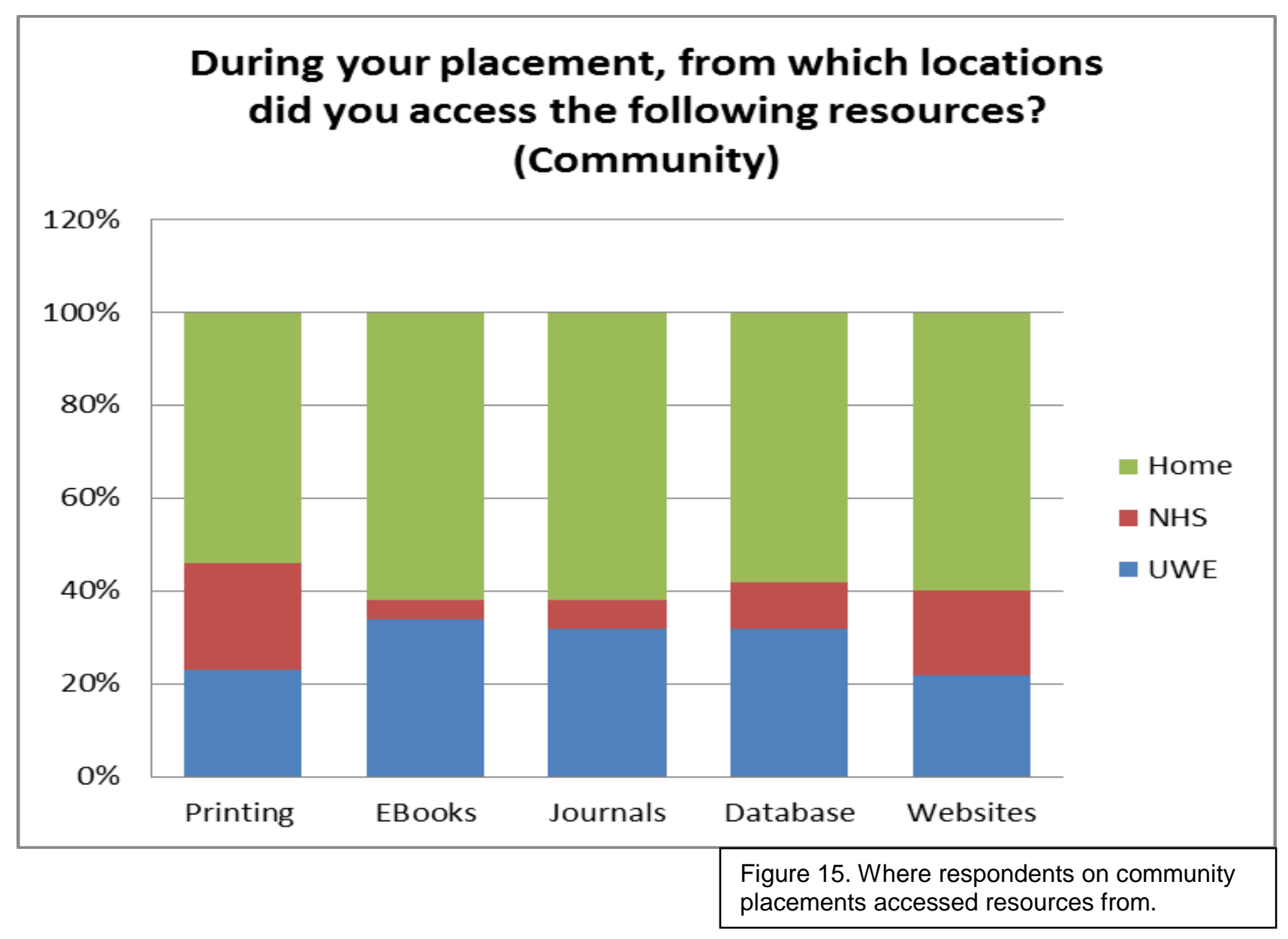


4.10.2 Hospital

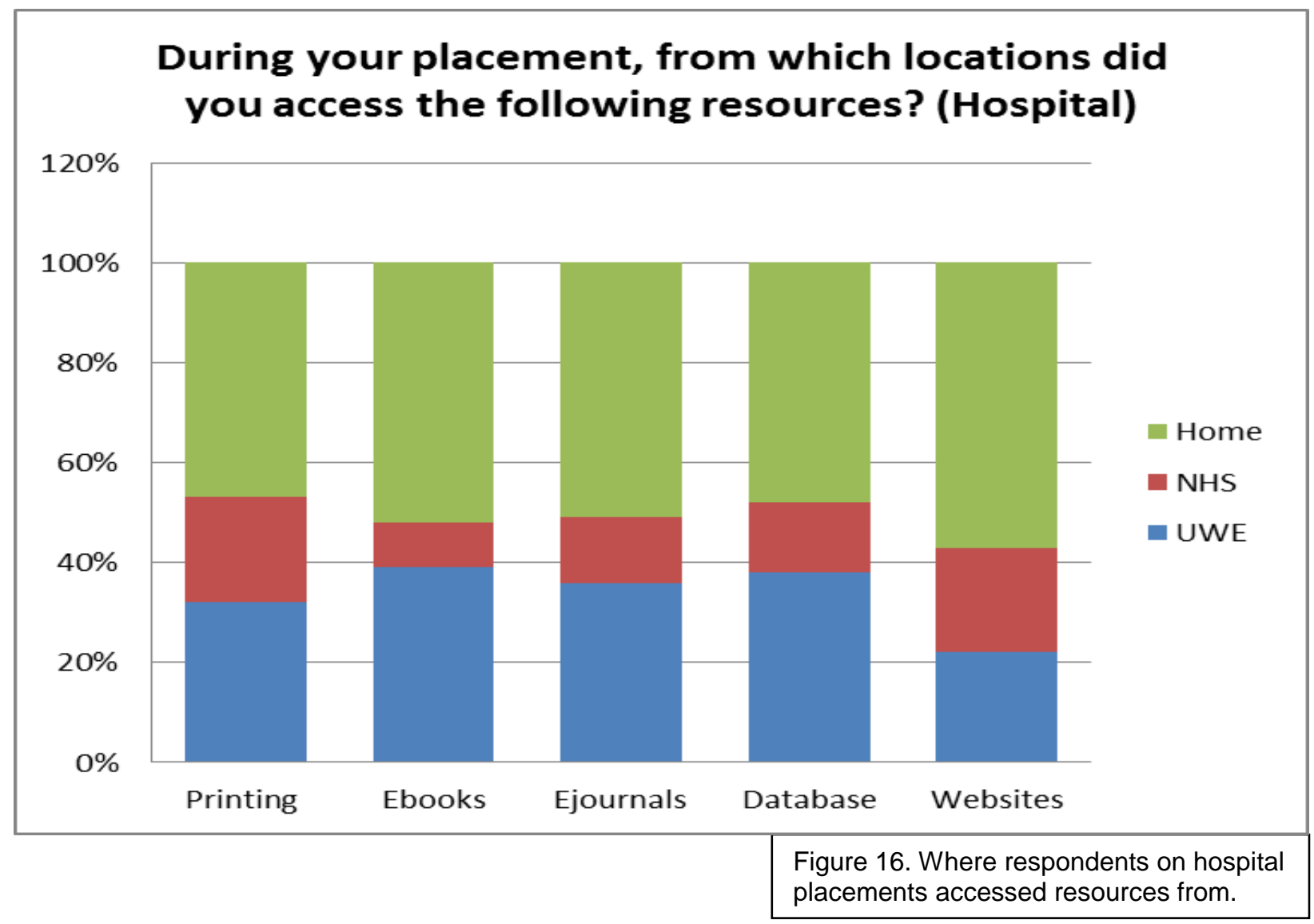

4.10.3 Combined Community and Hospital

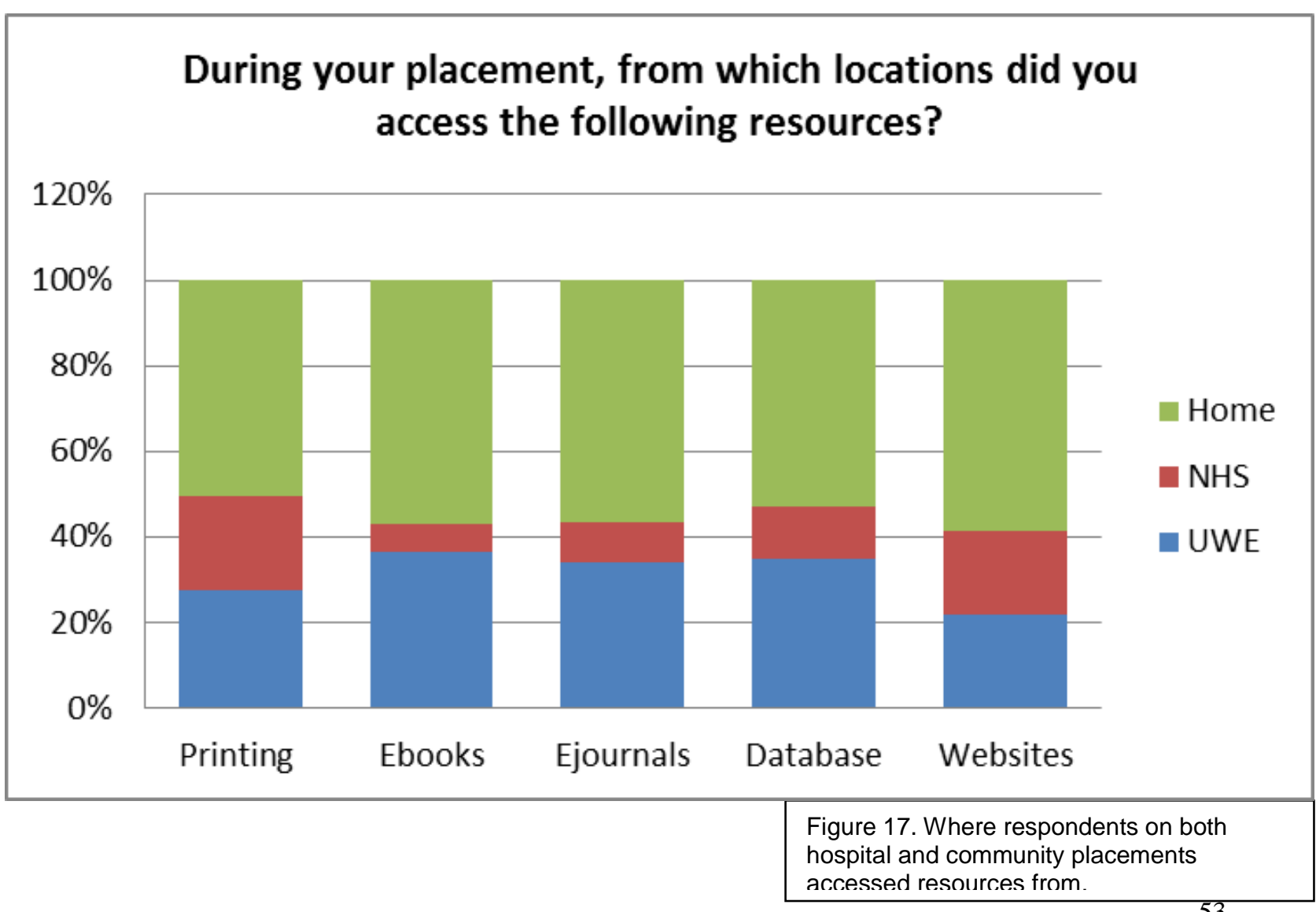


The research shows that most people access electronic resources from home. The second most used location was UWE - this may be explained by students attending UWE on SOL days - with NHS Libraries way behind, which once again supports results in previous questions.

There is a slight preference for accessing e-resources from home among students on a community placement and this may be accounted for by the greater likelihood of being able to access a computer on a hospital site.

Glenside has the most fantastic resources and I really appreciate being able to access e-books and journals from home very good to be able to access everything online from everywhere I now manage to access e-books/journals from home without too much trouble

It is easy to get access to library resources via the Internet away from UWE, so looking up journals and books was really easy

There is no doubt that convenient, easy access to electronic resources is absolutely vital for students, something which is aptly demonstrated in the title of a recent article: "If it's too inconvenient I'm not going after it" (Connaway, Dickey and Radford, 2011). This is borne out by recent UWE results from the LibQual Survey 2012, which reveal that what our students and staff want above all else is "electronic resources available from home or office" with this being rated at 8.2 out of 9 (University of the West of England, 2013).

Interestingly, most people also print from home while on placement, demonstrating that students also have access to desktop printers. 


\subsection{Question 11 - Do you have access to any of the following at home?}

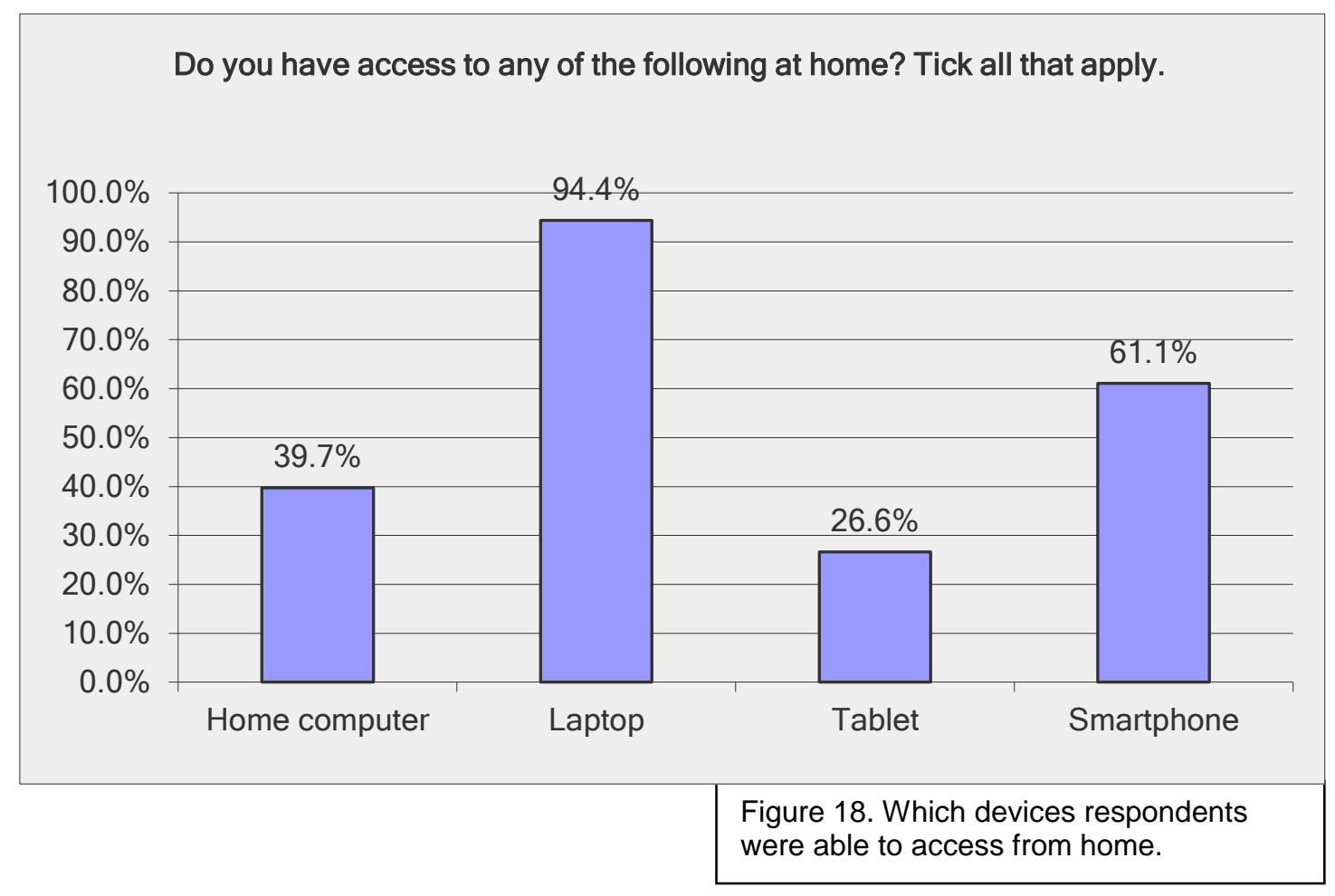

It is evident that student ownership of laptops is very high (94\%), more than twice that of home desktop computers. Moreover, over $60 \%$ of students have a smartphone which is almost identical to the earlier ECAR (2012) statistics. Tablet ownership is also quite high $(26 \%)$ reflecting national trends in the adoption of digital devices. These statistics also represent an increase in access to these devices and independent access to the Internet since Lloyd (2012), most strikingly the increase in tablet and smartphone ownership. These astonishing statistics mean that the majority of people can now access the Internet via their mobile devices and reflect a desire to access information anytime, anywhere.

To highlight the fact that some students own multiple devices, we found that some students had access to two, three or four (10\%) devices. These figures support similar statistics from the ONS (2012) and Mintel (2012). 


\section{How many devices do you have access to?}

घ One Device $\square$ Two Devices $\square$ Three Devices $\square$ Four Devices

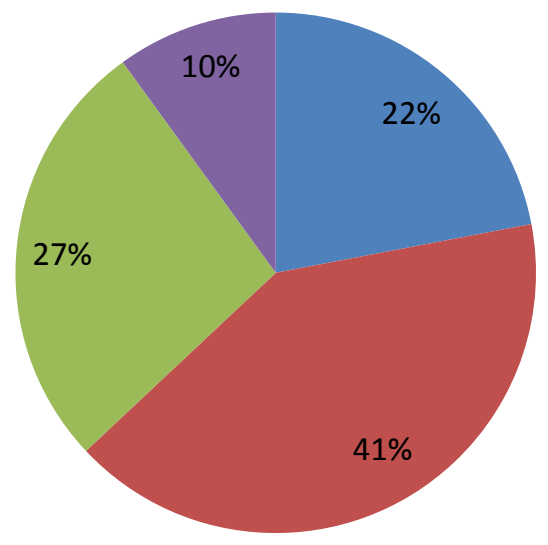

Figure 19. The number of devices respondents had access to. 


\subsection{Question 12 - Before going on placement, do you feel you received enough information about how to access library resources from off campus?}

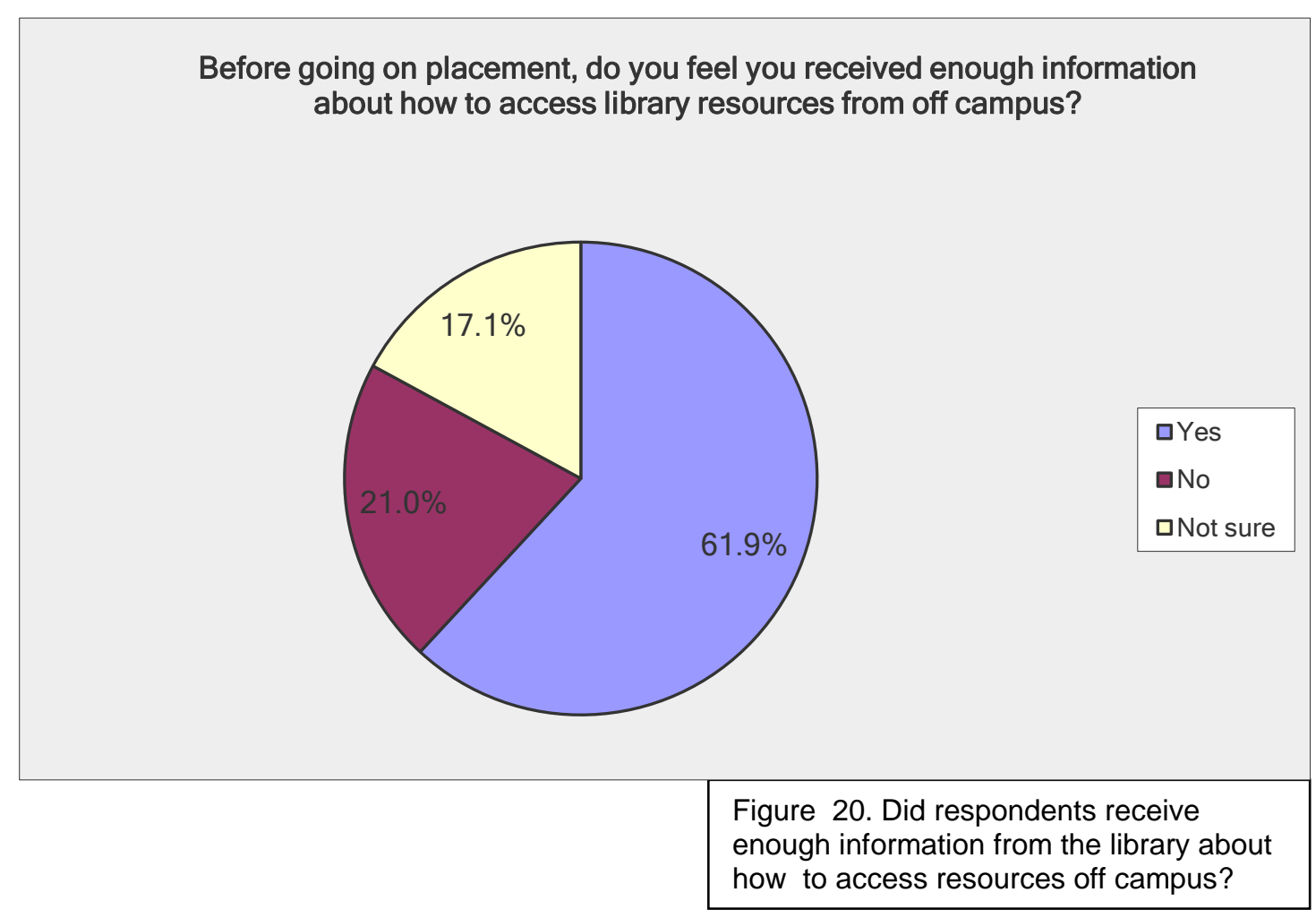

The research indicates that $62 \%$ of students did feel they received sufficient pre-placement information. This figure is quite high (Raynor, 2009, suggested $50 \%$ ) and is consistent with Lloyd (2012), but there is room for improvement with a significant $38 \%$ saying not sure or no to the question.

Callaghan (2008, p.129) argued that

It was clear that the students believed that preparation for placement was of great importance to their placement learning experience.

and that

not enough attention was given to induction and training to access and use library based and electronic resources (2008, p.258) 
However, historically within UWE, there has been a sense that many students on placement have not

accessed the pre-placement information that we provide (Lloyd, 2012, p60)

This is supported by the comment regarding the availability of NHS libraries that

I only found out about NHS library through another student and not placement mentor or other staff.

The Academic in Practice we interviewed also highlighted the situation where pre-placement information could be more efficiently displayed and more easily accessed.

AiP: $A R C$ is the system that we use for a repository of practice-related things, is being developed and the practice support net will be subsumed into ARC and the PS net is where mentors if they need information can go so the only thing that I can suggest that you might want to consider, in terms of moving things forward is to have a dedicated tab and then you can click on it because it has got to be quick, it's got to be easy, it's got to be something mentors can see I can click on that, I can find what I want, job done and if you could perhaps think of ways you could link into the support because the access of evidence could be the way you could link into practice is via that practice support mechanism

AiP: That's what they will be using is going online later on in this year and it will be enhanced, it's got a lot of facilities in it but I just know for the PS net at the moment, there is a list of FAQs but you need a tab or something that clearly flags quick links to help for access for whatever you need AiP: That might actually be one way of getting support out there in the right place because that is what mentors will want to be using and we will be doing that

AiP: What about links to other related websites like the DOH, like NICE, all those other related professional organisations 
JL: Delicious type stuff

PS: Quick links

AiP: Yeah quick links to the NMC, quick links that are overt instead of covert, because when you start to drill in you think you haven't got the time to do this

NHS libraries reported that some groups (though not all) of placement students have an NHS library induction at the start of their placement, although this doesn't seem to be consistent across all sites, is mainly for nursing students and would seem to favour students on acute hospital rather than community-based placements. There is generally a UWE student guide to NHS library resources/facilities which can be handed out or accessed online or from the NHS library.

Within UWE, all students have a main university library induction session, although at present, no specific pre-placement induction. This has been investigated historically, and was decided to not be practical as placements commenced over such a wide range of potential dates. Adult nursing students at levels 1,2 and 3 have library input into their practice-based modules, and there are plans to extend this to an input into future SOL days. Some other groups may have a pre-placement library induction, but this is sporadic, and there is also some liaison between UWE and NHS librarians over joint induction for placement students, particularly at Bath RUH. 


\subsection{Question 13 - During your placement how often did you}

contact any of the following for support in using library resources or facilities (tick all that apply)?

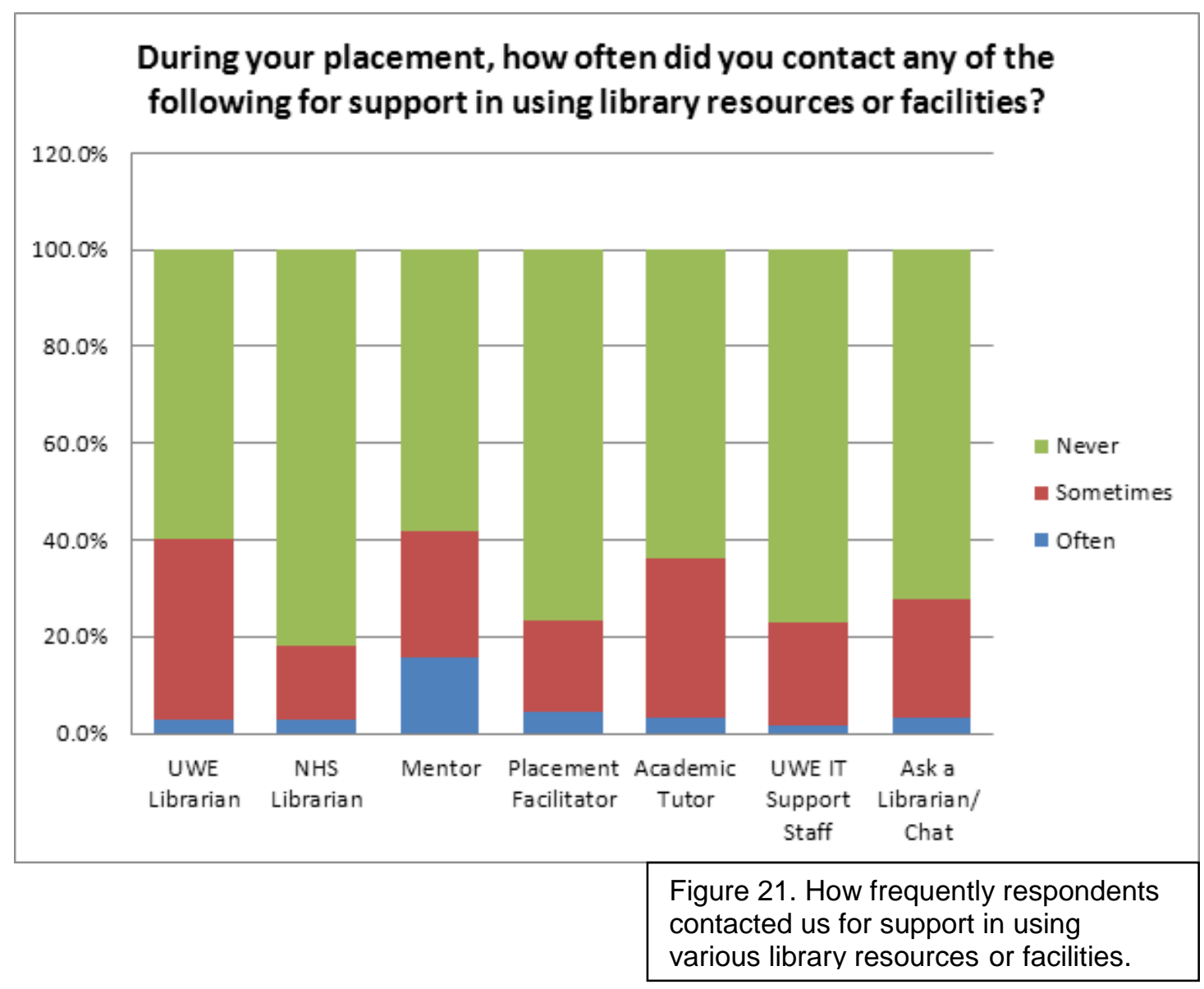

The single source of support most often contacted was a mentor, which we understand from an academic in practice largely relates to the assessment of the student's clinical practice and competency (see Appendix 5).

The percentage of students who never contacted an NHS librarian is very high. In fact, these were the least contacted group overall. This broadly supports evidence found in interviews and questionnaires with NHS librarians.

A significant proportion of students sometimes contacted a UWE librarian, and this figure could be significantly increased if we were to add the numbers from Ask a Librarian / Chat. 
Details of what sort of support was sought can be evidenced in some of the qualitative responses below e.g. problems relating to the circulation of books:

Advice on returning items when away from home in Bristol

Trying to renew books remotely from home

Approximately a quarter have also used Ask-a-Librarian or CHAT at some time.

I found CHAT very helpful with references or in locating difficult to find books. I live three hours away from UWE so

often need to source things online. CHAT is invaluable

\subsection{Qualitative Response Analysis}

The final four survey questions (Qs 14,15, 16 and 17) allowed respondents to make free-text qualitative comments, so we have drawn out some broad general themes:

\subsubsection{Circulations/books}

Includes issues such as borrowing, finding books, renewing, returning, holds and transferring books. The research would suggest that students on placement still experience certain problems concerning the management of textbooks and there were requests for the reinstatement of placement loans.

The length of loans are too short for when on placement. 
A senior UWE Library Manager advises that:

Placement loans were previously available to HSC students but were discontinued as it disadvantaged a greater number of students than it helped. Due to the length of placements, books can become unavailable for at least 2 months at any one time. When other students are looking to study from texts and write assignments books are not available to help them. Experience of book loans suggests that the preference for most students is to have stock available to them at the point of need. The Library Service ensures that students can place reservations on items they require, thereby blocking the current loan from being renewed. This provides all with equal access.

Students also complained about the inability to renew books due to holds this despite the fact that we have increased the number of renewals from three to five this academic year - and difficulty in returning books when at a distance from the campus.

renewing books from home. There is no advanced warning that you cannot renew your books lots of times.

A senior UWE Library manager advises that:

When a reservation is placed we are currently unable to notify a user due to the way we currently deal with reservations.... This is something which is requested and therefore we will continue to investigate with our current system and look to have as part of our new LMS in the future.

As regards returning books, they can be posted back but this obviously incurs a certain cost. Historically there were regular van runs to the main NHS hospital sites, but the only existing van run to Swindon will end in summer 2013 and hence the ability to return books at NHS hospital sites will end. This means that books will have to be handed in at UWE rather than these locations from then on. 
There were quite a few comments from students about the general lack of print books e.g. "no books available" and this probably reflects the high level of demand and usage of our popular textbooks.

Any good books are always reserved as there is usually only one copy

The current collection development policy is to buy only two copies of any one book - instead we purchase other titles on the same subject - hence the books on reading lists tend to be out on loan much of the time, ostensibly leaving none on the shelves.

Regional NHS libraries are regularly supplied with lists of key subject texts for UWE health and social care students, which they buy to be made available to students on placement, as well as their own professional staff. They also have arrangements for the transfer of books between NHS library sites for items requested by UWE students.

A clear theme from the qualitative responses was to "get more e-books."

No difficulties other than some books are only available physically from the library, not available as e-books

not having the correct books at time or not having enough of them! Also these books were not readily available as e-books

It seems evident that students have fully embraced the library's move towards a greater e-book collection.

Online library and e-books are fab for distance learners. More please.

UWE libraries recognise the need to buy books which are directly relevant to students' immediate information requirements and have been trialling Patron Driven Acquisition (PDA) in a number of subject areas. 
Last year, we trialled the use of Patron Driven Acquisition (PDA) with DawsonEra e-books in a couple of specific Health and Life Science areas. The trial was very successful, with 265 e-books triggered for purchase by library users over the course of the spring and summer terms, many of which have received high usage since (Cross, Feb 2013).

This topic will be discussed further in the recommendations.

\section{$\underline{4.14 .2 \text { E-resources }}$}

One of the main reasons for contacting library staff for support is for assistance with accessing and using electronic resources. However, the evidence would also suggest that most queries are quickly and satisfactorily resolved either by using CHAT or face-to-face contact.

\section{Online chat if I can't get into an article}

One particular e-resource - RefWorks - appears to have caused a few problems, but again, these were easily resolved.

In addition, the number of queries on literature searching suggests that students may be working on their dissertations whilst on placement.

\subsubsection{Referencing}

Another area where people have contacted us for support is with referencing queries. UWE uses a unique form of Harvard referencing which can be the cause of some concern for students.

\section{I found chat very helpful with referencing queries}

We seem to be able to resolve most of these queries either via CHAT or pointing students to the guidance on the library website. 


\subsubsection{Mobile technologies}

It is interesting to see a sharp rise in the number of queries regarding mobile devices e.g. Kindle, tablet, laptop, etc which demonstrates the massive changes in digital device ownership.

Frustrating not to be able to access Dawsons books on an Android device.... Shame that many books aren't available on Kindle

Kindle format would be fab too

It would also be helpful to have alternative methods to access e-books (tablets etc) other than PCs or Apple ipads

Some students also mentioned the lack of Internet access or free Wi-Fi availability on hospital sites.

living in hospital residence with no internet access

except dongle and no printing is biggest problem

needed Ethernet cable for internet use of own devices

Correspondence with a UWE academic on the same subject would be instructive to quote in full:

I'm not sure if you will be able to help me with this but I have had a call from a student today who is on placement at Cirencester Hospital and is living on site there but is getting very frustrated that he hasn't got internet access. He has asked me if there is anything UWE can do to help? As far as I am aware there isn't but I said l'd run it by you also. The student he is with has bought a dongle (so he is aware this is an option) but she has limited access and is having to pay top up fees. Other than this option is there anything else he can do? The library on site shuts at 5pm as do the places in town he has found.

Interestingly, the AHP department at UWE has already done some research on problems with IT provision in accommodation and NHS Trusts during 
clinical placements. They received feedback from students placed at geographically distant sites from UWE.

\section{Before:}

Awful. Our flat didn't have its own internet access and we were allowed to "borrow" another flats, however, this connection was very weak and would constantly drop out when researching articles. This made study in the accommodation a difficult and time consuming process.

I had no access to the internet, so I brought a dongle out of my own money so I could do my logs in my room to save going to the library of an evening.

Appalling!!! Utter disaster as there was no internet which made the whole process of logs, especially the MSc section a nightmare. It meant trips home to use internet, long nights in the library and doing work had to be planned, rather than just being able to grab your laptop and work when you wanted.

They decided to provide selected students with laptops and dongles for the duration of their placement. The feedback was overwhelmingly positive.

After

The use of the university laptop and the dongle have been invaluable resources for my studies.

Use of the laptop has stopped late nights in the library and I can be warm and at home and the dongle has allowed me to use the internet for such things as reading journals whilst travelling, enabling me to make the most of my time! This is especially useful alongside clinical placements as there is a lot of work outside of the practicality of the working placement days. 


\section{$\underline{4.14 .5 \text { Library support }}$}

It is pleasing to see the huge number of positive comments relating to library support.

UWE staff are extremely helpful with everything and so are the staff at GRH Hospital

I am in close contact with library staff at placement and UWE. They are "my right arm". I couldn't manage life at university without their support. They are an amazing bunch....always ready to help.

RUH NHS library is really good and the staff are really knowledgeable

There were a number of comments from students with disabilities about the library support they received and this is something that will need to be considered in the future

I am dyslexic and require hands-on help to be made easily accessible

Staff were very knowledgeable, friendly and helpful.

They supported all my dyslexic needs

There are also a few negative comments about opening hours and staff availability. These may refer to Alexander Warehouse library which does have slightly more restricted opening hours.

Gloucester UWE library is not open at anytime when we are not

Working i.e. evenings and weekends which makes it impossible to use

There seems to be a very positive view of the library CHAT service with lots of comments on the ease and convenience of using CHAT and Ask-a-Librarian to contact UWE.

CHAT is invaluable

24 hour library chat online is fantastic and has helped me several times

Live chat able to get the answers I needed immediately

Online chat because it's immediate and fast. 


\section{$\underline{\text { 4.14.6 Time }}$}

There are a significant number of comments regarding lack of time either to study, access library resources or go to the library whilst on placement.

When you're working full time hours on a busy ward I don't understand how you're supposed to have time to access library resources except in your free time at home

I have never had the chance to use the library during placement time, neither at UWE or an NHS library. The time is not given to go off and do this, if we are on placement we are expected to work on placement for the shift hours, all the work I have needed to do had to be done in my own spare time and on my days off.

access and time needs to be encouraged by placement mentors and tutors

The tension between time for study, clinical work and a normal life on placement was also raised by the academic in practice.

I completely get it, it's really demanding and hard out in practice they get home after a busy shift, completely wrecked, sore feet, a headache, had nothing to eat or drink all day and then they've got to turn around and search the library and I don't think they will after a long hard day at work. But they will when they are on SOL days or when they are here or on days off.

This frustration will be addressed in the discussion and recommendations. 


\subsubsection{NHS Libraries}

It would appear that more information about NHS library facilities is required. There seems to be a certain lack of understanding or awareness regarding whether or when students can access and use NHS libraries whilst on placement.

like to know more about NHS library facilities

I only found out about NHS library through another student...

would be nice to know if we are allowed to do so during placement hours.

I haven't because I thought we weren't allowed

not quite sure how student nurses register and

how much access we are entitled to

This will be discussed further in the discussion and recommendations. 


\section{DISCUSSION}

\subsection{Summary}

Clinical placements for students now account for around $50 \%$ of students' course time and take place in a wide range of challenging and diverse locations. As such, we feel that the placement experience as a whole is of huge importance to the students' overall impression of the course and University, as well as their future competence and success as a health professional in practice. This is especially relevant in the light of UWE's strategy for 2020 which describes its ambition to become the best University for

Professionally recognised and practice-orientated programmes, which contribute to an outstanding learning experience and generate excellent graduate employment opportunities and outcomes for all students (UWE, Bristol, 2013).

We are very aware of the competing pressures on the time of a student on placement, and how this can be impacted upon by clinical demands, ward cultures and ethos, academic work requirements, and the need to strike a reasonable work vs life balance. All this is happening against the backdrop of massive changes in the nature and potential modes of study for our students, with access to the Internet and a bewildering amount of information via an exciting range of devices fundamentally altering the ways and locations in which study can take place. 
Our discussion and subsequent recommendations for future practice are therefore led and informed by these basic principles:

- The holistic student experience on placement is of paramount importance

- Curriculum changes may increasingly allow students to devote more placement time to own study and clinical work, rather than for assignment completion or other academic work

- New technologies make access to the Internet and a range of electronic resources more widely available than ever, and UWE and NHS IT capacity needs to recognise this change in access potential

Looking in turn at each of the survey questions asked, we will discuss the findings and responses previously described.

\subsection{Question 4: During your placement how frequently did you use the following libraries?}

The significant majority of students don't use NHS libraries whilst on placement, which we believe is largely due to time and work pressures during their clinical practice and the increasing ability to and convenience of accessing electronic library resources remotely. There is also a suggestion of an awareness issue regarding the use of NHS library facilities.

UWE libraries are visited more often (but this is still quite low) which we believe may be linked to their mandatory SOL days. This suggests that access to a physical library while on placement is becoming less relevant.

\subsection{Question 5: At your placement venue, which of the following facilities were available for your use?}

Most placement venues have a computer with Internet access available for students' use. However one significant change from previous recent research is the noticeable reduction in the number of negative comments about not 
being able to access NHS computers or problems with NHS logins and this appears to be largely dependent upon which location the placement is in and the prevailing attitudes on the wards.

Students on community-based placements are much less likely to be able to access a library, possibly increasing their sense of isolation and ways of reducing this may need to be considered.

Finally, a significant proportion of students also didn't know whether they even had access to a library, thus confirming an issue around awareness and knowledge of NHS libraries.

\subsection{Question 6: Which of these facilities was most important to you?}

As by far the most important facility for students on placement is access to a computer, this would tend to support the view that students are increasingly happy to use electronic information resources.

Qualitative responses have suggested that the importance of access to a computer is also linked to students' need to keep in touch with friends and family and communicate with their support network.

It is therefore important that up-to-date information about computer access and the availability of $\mathrm{Wi}-\mathrm{Fi}$ at the various different placement locations is readily available for students.

\subsection{Question 7: How important was it for you to access library resources whilst on placement?}

It may be possible that changes to the curriculum are leading to a change in students' attitudes towards library resources whilst on placement. However, given our earlier reservations about the framing of the question, it may be unwise to draw too strong a conclusion from this. 


\subsection{Question 8: What was your main reason for using library resources?}

There does seem to be a trend away from completing an assignment whilst on placement towards doing other types of study. This may be due to changes in the UWE curriculum, with the need to complete exercises such as blogs, reflective practice or learning logs instead of academic assignments. It is worth noting that $33 \%$ of students stated that they used library resources to support their clinical work. This suggests that the clinical practice element is becoming the most important aspect of their placement and that evidencebased practice is also well rooted in practice.

Moving on to our subsidiary enquiries about students' general use of the Internet, we know that they increasingly use this for keeping in touch whilst on placement. Previous research suggested the high value of peer support and support networks between students (Lloyd, 2012, p63). In fact, Internet use is now seen as vital for communication, so access to Face-book, email and other social media options are of paramount importance to making the overall placement experience as valuable, worthwhile and stress-free as possible.

\subsection{Question 9: Where did you do most of your studying?}

High statistics show that most people study from home. It is clear that the overwhelming availability of e-resources and their increasing ease of access have facilitated this cultural shift. It is also possible that the time and work constraints previously discussed in the qualitative response analysis, and the need to have a reasonable work vs life balance, mean that students prefer to study from home. It is therefore important that we make sure that all of our online resources are easy to find and easily accessible, with help readily available $24 / 7$. 


\subsection{Question 10: During your placement, from which location did you access the following library resources?}

The trend towards students on placement accessing electronic resources from home supports UWE Libraries' increased emphasis and spending on electronic resources, especially e-books. This once again means easy and seamless access to e-resources is vital.

Qualitative evidence from academic members of staff tells us that students often use Google rather than UWE Library Search as this is seen as long winded. However, for optimum results the recommended route to library resources is via the library web pages where all the links have been checked. There are key training implications here for both UWE and NHS librarians.

\subsection{Question 11: Do you have access to any of the following at home?}

Laptop ownership is incredibly high and access to smartphones is also both high and on the increase. The portable nature of these devices suggests the need for either a reliable Internet connection or dongle availability if students are using them in locations where $\mathrm{Wi}-\mathrm{Fi}$ is unavailable. However, if students have smartphones or tablets with $3 G$ access then Trust Wi-Fi is not so important.

Given the high numbers of handheld devices, it is important that not only the UWE Library website is mobile compliant, but also the e-resources that we purchase or subscribe to e.g. e-books.

A senior member of the Library IT team explained that

we're making sure that our website, and our other core online services such as Summon, have websites that are mobile friendly (Wyatt, 2013) 
The comments relating to whether e-books are available on Kindle and Android technologies in the qualitative response analysis are timely and UWE Library Service should investigate other methods of access i.e. offline mobile access.

\subsection{Question 12: Before going on placement, do you feel you received enough information about how to access library resources from off campus?}

Whilst all UWE students receive library induction sessions and subsequent information literacy skills training, the current level of specific pre-placement training is low and inconsistent across programmes (at the moment these are only timetabled for adult nursing students).

The fact that $38 \%$ of students said that they either weren't sure or didn't receive enough information would suggest that library involvement in both pre- and during placement activity needs to be increased and improved, so that all students receive an equal and satisfactory level of preparation.

We feel that the existing online placement-related materials are not easily accessible as the information is located in various different places. There is also a problem with the currency of materials.

\subsection{Question 13: During your placement, how often did you contact any of the following for support in using library resources?}

The fact that the most often contacted person is a mentor perhaps confirms the view that students are more worried about and focussed on passing the clinical side of their placement than on accessing library resources for study purposes.

The second most frequently contacted group were UWE librarians, and NHS librarians were contacted relatively infrequently. It might be worth investigating 
the possibility of using other technologies such as Skype, Lync or other synchronous technologies to facilitate communication between students and UWE librarians (as well as between UWE and NHS librarians), as this would reduce the need for travel to placement locations.

However, the research suggests that when contacted, all the support given was of a very high level - this was also positively evaluated in the recent LibQUAL survey - and very much appreciated as indicated in the qualitative response analysis. This is especially true with regard to support for students with dyslexia.

The high level of Ask-a-Librarian queries and the extremely positive feedback on CHAT demonstrates the value of a 24/7 service which can provide support and advice at the time of need. 


\section{RECOMMENDATIONS}

\subsection{To have a named UWE NHS liaison and placement librarian}

- This person (the placement librarian) will be the lead librarian who will co-ordinate all aspects of placement support and be responsible for implementing the recommendations from this research. The role will carry out a six-monthly evaluation of these recommendations in conjunction with the Faculty Librarian.

- The placement librarian will endeavour to gain an overview of all practice placements in order to better appreciate the student experience. (This may include mapping the student placement "journey" from their first placement to their last.)

- The six-monthly evaluation should include discussions with the Faculty (the Dean) around ways of increasing student participation in some future focus groups to evaluate the placement support provision.

- The next phase of the research (including the evaluation) should include collaboration between UWE and NHS libraries in the region, Funding will be sought from the Higher Education Academy in terms of a Teaching Development Grant, and from Health Education England.

\subsection{UWE and NHS liaison and communication}

- We recognise that our students are on placement for $50 \%$ of their course, therefore it is imperative that there is regular liaison between UWE librarians and NHS librarians.

- The UWE placement librarian should lead on this liaison and continue with the schedule of NHS visits, but with support from other HSC librarians.

- The placement librarian to oversee the purchase of tablets and dongles for all HSC librarians which would enable them to visit and support students out on placement. 
- The placement librarian to facilitate training for UWE HSC librarians to ensure that they are familiar with NHS resources e.g. NICE Evidence. This is important as UWE students can now access NHS resources via NHS Athens.

- The placement librarian to work closely with the Placement Practice Office (PPO) and be aware of and respond to any library issues that may be raised in the placement evaluation survey.

- The placement librarian to organise an annual meeting with regional NHS librarians to discuss any library placement issues. The first meeting of this kind could be organised for next April in order to include the evaluation of this new placement support service.

- The placement librarian to work closely with NHS librarians to develop training and awareness materials for NHS mentors working with UWE students.

\subsection{Technological solutions}

- The placement librarian to investigate and implement a trial dongle scheme for students to address potential problems of access to the Internet in locations without $\mathrm{Wi}-\mathrm{Fi}$. This should initially target students on community-based placements where Wi-Fi connectivity may be less likely.

- The placement librarian to liaise with the PPO with a view to compiling an accurate, up-to-date list of Wi-Fi enabled placement locations in the south-west.

- The placement librarian to keep abreast of IT changes and developments within the NHS, and to report these as appropriate to library colleagues.

- The placement librarian to investigate better use of the potential of Skype or Lync (Appendix 13) solutions to overcome problems of distance and cost of travelling to sites. This could include improving the effectiveness of liaison with NHS librarians and NHS placement mentors (online training sessions), and also offering another means of 
communication with Glenside library for students on placement who have queries or concerns to discuss.

- UWE Library Services to continue to build on the success of 24/7 CHAT and promote it wherever possible.

\subsection{Training and support}

- The placement librarian to increase levels of pre-placement training for all groups prior to their first placement, as this is key information for $50 \%$ of their course. This may include leading library discussions on how to implement and embed this and liaising with appropriate parties over a schedule for this training.

- The placement librarian to organise a generic pre-placement induction package which may include how to renew items online; awareness of opening hours at all sites; how to use Library Search and the advantages of accessing resources via the library website; awareness of e-books; know where to get help.

- This training will be delivered by the placement librarian in conjunction with all HSC librarians, who can focus on their specialist subject areas, thus providing some continuity of support.

- The placement librarian to co-ordinate and grow the library's ongoing placement support activity via the SOL days. This should include discussions with all HSC librarians on how to become involved in SOL days for their subject area.

- The placement librarian to involve the UWE IT Assistant in preplacement training sessions to offer specific IT support e.g. for dongles.

- The placement librarian to review the provision of joint library inductions from both placement librarian and NHS librarians at sites.

- The placement librarian to liaise with the Faculty Librarian regarding implementation of Peer Assisted Learning for students on placement. 


\subsection{E-resources}

- UWE Library Services to continue to grow its collection of e-books, especially in HSC.

- The placement librarian to liaise with UWE Library colleagues regarding future developments in e-books and offline access.

- The placement librarian to liaise with UWE IT colleagues to ensure that not only the UWE Library website is mobile compliant but, where possible, also the e-resources that we purchase or subscribe to.

\subsection{Website improvements}

- The placement librarian to implement a holistic review of the content and effectiveness of the various UWE webpages relating to placement activity and support. This should include reviewing the HSC Library webpages to include a link to "Are you going on placement?" to tie in with the display in Glenside Library.

- The placement librarian to maintain the currency of all links and information on the revised Practice Support Net webpages.

- The placement librarian to liaise with the PPO regarding the planned redevelopment of ARC (the management information system designed to cover all aspects of student management around practice placement). This will include updating of NHS location profiles, thus enabling students to be better prepared for placement.

- The placement librarian to explore a range of methods in order to raise awareness of the support available to students on placement, such as vodcasts, promotional materials on the UWE website. 


\section{$\underline{6.7 \text { Next steps }}$}

At the recent NHS Libraries study day, this research was discussed, a commitment to further collaboration regarding the issues raised in the research was expressed, and the following actions should be taken forward for future consideration:

- several specific recommendations regarding awareness of NHS libraries and how to promote the services available to placement students were discussed and have been incorporated into the recommendations in the report (in section 6.1, 6.2, and 6.6).

- steps should be taken for further collaboration between UWE, NHS libraries, Health Education England and the Higher Education Academy, toward taking the research process forward, which should include the six monthly evaluation of this research.

- that a joint conference should be considered for 2015 to further discuss and disseminate the issues raised in the research at a national as well as regional level. This would be run in conjunction with Health Education England and the Higher Education Academy. 


\section{REFERENCES}

Baglin, M.R. and Rugg, S. (2010) Student nurses' experiences of communitybased practice placement learning: a qualitative exploration. Nurse Education in Practice [online]. 10 (3), pp.144-152. [Accessed 19 June 2013].

Bailey, P., Cook, G., Thynne, E., Weatherhead, E., Glenn, S. and Mitchell, A. (2004) Distance learning in post-qualifying nurse education at Northumbria University: implications for the role of the library and library staff. Health Information and Libraries Journal. [online] 21 (1,) pp.66-69. Available from: [Accessed 19 June 2013].

Baird, I., Peacock, D., Dobbins, S. and Walton, G. (2006) Exploring health pre-registration students use of learning resources whilst on clinical placement: replication of case study at Northumbria and Teesside Universities, UK. Health Information and Libraries Journal [online]. 23 (4), pp. 286-290. [Accessed 19 June 2013].

Baird, I., Blenkinsopp, J. and Dobbins, S. (2005) THESAL Teesside HEalth Students Access to Learning Resources Whilst on Placement. University of Teesside. pp.1-18.

Bertulis, R., and Cheeseborough, J. (2008) The Royal College of Nursing's information needs survey of nurses and health professionals. Health Information and Libraries Journal. [online] 25 (3), pp.186-197. [Accessed 19 June 2013].

Brettle, A., and Urquhart, C,. eds. (2012) Changing Roles and Contexts for Health Library and Information Professionals. London: Facet Publishing.

Brighton and Sussex Medical School (2012) Mobile Medical Education (MoMed). Available from: http://www.bsms.ac.uk/undergraduate/supportingyour-learning/it-and-learning-resources/momed/ [Accessed 20 June 2013]. 
Burns, R. (2000) Introduction to Research Methods. $4^{\text {th }}$ ed. London: Sage Publications Ltd.

Callaghan, L., Lea, S., Charlton, R. and Whittlesea, E. (2008) Accessing library resources while on placement: can mobile devices help students?. In: Needham, G.F. and Ally, M. (2008) M-libraries Libraries on the move to provide virtual access. London: Facet, pp. 125-134.

Callaghan, L., Doherty, A., Lea, S. and Webster, D. (2008) Understanding the information and resource needs of UK health and social care placement students. Health Information \& Libraries Journal [online]. 25 (4), pp.253-60. [Accessed 19 June 2013].

Casebourne, I. (2012) Research Report Mobile Learning for the NHS. Epic: NHS South of England.

Child, J. and Langford, E. (2011) Exploring the learning experiences of nursing students with dyslexia. Nursing Standard [online]. 25 (40), pp. 39-46. [Accessed 19 June 2013].

Connaway, L., Dickey, T. and Radford, M. (2011) "If it is too inconvenient I'm not going after it:" convenience as a critical factor in information-seeking behaviors. Library and Information Science Research [online]. 33 (3), pp179190. [Accessed 20 June 2013].

Cox, H. (2013) Email to Caroline Plaice, $28^{\text {th }}$ June 2013.

Crawford, J. (2002) A study of issues in administering library services to nursing studies students at Glasgow Caledonian University. Health Information and Libraries Journal [online]. 19 (2), pp. 90-7. [Accessed 19 June 2013].

Dahlstrom, E. (2012) The ECAR Study of Undergraduate Students and Information Technology, 2012. EDUCAUSE Centre for Applied Research [online] Available from:

http://net.educause.edu/ir/library/pdf/ERS1208/ERS1208.pdf [Accessed 20 June 2013]. 
Denscombe, M. (2010) The Good Research Guide: For Small-scale Social Research Projects $4^{\text {th }}$ ed. Maidenhead: Open University Press.

Department of Health (2008). NHS Next Stage Review. Our Vision for Primary and Community Care. Available from: http://www.dh.gov.uk/prod consum dh/groups/dh digitalassets/@dh/@en/do cuments/digitalasset/dh 085947.pdf [Accessed 28 October 2011].

Department of Health (2008). NHS Next Stage Review. Our Vision for Primary and Community Care: What it Means for GPs and Practice Staff. [online] London: Department of Health. Available from: http://www.dh.gov.uk/prod consum dh/groups/dh digitalassets/@dh/@en/do cuments/digitalasset/dh 085954.pdf [Accessed 28 October 2011].

Department of Health (2008). NHS Next Stage Review. Our Vision for Primary and Community Care: What it Means for Nurses, Midwives and AHPs [online]. London: Department of Health. Available from: http://www.dh.gov.uk/prod consum dh/groups/dh digitalassets/@dh/@en/do cuments/digitalasset/dh 085956.pdf [Accessed 28 October 2011].

Department of Health (2008). NHS Next Stage Review. Our Vision for Primary and Community Care: What it Means for the Third Sector. [online] London: Department of Health. Available from: http://www.dh.gov.uk/prod consum dh/groups/dh digitalassets/@dh/@en/do cuments/digitalasset/dh 091822.pdf [Accessed 28 October 2011].

Emerson, R. J. and Records, K. (2008) Today's challenge, tomorrow's excellence: the practice of evidence-based education. Journal of Nursing Education. [online] 47(8), pp. 359-370. [Accessed 20 June 2013].

English National Board for Nursing, Midwifery and Health Visiting, and Department of Health. (2001) Placements in Focus. Guidance for Education in Practice for Health Care Professionals. [online] London: Department of Health. Available from: 
http://www.dh.gov.uk/prod consum dh/groups/dh digitalassets/@dh/@en/do cuments/digitalasset/dh 4058368.pdf [Accessed 14 October 2011].

Gannon-Leary, P., Wakeham, M. and Walton, G. (2003) "Making a Difference" to nurse education: the impact on HE libraries. Journal of Librarianship and Information Science [online]. 35 (1), pp. 31-46. [Accessed 19 June 2013].

Health Education South West (2013). Learning and Development Agreement. [online]. Taunton: Health Education South West. [Accessed 16 July 2013].

Holmes, K. (2012) Email to JISC Health Libraries Group HLG members, 8 March 2013.

Johnson, G. (2005) By any means necessary: a future for multiple copy provision? SCONUL Focus. 34 (Spring) pp. 21-26.

Koh,L. (2002) Practice-based teaching and nurse education. Nursing Standard. 23 (16), pp. 38-41.

Lea, S. and Callaghan, L. (2011) Enhancing health and social care placement learning through mobile technology. Educational Technology and Society, 14 (1), pp.135-145.

Lloyd, J. (2012) Comparing the Experience of Library Support for Preregistration Nursing Students on Hospital Based Clinical Placements, and Those on Placements in the Community and Third Sector. MSc, University of the West of England.

Lord, M. (2002) Making a difference: the implications for nurse education. Nursing Times [online]. 98 (20), pp. 38-40. [Accessed 19 June 2013].

Mailer, L. (2006) The UK's SMARTAL Project: St MARTin's College health students access to Learning resources whilst on placement. Health Information and Libraries Journal [online] 23 pp. 110-117. [Accessed 19 June 2013]. 
Marriott, R. (2005) Access to learning resources for students on placement in the UK: what are the issues and how can we resolve them? Health Information and Libraries Journal [online]. 22 (4), pp. 262-266. [Accessed 19 June 2013].

Middleton, A., Rowell, G. and Walton, G. (2002) Health and Education Northumbria Students Access to Learning Resources (HENSAL) Project: Case Studies of NHS Pre-registration Students and School Centered Initial Teacher Training (SCITT) Students. Newcastle: Northumbria University.

Mid Staffordshire NHS Foundation Trust Public Inquiry (2013) Report of the Mid Staffordshire NHS Foundation Trust Public Inquiry (Francis Report). [online] London: Stationery Office. Available from: http://www.midstaffspublicinquiry.com/report [Accessed 20 June 2013].

MINTEL (2013) Digital Trends Autumn - UK - March 2013 [online] London: Mintel. [Accessed 20 June 2013].

National Institute for Health and Care Excellence (2013) Who is eligible/NHS Family? Available from: http://www.library.nhs.uk/athens/eligibility [Accessed 20 June 2013].

NHS Strategic Health Authority Library Leads (2012). NHS Library Quality Assurance Framework (LQAF) England. Version 2.2 [online]. London: SHALL. Available from http://workforce.southwest.nhs.uk/libraries/quality [Accessed 13 May 2013].

Nursing and Midwifery Council (2010). Pre-registration nursing education in the UK. Available from: http://standards.nmc-uk.org/Documents/Preregistration\%20nursing\%20education\%20in\%20UK\%20FINAL\%2006092010. pdf [Accessed 20 June 2013]. 
Nursing and Midwifery Council (2008). The Code: Standards of Conduct, Performance and Ethics for Nurses and Midwives. Available from:

http://www.nmc-uk.org/Publications/Standards/The-code/Provide-a-highstandard-of-practice-and-care-at-all-times-/ [Accessed 01 July 2013].

Norton, F. and Spoor, P. (2002) Delivering information to university health students on placement. IFMH Inform [online] 13 (2) pp.3-5. [Accessed 19 June 2013].

Norton, F., Spoor, P., Gill, M., Mottram, S., Clowes, M. (2003) The Liquid Library Project: Accessing Information While on Clinical Placement: the Experience of Leeds University Students. Leeds: University of Leeds.

OCLC (2013) QuestionPoint at a Glance. Available from:

http://www.oclc.org/questionpoint/about.en.html [Accessed 20 June 2013].

Office for National Statistics (2013) Internet Access - Households and Individuals, 2012 part 2. Available from:

http://www.ons.gov.uk/ons/dcp171778 301822.pdf [Accessed 20 June 2013].

Pickard, A.J. (2007) Research Methods in Information. London : Facet Publishing.

Quality Assurance Agency (2007) Code of Practice for the Assurance of Academic Quality and Standards in Higher Education. Section 9: Work-based and Placement Learning - September 2007. [online] Available from: http://www.qaa.ac.uk/Publications/InformationAndGuidance/Documents/COP 9PlacementLearning.pdf [Accessed 19 June 2013].

Raynor, M. (2009) Access all areas: exploring the use of library and IT facilities by the University of Salford pre-registration diploma nurses during periods of clinical practice placement. Evidence Based Library and Information Practice. [online] 4 (3), pp. 4-18. [Accessed 19 June 2013]. 
Riddington, L. (2008) An Investigation into Pre-registration Nursing Student's Use of Library Resources, Services and Support during Clinical Placement: the Views of Students and University Staff. MSc, University of the West of England.

Research Information Network (2011) E-journals: their use, value and impact final report. Available from:

http://www.rin.ac.uk/our-work/communicating-and-disseminating-research/ejournals-their-use-value-and-impact [Accessed 13 May 2013]

Royal College of Nursing (2006) Helping Students Get the Best From Their Placements. [online]. London: Royal College of Nursing. Available from: http://www.rcn.org.uk/ data/assets/pdf file/0011/78545/001815.pdf [Accessed 19 June 2013].

Royal College of Nursing (2011) How trustworthy is your information? [online] London: Royal College of Nursing. Available from:

http://www.rcn.org.uk/development/learning/learningzone/personal skills/how trustworthy is your information [Accessed 18 June 2013].

SCONUL (2012) Annual Library Statistics 2010-2011. Available from:

http://www.sconul.ac.uk/sites/default/files/documents/ALS1011.pdf [Accessed 20 June 2013].

University of Leeds (2010) 'Generation Y' student doctors swap textbooks for iPhones. Available from:

http://www.leeds.ac.uk/news/article/895/generation y student doctors swap textbooks for iphones [Accessed 20 June 2013]

University of Plymouth (2012) Psychology students to benefit from e-ngaging new digital book project. Available from:

http://psychology.plymouth.ac.uk/en/courses/quality-teaching/free-textbooks/ [Accessed 20 June 2013] 
University of the West of England (2010) Critical Review of the Curriculum for the Adult Nursing Programmes: Dip HE/BSc(Hons)/Graduate Diploma. Bristol: University of the West of England.

University of the West of England (2011) Agreement for the provision of library services. Bristol: University of the West of England.

University of the West of England, Department of Nursing and Midwifery. (2013). Undergraduate Modular Scheme. BSc (Hons) / Graduate Diploma Nursing Pre-registration Curriculum. Contextual Documentation for Validation. Bristol: UWE.

University of the West of England (2013) UWE Bristol Strategy 2020.

Available from:

https://share.uwe.ac.uk/sites/marketing/VCUpdate/Documents/UWE-BristolStrategy-2020.pdf [Accessed 20 June 2013].

University of the West of England. (2013) UWE Library Services Survey (LibQual) 2012 - Results. Bristol: University of the West of England. Available from: http://crln.acrl.org/content/73/6/311.full.pdf [Accessed 20 June 2013].

Urquhart, C. and Davies, R. (1997) EVINCE: The value of information in developing nursing knowledge and competence. Health Libraries Review. 14, pp.61-72.

Walton, G., Smith, A., Gannon-Leary, P. and Middleton, A. (2005) Supporting learning in practice in the EBL curriculum: pre-registration students' access to learning resources in the placement setting. Nurse Education in Practice [online]. 5 (4), pp. 198-208. [Accessed 19 June 2013].

Walton, G., Childs, S. and Blenkinsopp, E. (2005) Using mobile technologies to give health students access to learning resources in the UK community setting. Health Information and Libraries Journal [online]. 22 pp. 51-65. [Accessed 19 June 2013]. 
Ward, R. and Moule, P. (2007) Supporting pre-registration students in practice: a review of the current ICT use. Nurse Education Today [online]. 27, pp. 60-67. [Accessed 19 June 2013].

Wyatt, G. (2013) Email to Pauline Shaw, 25 April 2013.

Yeoh, J. and Morrissey, C. (1996) Selection of library services by postregistration nursing, midwifery and health visiting students. Health Libraries Review. 13 (2), pp. 97-107. [Accessed 19 June 2013].

Young, P., Moore, E., Griffiths, G., Raine, R., Stewart, R., Cownie, M. and Frutos-Perez, M. (2010) Help is just a text away: the use of short message service texting to provide an additional means of support for health care students during practice placements. Nurse Education Today [online]. 30 (2), pp. 118-123. [Accessed 19 June 2013].

Younger, P. (2010) Internet-based information-seeking behaviour amongst doctors and nurses: a short review of the literature. Health Information and Libraries Journal [online]. 27, pp. 2-10. [Accessed 19 June 2013]. 


\section{APPENDICES}

\section{APPENDIX 1}

Detailed breakdown of the Literature Review search strategy.

Table 1: Databases used

\begin{tabular}{|l|l|}
\hline Database & Provider \\
\hline $\begin{array}{l}\text { AMED (The Allied and } \\
\text { Complementary Medicine Database) }\end{array}$ & Ebsco \\
\hline $\begin{array}{l}\text { ASSIA (Applied Social Sciences Index } \\
\text { and Abstracts) }\end{array}$ & Proquest \\
\hline BNI (British Nursing Index) & Proquest \\
\hline $\begin{array}{l}\text { CINAHL Plus (Cumulative Index to } \\
\text { Nursing and Allied Health Literature) }\end{array}$ & Ebsco \\
\hline Education Research Complete & Ebsco \\
\hline Embase & Ovid \\
\hline $\begin{array}{l}\text { Library and Information Science } \\
\text { Abstracts (LISA) }\end{array}$ & Proquest \\
\hline $\begin{array}{l}\text { Library, Information Science \& } \\
\text { Technology Abstracts (LISTA) }\end{array}$ & Ebsco \\
\hline MEDLINE & Ebsco \\
\hline PsycINFO & Ebsco \\
\hline
\end{tabular}

Table 2: Identifying appropriate terminology

\begin{tabular}{|c|c|c|}
\hline $\begin{array}{l}\text { Concept/Word group } 1 \\
\text { "nursing student" }\end{array}$ & $\begin{array}{l}\text { Concept/Word group } 2 \\
\text { "clinical placement" }\end{array}$ & $\begin{array}{l}\text { Concept/Word group } 3 \\
\text { "library support" }\end{array}$ \\
\hline $\begin{array}{l}\text { Student* }^{\star} \\
\text { Pre-registration } \\
\text { Pre-qualif* }\end{array}$ & $\begin{array}{l}\text { Clinical placement }{ }^{*} \\
\text { Practice placement }\end{array}$ & $\begin{array}{l}\text { Librar }^{\star} \\
\text { Learning resource } \\
\text { Information resource* }\end{array}$ \\
\hline
\end{tabular}




\section{Table 3: Final search strategy}

Advanced search carried out with terms used a keywords and mapped to default range of fields.
1) Student* or pre-registration or pre-qualif*
2) Clinical placement* or practice placement
3) Librar* or learning resource* or information resource*
4) 1 and 2 and 3 and 4
5) Limit 4 to English language
6) Limit to 2010 onwards (since previous research carried out) 


\section{APPENDIX 2}

Chart showing home, like home etc from 2010 Adult Nursing curriculum.

Proposed Conceptual Model for Professional Practice (UWE, 2010

\begin{tabular}{|c|c|c|c|}
\hline Placement & Description & Example & Explanation \\
\hline Home: & $\begin{array}{l}\text { The patient lives and receives } \\
\text { care at home. }\end{array}$ & $\begin{array}{l}\text { Placement with a } \\
\text { Community } \\
\text { Practitioner (i.e. } \\
\text { District Nurse) }\end{array}$ & $\begin{array}{l}\text { Includes a range of tenures including: Owner occupier/private } \\
\text { or LA tenant/leaseholder/sheltered housing tenant. } \\
\text { May include rehabilitative/preventative/palliative care. }\end{array}$ \\
\hline Like Home: & $\begin{array}{l}\text { The patient resides and } \\
\text { receives care in a setting that } \\
\text { replaces or strives to replace } \\
\text { the patient's own home. }\end{array}$ & $\begin{array}{l}\text { Hospice, Care } \\
\text { Home Settings. }\end{array}$ & $\begin{array}{l}\text { The institution aims to replace or replicate home with home like } \\
\text { surroundings with a permanent or semi permanent alternative } \\
\text { to home for a short or prolonger period of time. }\end{array}$ \\
\hline $\begin{array}{l}\text { Near to } \\
\text { Home: }\end{array}$ & $\begin{array}{l}\text { The patient receives care in a } \\
\text { locality centre close to their } \\
\text { home. }\end{array}$ & $\begin{array}{l}\text { Clinics. Health } \\
\text { centres. } \\
\text { Treatment } \\
\text { centres. }\end{array}$ & $\begin{array}{l}\text { Short term care provided for individuals and groups on a local } \\
\text { basis. }\end{array}$ \\
\hline
\end{tabular}




\section{APPENDIX 3}

\section{RESEARCH QUESTIONNAIRE}

Supporting the Library and Information needs of UWE health and social care students on placement.

The results of this survey will be used to inform the development of a new service to support health and social care students on placement.

Please relate all your answers to your most recent clinical placement.

1. What programme are you studying?

3. What is your current year of study?

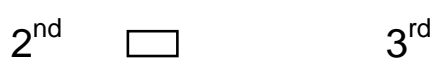

3. Where was your last placement? (i.e. name of hospital, health centre, venue)

4. During your placement how frequently did you use the following libraries?

\begin{tabular}{|l|l|l|l|l|l|}
\hline & \multirow{2}{*}{$\begin{array}{l}\text { A few } \\
\text { times a } \\
\text { week }\end{array}$} & Weekly & Monthly & Occasionally & Never \\
\hline & & & & & \\
\hline & & & & & \\
\hline $\begin{array}{l}\text { UWE e.g. } \\
\text { Glenside, } \\
\text { AW }\end{array}$ & & & & & \\
\hline $\begin{array}{l}\text { NHS library } \\
\text { on hospital } \\
\text { site }\end{array}$ & & & & & \\
\hline $\begin{array}{l}\text { Other e.g. } \\
\text { public }\end{array}$ & & & & & \\
\hline
\end{tabular}


5. At your placement venue, which of the following facilities were available for your use?

Study Space.

Library/Resource

Centre.

Computer with

Internet access.

\section{Available Not available Don't know}

6. Which of these facilities was most important to you?

7. How important was it for you to access library resources whilst on placement?

Important $\square \quad$ Useful but not essential $\square \quad$ Unimportant

8. What was your main reason for using library resources? Please tick one.

Completing an assignment.

Studying.

Professional updating.

To support clinical work.

Other.

Please

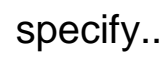

9. Where did you do most of your studying?

UWE library

NHS library

Other eg public library

Home

Other (please specify)

10. During your placement, from which locations did you access the following library resources? Tick all that apply.

UWE NHS Home

Printing/copying.

Printed resources

Books.

Journals. 
Electronic resources

e-books.

e-journals.

Databases.

Websites.

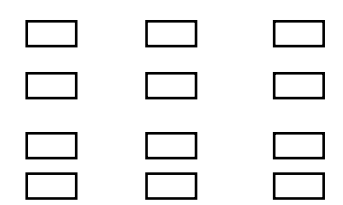

11. Do you have access to any of the following at home? Tick all that apply.

PC at home.

Laptop.

Tablet.

Smartphone

Access to the

Other (please specify)

12. Before going on placement, do you feel you received appropriate preparatory training on how to access library resources from off campus?

Yes $\square \quad$ No $\square \quad$ Not sure

13. During your placement, how often did you contact any of the following for support in using library resources or facilities? Tick all that apply.

UWE librarian.

NHS librarian.

Mentor/Placement facilitator.

Academic tutor.

UWE IT support staff.

Ask a Librarian / Chat

Other (please specify)

\section{Often Sometimes Never}

14. Please describe the main reason(s) why you contacted staff for support in using library resources or facilities. If possible, please also indicate who this was: 
15. When using library resources, or accessing staff for support in using library resources, what went well for you and why? [please specify]

16. When using library resources, or accessing staff for support in using library resources, did you experience any particular difficulties? [please specify including if at a specific location]

17. If you would like to add any other comments regarding your use of library resources and services on placement please do so below.

Thank you for your help.

\section{paneine Shaw and Jon Lleyd}

Pauline.Shaw@uwe.ac.uk or 01173288405 (Glenside Campus Library)

Jon.Lloyd@uwe.ac.uk or 01173288569 (Glenside Campus Library) 


\section{APPENDIX 4}

Janet 3G price list

\section{janet 3G}

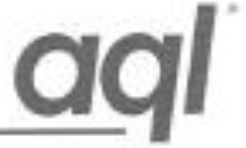

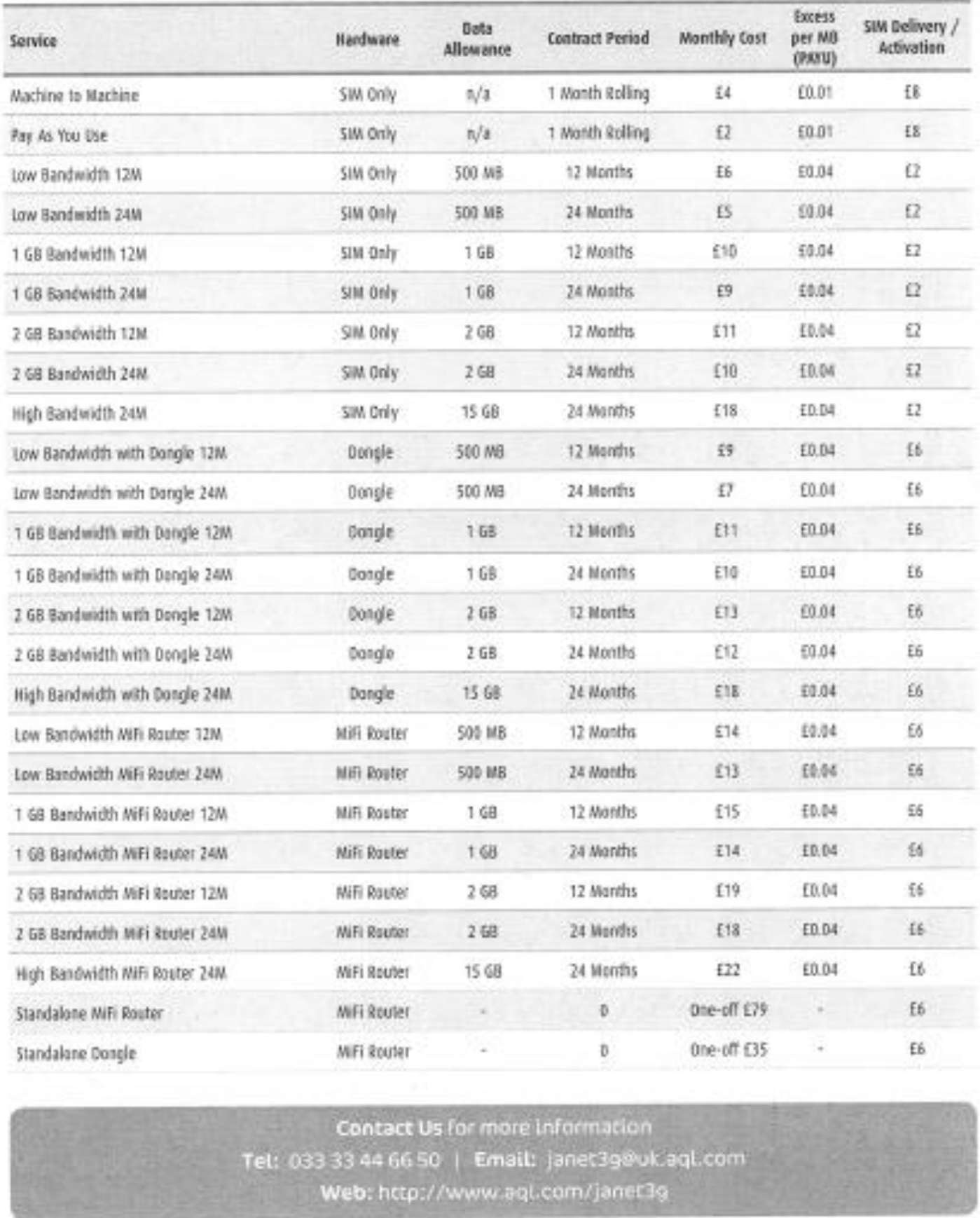




\section{APPENDIX 5}

\section{Structured interview questions - Academic in Practice}

1 - What types of queries relating to library resources do you receive from mentors/UWE students on placement?

2 - How often do you get asked questions about UWE library resources?

3 - If you are asked a question about UWE library resources which mechanisms do you use to resolve the query i.e. UWE CHAT, UWE Library webpages, NHS Liaison and Placement Support Librarian?

4 - Do you think that Academics in Practice would benefit from more training on UWE library resources in order to help you support UWE students?

5 - Is there any other information that you would find useful regarding library resources, which would assist you in supporting UWE students (or mentors) on placement?

6 - Are there any other comments or issues you would like to raise regarding students/mentors use of library/learning resources whilst on placement? 


\section{APPENDIX 6}

\section{Transcript of academic in practice interview}

LF: We've tried to ensure they're evidence based practices and that they link the theory to the practice, they're agenda is perhaps different to ours, they're agenda is to pass, they have to get through they have to do well, the difficulty we have is whilst they've got assignments to do they don't link up the relationship between looking for UWE resources and doing skills and practice at the same time. In terms of queries relating to library resources do I get from students? I don't

PS: They don't see the connection

LF: They don't see the connection. In terms of mentors wanting to know about library resources at UWE, the only time that might happen is if a registrant in the organisation is undertaking any CPD activity at UWE because what they will do and I've got a typical example, I saw a student, I've got a CPD student who works in the trust and doing her dissertation she's using the trust library to access all her materials she's not using the university library because its local it's easy to go into they can go in, chat to the librarian that is on site saying can you help me with this, they don't have to go far to get it so it's the convenience factor and they've already had that familiarity. But that's just one person, that's anecdotal so I don't know about other people and I think only then if people are doing CPD, certainly from my experience of doing CPD they access the UWE library when they are here. They won't tend to access the library because a) because if they've got to come here some of them are logistically travelling a long way or they may be able to go to Alexander Warehouse or they may get everything they need via their local providers library.

PS: We don't really think so much about just the physical library here, we are talking about all of the online resources that we subscribe

LF: But they don't, they go straight to their trust/NHS library, they just don't do it, in fact some of the students use the trust library instead of coming in or using our resources, and I don't know if that's a good idea, since we've changed our programme it's about students engagement in searching for literature and the ways we now prepare students for actively engaging in accessing and sourcing evidence I don't know what the change is. Quite often they separate it out, I completely get it, its really demanding and hard out in practice they get home busy shift, completely wracked, sore feet a headache had nothing to eat or drink all day and then they've got to turn around and search the library and I don't think they will after a long hard day at work. But they will when they are on SOL days or when they are here or on days off.

JL: Why do you think when they are on placement your impression is that they go to an NHS library over ours? Is it because their kind of frame of mind is that they are on practice and therefore they should be using the practice library

LF: I think for the CPD students that's often the case because they are often employed by that organisation so they are used to that library, if they are employed by that organisation and they have used that library throughout their employment its familiarity, they already know the library staff or whatever and they may have engaged in using them before they started and I think when you've got something to do you tend to resort to what familiar and known rather than entering into something new. Some work and live in the Forest of Dean and you know the forest is a bit of a strange place and some of them don't have internet access we can always assume, because this one lad said to me 'I had no internet for two days the snow came down and the world stopped' because it does in the forest of dean so those are other... we can't assume everyone has got quick easy internet access because some places are still battling against the odds

PS: In terms of the undergraduate students that are on placement then that's a slightly different kettle of fish so their mainly focussing on their practice placement

JL: so you don't think they really go to a library at all pretty much?

LF: I don't know

JL: Other than possibly when they are on an assignment

LF: I don't know, I really couldn't comment

LF: My sense is usually that it is assessment driven but that you know years of experience, I couldn't categorically say, they need to get on with it and they know they've got an assignment

JL: So does assessment driven mean someone is assessing them in practice? 
LF: No, through theoretical assessment, I don't know about whether or not its driven by, because there practice is assessed through different sets of things, through observation of practice from information they have done, they may have done numeracy or reflective accounts, you know then if they have to do something about a skill we tell them to refer to trust policies or the Royal Marsden manual. So there are key sources of text which students would automatically turn to because that's what the organisation uses to drive forward their policies and their practices so therefore they have to ensure they are doing that in order to meet their safe standards within the agreed requirements of the organisation JL: So do you have a role, we've mentioned about the mentors and the CPD, and do you have a role in terms of training mentors or working with mentors

LF: We do mentor updates, but the mentor updates are all about mentoring and assessing the students in practice, so it's about the assessment process and how we assess students in practice.

JL: So that's not the same as the FLAP course?

LF: No the FLAP course is the preparation for them to become assessors and mentors in practice and the NMC standards require them to have an accredited teaching and assessing module as part of their CPD before they can become mentors so that's an accredited module within the university

JL: But the mentor updates would be once they've got that qualification they are in process of...

LF: Yes, and the NMC require mentors to have an annual mentor update, so that's what the academic in practice team do and deliver on an annual basis, and we change it annually to reflect changes in programmes and practice related issues

JL: So in a mentor update setting would you discuss queries that they are getting from the students that are on placement and how the library links in with that?

LF: Nothing

JL: No

JL: Because the perception is that they are just worried about they're placement and they're

assignment, or because they have no questions?

LF: Well the nature of the update is to focus on the assessment process, and what mentors want to know is how to assess the student, what do I do if the student is failing and the student if they are failing will contact the university and the academic in practice team go in to look at action plans to actually get them to look at their knowledge base we revisit their skills because they have to complete skills sheets and you know we need to ensure they are evidence based but again they cant use huge sources of evidence in what we are expecting them to do because at the very least we would expect them to relate to trust policies maybe NICE guideline some of the key seminal pieces which should be used to inform what they are doing in practice

JL: So if the evidence that we have seen suggests that students on placement seek help from their mentor, about a range of issues, some of which may be accessing resources how to access library resources and things like that do you think that it would be a good idea to somehow train the mentors on answering those kinds of questions whatever training the mentors might be or do you think that wouldn't be something they would be interested I? Would they think well the library should be dealing with all of that and..

LF: I can't comment on that all I can say to you is at this moment in time staff are having all mandatory study days cancelled because of bed shortages lack of staff too many ill patients and not enough people on the ground so they are not attending those sorts of things so then the chances of that happening unless you did it via an online thing and then they are bombarded, I'm trying to think...

JL: So realistically it's not going to happen

LF: Realistically the only way it will happen is if we see those individuals within CPD, that's the way that it works most efficiently

JL: IN a perfect world do you think there would be any desire from the mentors to have updates..

LF: I don't know you'd have to ask them, I can't answer for them I'm really sorry

JL: Okay no that's fine

LF: But I think you'd need to ask them, and again it all depends on individual agendas

JL: And time and pressures etc

LF: And why would they want to use our library resources as opposed to the trust library resources and I know for a fact that in the community provision there are some practitioners there are seven practitioners sharing one computer

PS: Says it all really

LF: You know, and when you've got seven practitioners sharing one computer and you've got to get patient records done and updated those are the pragmatic problems that people are facing out in practice.

LF: ARC is the system that we use for a repository of practice related things its being developed and the practice support net will be subsumed into ARC and the PS net is where mentors if they need 
information can go so the only thing that I can suggest that you might want to consider, in terms of moving things forward is to have a dedicated tab and then you can click on it because it has got to be quick it's got to be easy it's got to be something mentors can see I can click on that I can find what I want job done and if you could perhaps think of ways you could link into the support because the access of evidence could be the way you could link into practice is via that practice support mechanism PS: That's a really good idea actually

JL: Even if it's just got a link to chat

LF: I think mentors need to find help and support for students in practice so therefore if you and you'd need to link in with the working group on ARC to do that

PS: But that's where they go, that's what they use

LF: That's what they will be using is going online later on in this year and it will be enhanced, its got a lot of facilities in it but I just know for the PS net at the moment, there is a list of FAQs but you need a tab or something that clearly flags quick links to help for access for whatever you need

LF: That might actually be one way of getting support out there in the right place because that is what mentors will want to be using and we will be doing that

JL: But that will be used by both mentors and by the students, almost like that would be a better place to site the information hub than on the library webpages, I mean you would have it in both places but they might go to that first

LF: Because the universities' website is incredibly clunky and hard to get round but when I go into practice and see mentors because they have to put mentor updates online through the PS net so while they are there they bookmark it in their favourites now you've got it bookmarked so them this is what you use it for, it will be just another string to the bow on trying to provide a different type of support JL: Just from you're knowledge of mentors and students on placement in general terms and ultimately from this search me and Pauline are trying to make recommendations for a new service based here rather than based out in some of the sites, is there anything you can think that is already part of the service that could enhanced or something new like that ARC thing? Or is there a hit list of things that you often hear students saying it's alright but I wish..

LF: What about links to other related websites like the DOH like NICE all those other related professional organisations

JL: Delicious type stuff

PS: Quick links

LF: Yeah quick links to the NMC quick links that are overt instead of convert, because when you start to drill in your think you haven't got the time to do this

PS: Because there is a whole range of subjects the library webpages have to reflect you've got to get to the health and social care first but it is there, but maybe if we could link directly to it through ARC if they let us

LF: The practice support net you could use it you could nurse it in terms of professional silos for want of a better turn of phrase

PS: For example a quick link the Marsden because we've got that as an e-book

LF: Yeah, fab

JL: But from what you're saying we need to be very conscience of the fact that despite what we get on our surveys when students are on placement they are very very focused on their placement and they

have lots of time pressures and everything and we don't want

PS: We're actually quite low down the list of priorities

LF: Well the deadlines for UWE assessments and then all of a sudden it shifts up priority and I think that's human nature

LF: Everybody works to their own priorities 'I'll leave it until I know it's a priority and then when I know its pressing ill crack on and do it

JL: Is there anything else?

LF: I mean all of us are academics we've all studied degrees and masters

JL: How many of you are there?

LF: 15

JL: And that's covering every different kind of school and subject

LF: No its nursing, academics in practice are nursing focussed so we support students across all the four fields of nursing but that includes hospitals, care hospitals, community care settings and the independent and voluntary sector it could be a nursing home or it could be a very busy teaching hospital or it could be a GPs practice, and that's where you'll probably find seven sharing a computer PS: So how do the students communicate with you if they need to, is it all done by email?

LF: If they need support and help in practice they contact us via the practice support line and then the practice support line if they can't deal with the query themselves they will then distribute the query to 
the relevant academic in practice and they know who covers which patch, so for me if I've got a student at Gloucester Royal hospital that need support the practice support line will then redirect the query to me

JL: And if you then wanted to bounce a query onto us what mechanism, something about a library resource that you aren't able to answer what mechanism do you use to pass it onto us?

LF: Well if it's about assessments and student written work I usually direct them back to their module leaders because I am not familiar with the assessment that they are doing if you need help go back to the library for help or go to the appropriate module leader for help because I wouldn't be able to give them the right advice about their assessment because I'm dealing with practice I am not familiar with all the assessments across all the adult programmes

JL: If you said to them, you'll need to speak to the library about that is there a particular way that you would recommend they get in touch?

LF: No I say just go back to the library, because quite often they're taking half an hour out to see me so I just say can you go back to the library and I put the responsibility back into the call because this is adult learning, they need to take responsibility for that themselves

JL: That's another thing that we are working on, the potential mechanisms for people to get in touch with us, we've got these 24 hour chat, and whether we have a named person here who is in charge of placement queries or whether it's a pool of librarians, but that's interesting that you would be pointing people in our direction if it's the right things for us

LF: I'd say you'll have to go back to the library, if it was a chance conversation about a dissertation coming up looming on the horizon, and they can't find the literature I say well there is masses you need to go back to the library and ask for assistance if you don't know how to do a literature search you need to go back, sign up to a workshop, because quite often I've had it recently where a student says 'there's nothing available', I jolly well know there is and that is available and that suggests to me that your search skills are not up to scratch so go back and refine your search skills so if I do that's how I do it JL: In an average week are you able to give an estimate of how many queries you bounce onto the library or things that are around resources

LF: It's rare, only if I've got dissertation students, I can't even guess

JL: But as you said it might peak a little bit around assessment or dissertation time but apart from that...

LF: But then I would only get those queries from those that know im supervising for their dissertations, I might even have requests to go and look for the literature for them, I tell them they need to go look at that, that's part of the dissertation process, you need to go and do it yourself, but I wouldn't even be able to guess I haven't got a clue

JL: But it's not very often

LF: No not at all sorry

PS: No that useful information

JL: So does that mean they are coming straight to us

LF: I would hope so

JL: Or is it possible the stuff we have on the website is already dealing with all of their questions LF: Don't know

JL: Hopefully that will be what the survey will illuminate, it's what the focus groups would have illuminated if we'd have managed to put them together 


\section{APPENDIX 7}

\section{List of abbreviations}

AHP - Allied Health Professionals

ARC- UWE internal placement management system

BNF - British National Formulary

DoH - Department of Health

EBP - Evidence Based Practice

HASS - Health and Social Sciences

HE - Higher Education

HENSAL - Health and Education Northumbria Students Access to Learning

HLS - Health and Life Sciences

HSC - Health and Social Care

ICT - Information and Computers Technology

JISC - Joint Information's System Committee

LETBs - Local Education Training Boards

LQAF - Library Quality Assurance Framework

MPET - Multi-Professional Education and Training

NHS - National Health Service

NICE - National Institute for Health and Care Excellence

NMC - Nursing and Midwifery Council

NSS - National Student Survey

ONS - Office for National Statistics

PAL - Peer Assisted Learning

PDA - Patron Driven Acquisition

PGCE - Post-graduate Certificate in Education

Placement

PPO - Professional Practice Office

PS Net - Practice Support Network

QAA - Quality Assurance Agency

RCN - Royal Nursing College

RUH - Royal United Hospital

SCONUL - Society of College, National and University Libraries 
SCPHN - Specialist Community Public Health Nursing

SLA - Service Level Agreement

SLA - Senior Library Assistant

SMARTAL - St MARTin's College health students Access to Learning resources whilst on placement

SOL days - Supervision of Learning

THESAL - Teeside Health Students Access to Learning Resources whilst on

UHLMG - University Health and Medical Librarians Group

UWE - University of the West of England 


\section{APPENDIX 8}

Practice Support Net page and individual documents from this page

\section{Practice Support Net}

\section{About the Practice Support Net}

Welcome to the UWE Practice Support Net for mentors and assessors in practice

There is no need to log in or register to use this site.

You will see that we are in the process of reorganising the presentation of information on this site. When complete, we hope that it will be easier to access the information you want to view.

If you have any comments about how we could improve this site or have any information that you think should be here, then please email us HSCPracticeSupport@uwe.ac.uk

Thank you to all the practitioners who work with us to ensure that students on healthcare courses are fit for practice. 


\section{Practice Support Net}

Library Support

\section{UWE/NHS Link Liaison Librarian}

Phil $\sigma^{\prime}$ Shaughnessy is the UWE NHS Link Liaison and Placement Support Librarian. He acts as a link between students on placement and UWE Library Services. If you need help or advice please feel free to contact him via Ask a Librarian

Contacting the Library - http://www1.uwe.ac.uk/library/help.aspx

Help with referencing - http://iskillzone.uwe.ac.uk/RenderPages/RenderRoom.aspx?Context=108.Ares=8B.Room=25

Library recommended websites - https://delicious.com/ \#uwehlslibrarians

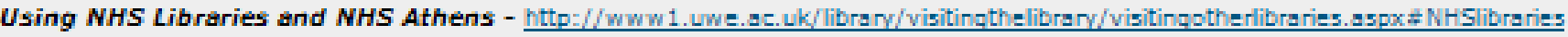

Help with Study Skills - http://www.uwe.ac.uk/library/ressurces/hub/

Study skills information

Disability Support - http://www1.uwe.ac.uk/students/studysupport/disabilityservices.aspx

At Glenside Library we offer individual disability support for library users.

If you would like more information or would like to discuss your specifie needs, contact Rhona Murphy to arrange an appointment on

01173288592 or emsil Rhong. Murphy Muwe.ac.uk 


\section{Library help}

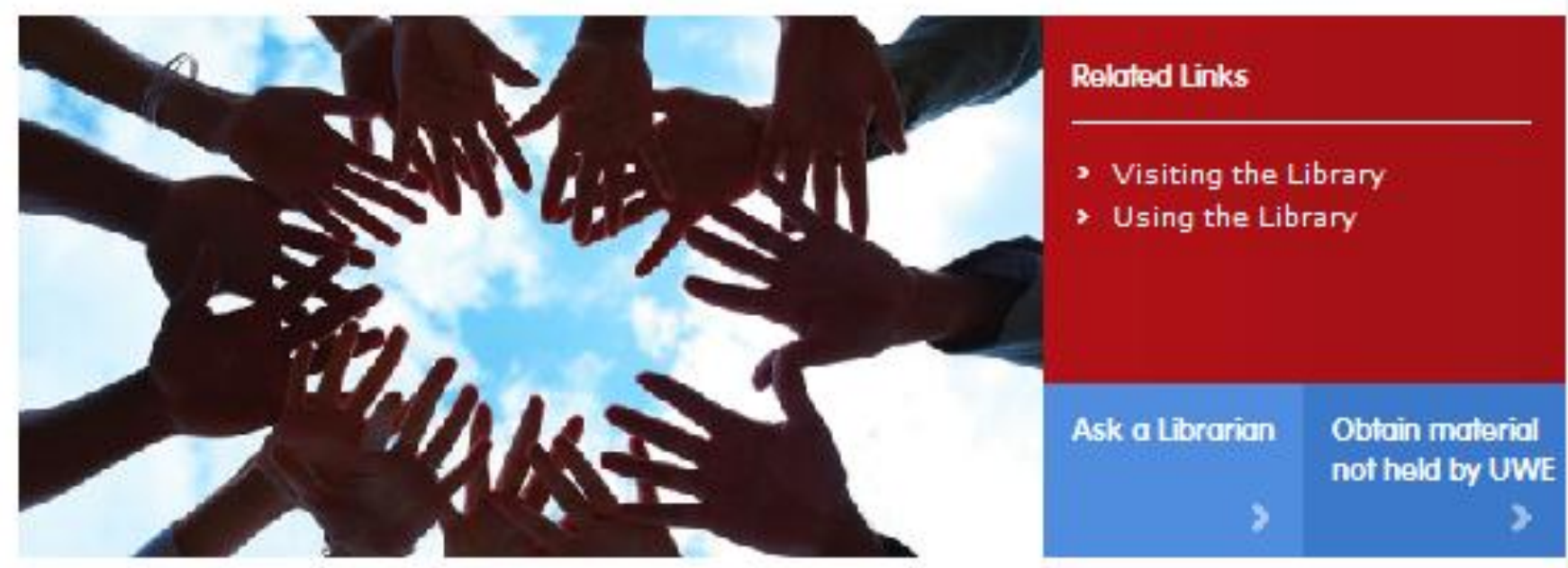

Contact the Library

Contact us by $24 / 7$ online chat, e-mail, phone or talk in person.

Printable library guides

Electronic versions of printed library guides.

\section{Contact the IT Support Centre}

For help with UWE IT, printing issues and laptop advice.

Library website inclex

Index of contents of the library website.
Library workehope and other study support events

- Advanced literature searching for Health and Life Sciences dissertation students (UWE Gloucester) 05/06/2013

- Introduction to RefWorks 06/06/2013

> RefWorks: established users surgery $11 / 06 / 2013$

- UWE Harvard Referencing $11 / 06 / 2013$

More study support events 


\section{SkilliZone}

Home

Getting Started

Types of

information

Finding Items in

the library

Finding journal articles

Plagiarism

Referencing

Evaluating information

Finding

information on the internet

Copyright

Literature review

Search

$\mathrm{Help}$
Home Area > Referencing

\section{Referencing}

In this section you will find...

What is referencing?

- Guide to referencing schemes:

UWE Harvard, MLA, Chicago, OsCOLA, Running Notes

- UWE Harvard referencing quiz and tutorial

- Referencing tools 


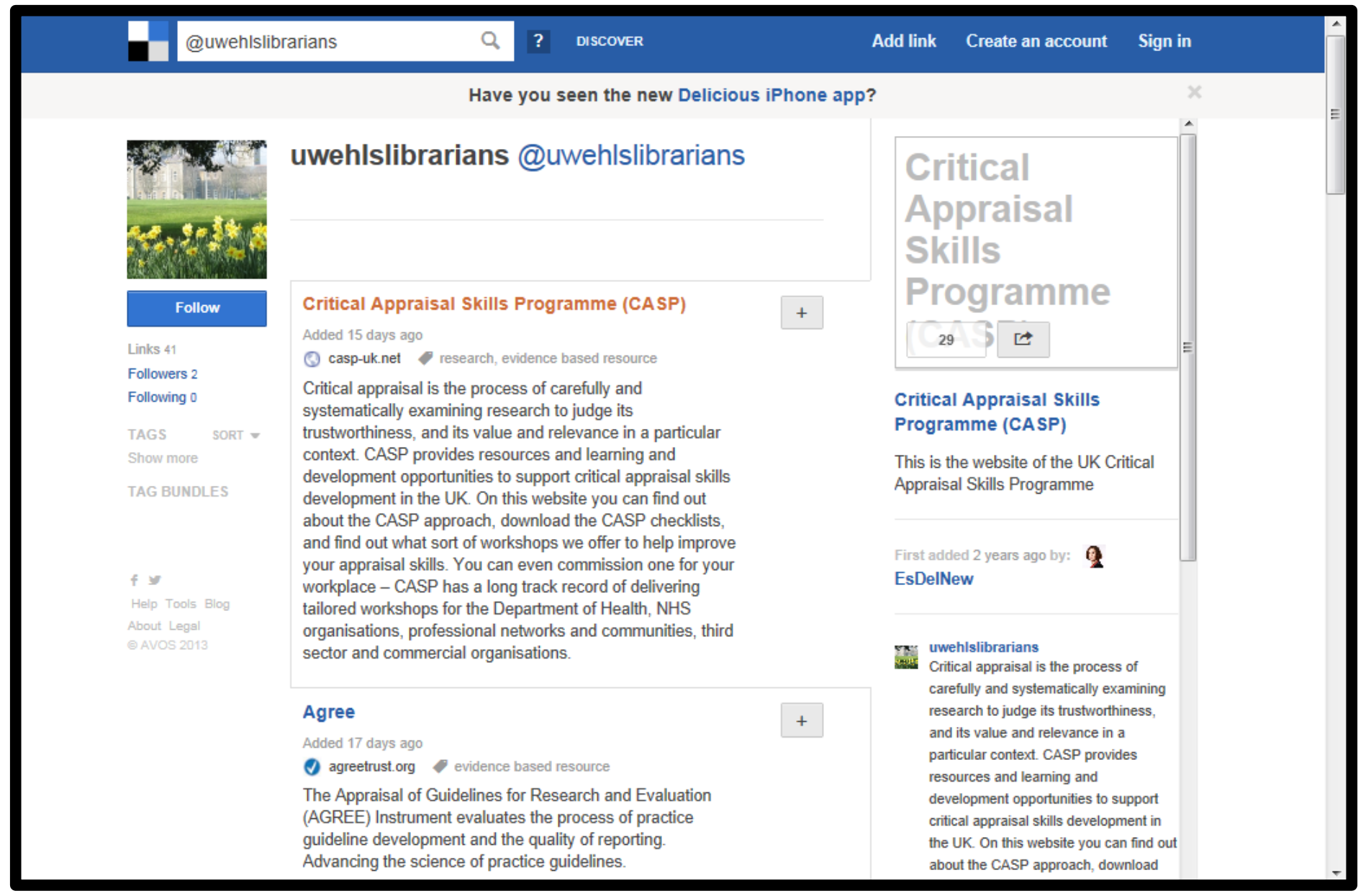


Study skills.

Finding information

Reading and writing

Referencing

Research skills

IT skills

Maths and statistics

Group work and presenting

\section{Time management}

Revision and exams

\section{Study skills}

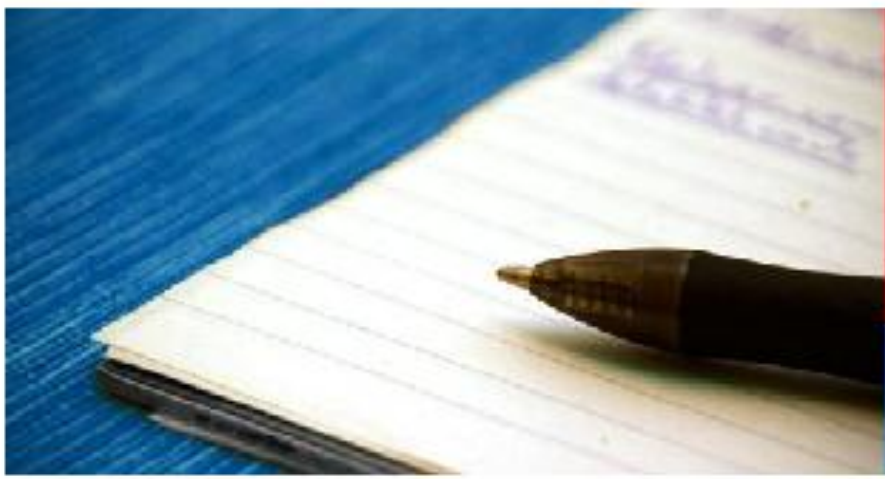

Online tutorials, advice, and 1-to-1 support to help you throughout your studies.

Related Liks

1. Faculty study support

- Internstionsi studert support

- Acodemic adice

- Hesth and wel being

- Careers and employab ty

Study support tibrury X

Finding information

How to find and evaluate information from the Library and online.

\section{Referencing}

uWE Harvard, OSCOLA, snd other reterenging standsrds.

\section{$\pi$ skills}

Computer skllis, Ineluding Microsot once.

Group work and presenting Working with others on group projests and presenting.

\section{Revision and exams}

Bxam preparation and tips to help you on

the $d x y$.
Reading and writing

Acsdemic resding, note taiking, eritica: thinking, writing, plsglarism and copyrignt.

Research skills

Ltergture reviews, reaserch methods and research sicll:

Maths and statistics

Core mothematica and statistics akells.

Time managernent

Getting organlsed will help you manspe your studies.
Coming to UWE

, Study skills for new studente

Study support events

1. Advanced literature sesrching for Hesith and Lfe Sclences dissertation students (UWWE Gloucester) $05 / 05 / 2013$

- Introduction to RePWorks $06 / 06 / 2013$

- ReNWarks; established users surgery 11/06/2013

- UWE Hanvard Referencing $11 / 06 / 2013$

More study support events 


\section{Disability Services}

Disability support at UWE

- Disabled Students Allowances

Access West of England

Specific impairments

Assistive technology

Support for applicants

Useful links

Contact Disability Services

\section{Disability Services}

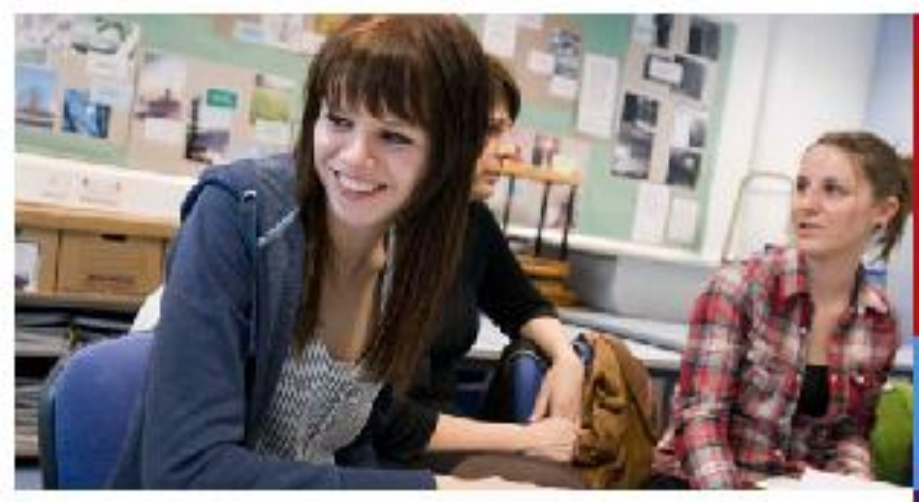

Whether you are a current student or thinking about applying to UWE, we have a range of support services for you. We can help you to access the full range of academic, cultural and social activities that the University has to offer.

Disability support at UWE

Cotering for UWE students' dimerent nesde.

Disabled Students' Allowances

Intormation on non meana tested allowsences for disabled students.

Access West of England

Disabled Students' Allowances nesds sasessments explsined.

Specific impaiments

Information about the types of support and adjustments avallabie.
Assistive technologies

Information on accessing the sas stive technologles sotware.

Support for applicants

Further information for those considering studying at UWE.

Useful links

Reievant links for further guldance.

Contact Disability Services

Usetul contast detals for disablity reloted aervices.
Rekated Liks

1. Studert Senvices

1. Fees and sunding

- Larany Semices

- Accommototion

Book an Alternative

appointment formats

y.

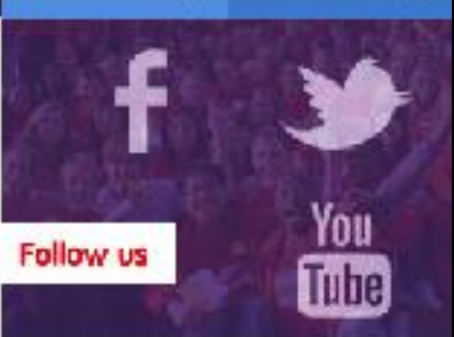

Related documents

Ressonsbie Adjuatment for Dissbisd 흘 Students

Students with a temporary disability or illness

If you have a temporary dsability or severe lliness doe likely to last less than a yesr) which has a substartisi emect on your capacity to study and/or taks sasessments, contact the Disabilit Service to find out how we can heip. 


\section{APPENDIX 9}

Details of the UWE Xternal Access (XA) System

\section{Welcome to the UWE External Access System called myXA (Xternal Access)}

\section{NHS Academies - External Access}

This system has been developed to allow access to UWE resources from external points with internet access. These designated sites, NHS Academies have been created to allow student access to UWE student labs as if they were physically on-site including the ability to print.

The information provided here will take you through the process of logging into this system and gaining access to the UWE Student Desktop.

If there are any problems that this information does not cover then please contact your local systems administrator, who will be able to help personally or refer queries or problems to the UWE Helpdesk as required.

Firstly you may have to log onto the local PC you wish to work on depending on the setup of the particular Academy site. Please do so as per local

instructions. From the desktop select the UWE icon 5 for the External Access system.

You will then be presented with the login screen to the system. Please refer to the External Access homepage for details of how to log in.

Once you have selected the Academy Services option the Remote Thin Client Desktop window will appear as below: 
97 hitps:/lixa.uwe.ac. uk

Fle Edt View Favortes Tods Hab

Aiddress

uweexternal access

Bookmarks | Help | Sign Out

Text version | InfoPoint | Contact us |

Search

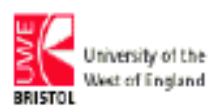

\section{Welcome to the UWE Remote Student Thin Client Desktop}

This allows you to access rour sadent desktop remotely just as you would from a UwE lab. If rou're

using a browser that supports Activex, such as lnternet Explorer you can open the following page:

Remote student desktop (embedded)

Different browser

If you are using a browser other than Micros oft Internet Explorer then you will need to download the dient software:

Citrix ICA Web pluq-in

Full screen mode:

If you have downl oaded the client software then you can access the student desktop in full-screen mode Remote Student Desktop (full-screen)

Page last updated 27/01/2005 11:29:03

(92004 University of the 'West of England, Bristol

Terms \& Conditions | Privacy Policy | Accessibility| Feedbadk

$<$

Select either the embedded option to open a small version of the desktop in the current browser window or select the full screen option to open a new browser window at $90 \%$ of the current screen size (to allow the local system controls to remain visible). 


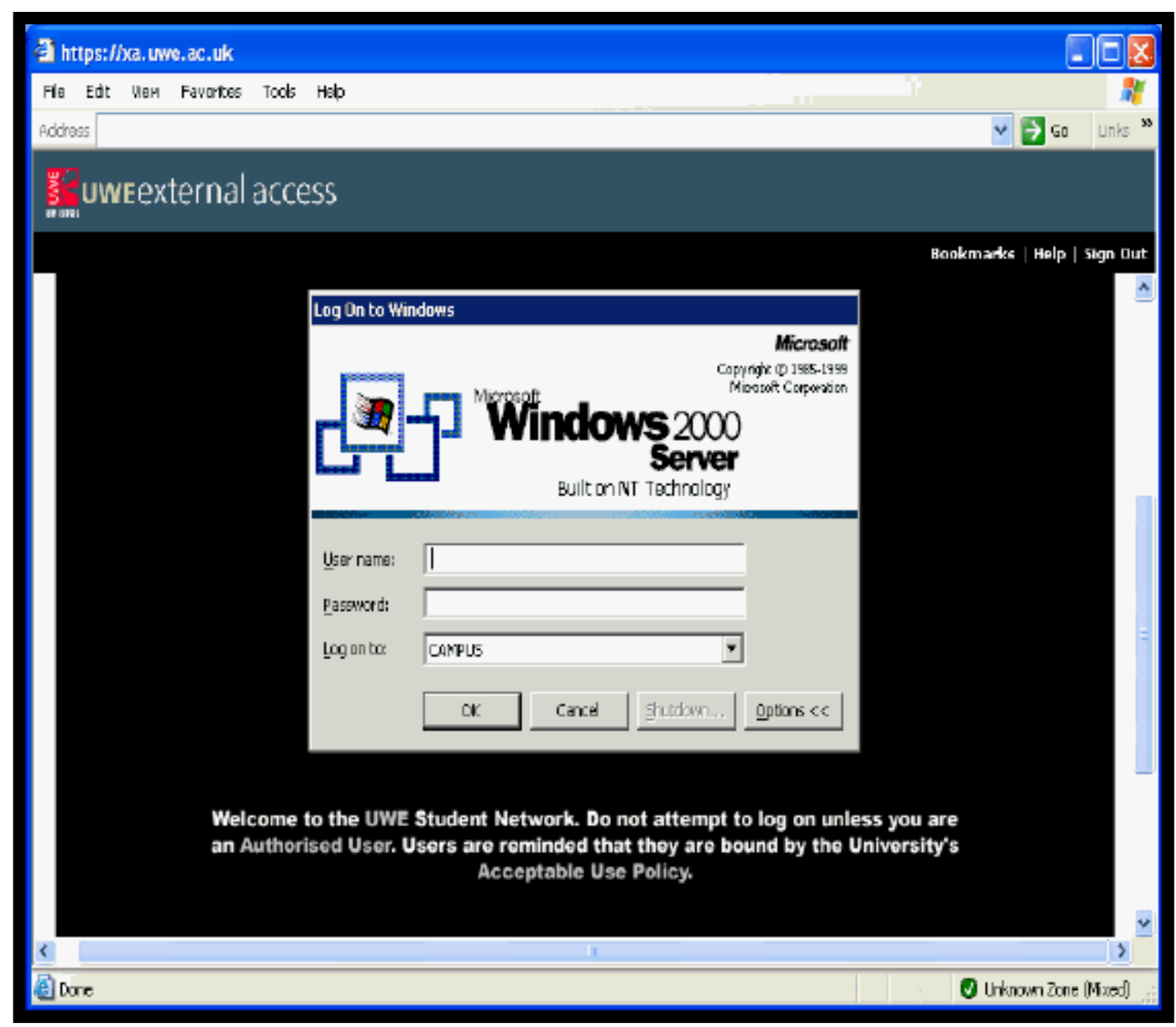

After either option is selected you will be prompted to log into the Remote Desktop session with your UWE id and password. On successful log in the desktop will begin loading.

You will be able to work exactly as you were able to back at UWE campus labs. A printer will be available for you to use which is local to you. There will be no print-station present so all print requests will go directly to the printer provided your Pharos account has sufficient funds. NOTE: If you do not have funds in your account any jobs sent will simply not print. You will need to go through the usual process (via the Pharos charge machines or faulty voucher system) to credit your Pharos account.

When you have finished your session please logoff from the UWE Student Desktop using the Start Menu, Logoff options. Then select the Sign Out option from the top right of your screen to exit the External Access completely.

The machine can be left at either window from this point ready to be used by the next person or alternatively all windows can be shutdown including the Session Manager using the $\mathrm{X}$ box in the top right corner of each window. 
APPENDIX 10

How to access resources at a distance or on placement

\section{Library Services for the Faculty of Health and Social Care}

\section{How to access resources at a distance or on placement}

Phil O'Shaughnessy is the link person between Library Services and placement students. If you need any help please contact him at:

Philip.O'Shaughnessy@uwe.ac.uk or on 01173288592

Electronic resources available on the Internet

\section{Databases}

Information along with printable user guides can be found at

http://www.uwe.ac.uk/library/elibrary/

\section{Electronic journals}

Use the Library Catalogue to find out whether a specific journal is available electronically. For more details about electronic journals, go to:

http://www1.uwe.ac.uk/library/usingthelibrary/findthings/searchforthingsaz/journalsearch.aspx

\section{Passwords}

Most electronic resources offered by UWE Libraries on the Internet require an Athens username and password. You log in to Athens authenticated resources using your UWE network username and password. These can be obtained by visiting your site faculty office or the Glenside Library enquiry desk. See http://www.uwe.ac.uk/library/info/faq/e-resources/, for more information or ask at any UWE library.

\section{Photocopy service}

Journal articles can be photocopied for you subject to copyright law. You need to determine if the material is held in the UWE Libraries by checking the Library Catalogue. To obtain photocopies of material held in UWE Libraries, you can collect photocopy request forms from the Library, or telephone to ask for some forms to be sent to you. The forms are also available to print out at: http://www1.uwe.ac.uk/library/usingthelibrary/borrowthings/putitemsaside/requ estanitembephotocopied.aspx. Fill the forms in, sign them and post to any of the Health \& Social Care Libraries and we will post the photocopies back to 
you. You will be charged at 10p per A4 sheet. The cost will be recorded and you can pay on your next visit. For obtaining photocopies from other libraries, see the section below called Requesting Inter-library Loans.

\section{Renewing items}

Items can be renewed via our 24 hour renewal line $(011732$ 82092) or via "Your Library Account" online. You will need your student number and 4 digit Library PIN.

See Library web page for more information:

http://www1.uwe.ac.uk/library/usingthelibrary/borrowthings/renewing.aspx

\section{Holds - Reserving items in UWE Libraries}

See Library web page for information on how to reserve items.

http://www1.uwe.ac.uk/library/usingthelibrary/borrowthings/placingholds.aspx

\section{Use of other libraries.}

\section{Requesting inter-library loans (ILL).}

To request journal articles or books that are not held in any of the UWE Libraries. Please ensure that you have as much information as possible about the item that you need as this will help to prevent any delays in processing your request. Also the ILL will be sent to the e-mail address on MyUWE so check this and if necessary amend it.

Check the Library Catalogue at http://www.uwe.ac.uk/library/catalogue/ for holdings at all UWE libraries to ensure that the item is not already in stock. If you find that the item is available at another UWE library go to http://www1.uwe.ac.uk/library/usingthelibrary/borrowthings/putitemsaside/requ estanitembephotocopied.aspx. which has more information about Intercampus loans (ICL) and photocopies. To submit a request go to www.uwe.ac.uk/library. To find the form and instructions click on using the library, then Find things/Obtain material not held at UWE/Make a request. Login to the ILL request form using your UWE username and password. Select book or journal article. Enter as much detail as you can. Submit the request. You are required to agree to the copyright regulations. You will receive an e-mail confirming that the library has received your request. The article will be sent as a link on an e-mail to your UWE e-mail addres.

\section{Sconul Access.}

Sconul Access enables you to borrow from other libraries that are close to where you live or work. The list of participating libraries is at http://www.access.sconul.ac.uk/members and includes the Universities of Plymouth and Southampton. You will need to apply to join the scheme at one of the UWE Libraries before you go on placement.

NHS Trust libraries. 
NHS Libraries offer resources and services for students on placement. It is well worth investigating what is available in your placement area. Go to www.hlisd.org to see where your nearest NHS library is.

\section{NHS electronic resources.}

When on placement in the NHS, students are entitled to access NHS electronic resources. This includes a similar collection of bibliographic databases to those available at UWE (e.g. British Nursing Index, CINAHL) and a large collection of over 2,000 full-text electronic journals. To access these resources you will need an NHS Athens password which students on NHS commissioned courses will be sent.

\section{Contacting the Library}

From the library homepage click on Ask a Librarian and contact us via 24/7

online chat or alternatively click on the link below this to e-mail or to phone us. 
NHS Athens FAQs from UWE Library Webpages

\section{Logging in to databases via NHS Athens: FAQs}

\section{What is NHS Athens?}

Athens is an authentication system used to control access to databases.

Your NHS Athens username and password will grant you access to databases subscribed to by NHS England.

One of the main benefits of NHS Athens is that this interface will be the one you use when you start work in the NHS.

Am I eligible to use NHS Athens?

If you are eligible you will automatically receive a registration e-mail giving you your NHS Athens username and password.

You are eligible if you are a healthcare student on an NHS (England) commissioned education programme which involves practice and placement within NHS services.

\section{How do I log in?}

Go to the NHS Athens login page, enter your username and password, then click on the NHS Evidence logo at the top right of the screen to access the resources.

\section{How long will access last?}

It will last for the duration of your UWE course. Initially the system will set you up with access for one year and then, if you are still eligible, access will be renewed automatically on a rolling one year cycle for the duration of your course. You do not need to do anything yourself to renew.

\section{Do I need to pay?}

No, access to databases with your NHS Athens username and password is free.

\section{What extra databases and other resources can I access?}

UWE resources and NHS resources are complementary. Extra resources you can access from the NHS include the following: 
- Health Business Elite - Health care administration and other non-clinical aspects of health care institution management

-Additional Electronic Journals

A full list is available at NHS e-resources information page.

How can I get training on these new databases?

Please contact your local NHS trust library. You can search for their details at HLSID.

I've lost my registration e-mail with my username. What do I do?

Contact the library and let us know. We will endeavour to help you as soon as possible.

I've forgotten my password. How can I get it?

You can reset the password yourself. Go to password reset 


\section{APPENDIX 12}

UWE staff guide to using Microsoft Lync.

Microsoft Lync 2010 makes it easy for users to create, moderate, and join ad hoc online video \& audio meetings with internal and external users. A rich user experience and a unified interface make it easy for people to work together effectively and often even when time or distance prevents in-person meetings.

Here are some of the reasons why we feel that Lync can be a useful tool to enhance your teaching sessions and learning experience.

- Lync is a robust and worldwide Microsoft supported and developed product

- Lync is fully supported by UWE trained technical staff

- Lync is embedded within the UWE intranet

- Lync can allow the simultaneous reviewing of documents - good for staff-student feedback of work

- Lync delivers PowerPoint slides similar to being in a lecture hall as well as the ability to annotate them using SMART style whiteboard features as used within UWE

Here are some examples of who you can contact using Lync

- Faculty Staff in their offices

- UWE Staff in their offices within other faculties

- UWE Staff working at home or offsite

- The UWE meeting rooms with Polycom conference equipment installed

- UWE Students in their accommodation

- People external to UWE 


\section{APPENDIX 13}

Focus group/ Surveymonkey bookmarks
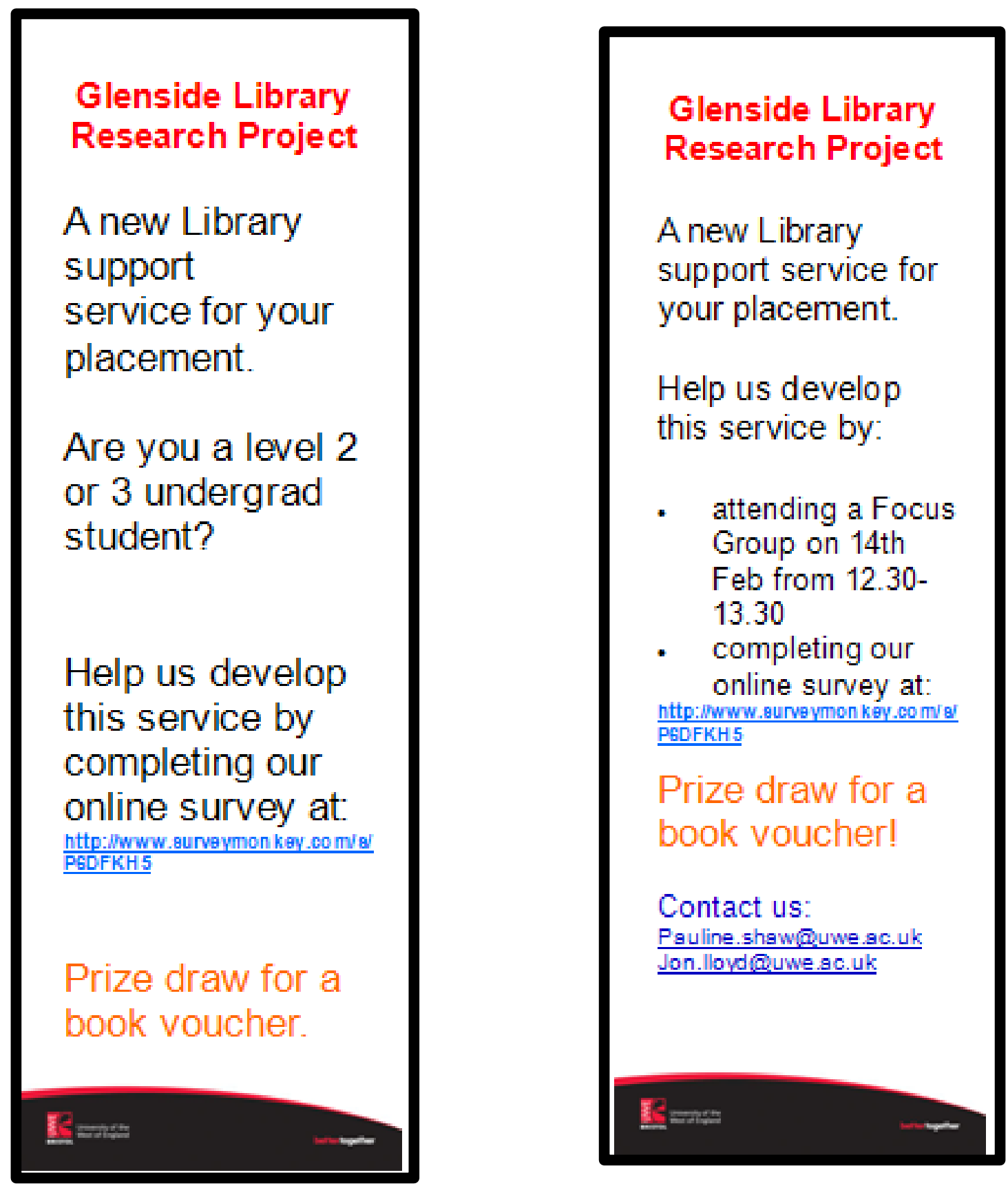


\section{APPENDIX 14}

\section{List of NHS Placement locations from Surveymonkey}

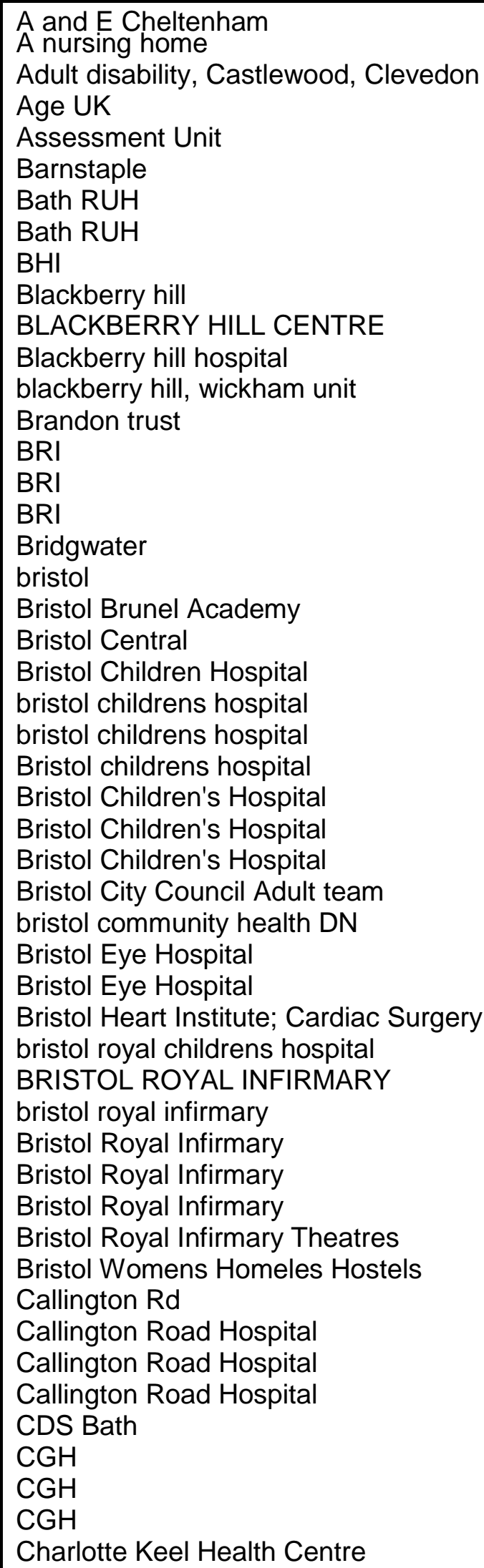

Charlton Lane

Cheltenham General

cheltenham general

Cheltenham general

Cheltenham General

Cheltenham General

cheltenham general

cheltenham general hospital

Cheltenham General Hospital

Cheltenham General hospital

Cheltenham General Hospital.

Emergency Department

Cheltenham Hospital

cheltenham primary mental health

care team

cherry orchards

childrens centre

Childrens ward Swindon

Chippenham Birthing Centre

Cirencester community nurses PCT

Cirencester Hospital

Clevedon children's centre, The Barn,

Clevedon

Clevedon community team

Clevedon Hospital

community

Community assertive outreach

cheltenham

Community- Childrens Centre

Community Hospital, Dursley

community in Bath

community older persons stroud

Community Placement

Corsham Health Centre with Health

Visitors

crisis team bristol

Crisis Team, Weston General Hospital

Cruckton Hall School, Shrewsbury

CYPS

Day Centre

delivery suite - southmead hospital

Devizes Neighbourhood Team

Dilke community hospital

district nurses locking hill surgery

District Nursing

Dorchester Cancer Centre, Poole

dune ward

Eastwood park prison

Elite Sporting College

ELIZABETH CASSON HOUSE 
Elm tree farm training resource centre Emersons Green

Endoscopy, Cheltenham General

Hospital

Eye Hospital

Filton Clinic

FOREST WARD SWICC SWINDON

Frenchay

Frenchay

Frenchay

Frenchay

Frenchay Brain Injury Unit

Frenchay Hospital

Frenchay hospital

Frenchay Hospital

Frenchay Hospital

Frenchay Hospital

Frenchay Hospital

Frenchay Hospital

Frenchay Hospital

Frenchay Hospital

Frenchay Hospital, Intensive Care

Frenchay ITU

Frenchay ward 202- orthopaedic

trauma

Frenchay/Southmead Rotation

frome community hospital

Fromeside

Fromeside

Fromeside Medium Secure Unit

Fromeside, Blackberry Hill

Gloucester hospital - children's centre

Gloucester Rd Medical Centre

gloucester royal

gloucester royal

Gloucester Royal

Gloucester Royal

Gloucester Royal Hospital

Gloucester royal hospital

Gloucester Social Services

Gloucester, Stroke Ward

Gloucestershire Royal Hospital

GP Surgery. Somerset

great western hospital

Great Western Hospital

GREAT WESTERN HOSPITAL

Great Western Hospital, Victoria

Centre

green ark children's centre

$\mathrm{GRH}$

GRH 3A

GWH

Hamdon medical centre, stoke-sub-

hamdon health centre

Health Centre

health centre

health Visiting Stroud

Holly lodge pewsey

Hollybrook, Stroud

hospital

hospital

hospital

Hospital

HOSPITAL

Hospital

hospital

hospital outpatients

INTERMEDIATE CARE -

HAZELBROOK

kingswood health centre

Knightstone Housing Ass

Knowle Clinic

knowle clinic

Lawrence Hill health centre

Longreach Hospital

Lumsden Walker CAMHS Bristol \&

Ashfield YOI Pucklechurch

lydney hospital

Managing memory services

marina healthcare centre portishead

Mental Health Liaison Team, RUH,

Bath

Minchinhampton Surgery

minor inquuries cirencester

$\mathrm{N} / \mathrm{A}$

Newcombe Lodge, Stroud

None

North Bristol Trust Frenchay

north somerset community partnership

Oakwood Children's Centre

only have one placement on the

course - tavistock devon

Painswick District Nursing Team

PMLD School

Poole

Poole

Poole hospital

Primary Mental Health (community)

prospect

queens day unit

Residential Home

Royal Devon and Exeter Hospital

Royal United Hospital Bath

Royal United Hospital Bath

$\mathrm{RUH}$

RUH Bath

Saplings Taunton Somerset

School nurses 
secodary school

Seqol community

Severn Ward, Tewkesbury Hospital

Social Services

Somali Development Group

Somerset County Cricket Club

south bristol community hospital

South Bristol Community Hospital

South Bristol Community Hospital

South Glos City Council

south gloucestershire council

South Gloucestershire Early

Intervention in Psychosis Community

Team

South Petherton Medical Centre

Southmead

Southmead health centre

Southmead Hospital

southmead hospital

southmead hospital

Southmead Hospital

Southmead Hospital, Bristol

Southmead hospital, outpatients dep

Southmead Mendip Ward

Southmead NICU

spire

Spire Hospital

St Martins Hospital, Bath

St Michaels

St michaels
St. Michael's

St. Paul's medical centre

Stirling road health care centre

Storehouse District Nursing

stroud community adult social care

Stroud general hospital

Stroud Maternity Unit

Taunton

TEST

the great western

The Great Western, Swindon

The vale, minor injury unit

Truro Health Park

UHB Bristol royal infirmary

WARD 203 FRENCHAY

ward 31

WARMINSTER HOSPITAL

West Wansdyke Health Visiting Team

based at Paulton Hospital

Weston General Hospital

Weston general hospital

weston general hospital

weston general hospital

Weston HospiceCare

Whitchurch health centre

windmill house, clevedon

Working with NEET young people in

the voluntary sector

Worle Health Centre

yeovil district hospita 


\section{APPENDIX 15}

Qualitative and Quantitative outputs from Surveymonkey

Question 2

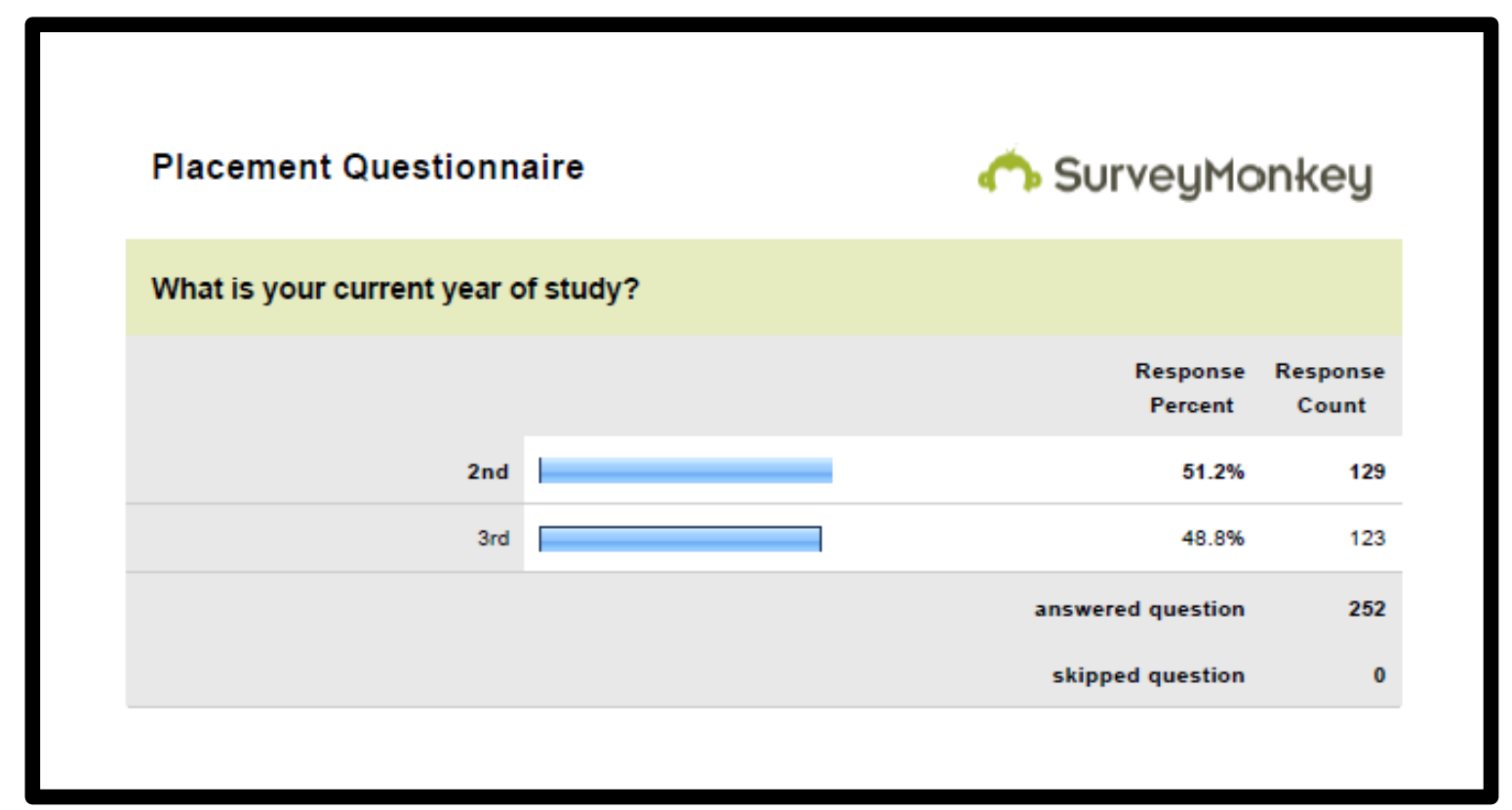


Question 4

Placement Questionnaire

SurveyMonkey

During your placement how frequently did you use the following libraries?

\begin{tabular}{|c|c|c|c|c|c|c|}
\hline & $\begin{array}{c}\text { A few } \\
\text { times a } \\
\text { week }\end{array}$ & Weekly & Monthly & Occasionally & Never & $\begin{array}{l}\text { Rating } \\
\text { Count }\end{array}$ \\
\hline UWE e.g. Glenside, Gloucester & $8.6 \%(21)$ & $17.6 \%(43)$ & $17.6 \%(43)$ & $31.0 \%(76)$ & $25.3 \%(62)$ & 245 \\
\hline NHS library on hospital site & $3.9 \%(9)$ & $11.8 \%(27)$ & $4.4 \%(10)$ & $24.0 \%(55)$ & $\begin{array}{c}55.9 \% \\
(128)\end{array}$ & 229 \\
\hline Other e.g. public & $1.4 \%(3)$ & $5.6 \%(12)$ & $6.1 \%(13)$ & $14.5 \%(31)$ & $\begin{array}{c}72.4 \% \\
(155)\end{array}$ & 214 \\
\hline & & & & \multicolumn{2}{|c|}{ answered question } & 252 \\
\hline & & & & \multicolumn{2}{|c|}{ skipped question } & 0 \\
\hline
\end{tabular}

Question 5

Placement Questionnaire

SurveyMonkey

At your placement venue, which of the following facilities were available for your use?

\begin{tabular}{|c|c|c|c|c|}
\hline & Available & Not available & Don't know & $\begin{array}{l}\text { Rating } \\
\text { Count }\end{array}$ \\
\hline Library / resource centre & $55.8 \%(139)$ & $32.9 \%(82)$ & $11.2 \%(28)$ & 249 \\
\hline Study space & $58.1 \%(143)$ & $32.1 \%(79)$ & $9.8 \%(24)$ & 246 \\
\hline \multirow[t]{3}{*}{ Computer with Internet access } & $78.6 \%(198)$ & $17.5 \%(44)$ & $4.0 \%(10)$ & 252 \\
\hline & & & answered question & 252 \\
\hline & & & skipped question & $\mathbf{0}$ \\
\hline
\end{tabular}


Question 7

Placement Questionnaire

\section{SurveyMonkey}

How important was it for you to access library resources whilst on placement?

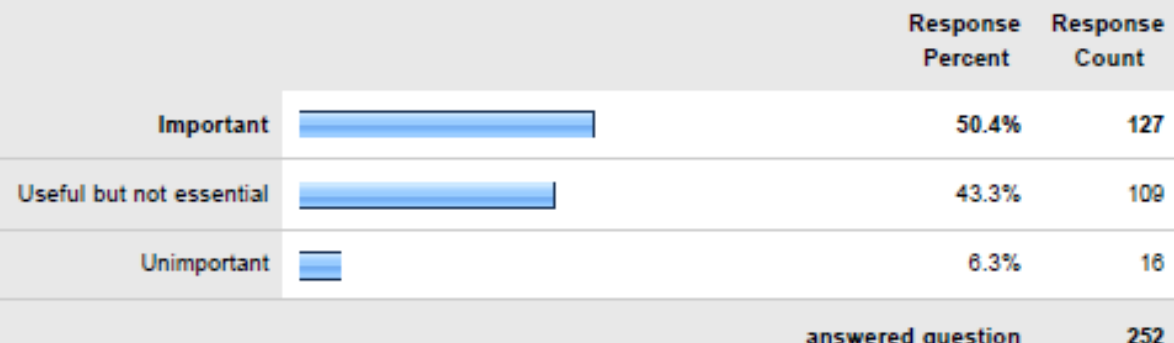

answered question

Question 8

Placement Questionnaire

SurveyMonkey

What was your main reason for using library resources? Please tick one.

\begin{tabular}{rrrr} 
& & & $\begin{array}{r}\text { Response } \\
\text { Percent }\end{array}$ \\
Completing an assignment & $\begin{array}{c}\text { Response } \\
\text { Count }\end{array}$ \\
\cline { 2 - 5 } Studying & & $47.6 \%$ & 120 \\
\hline Professional updating & Z & $16.7 \%$ & 42 \\
\hline To support clinical work & & $2.8 \%$ & 7 \\
\hline
\end{tabular}

Other (please specify) 
Question 9

Placement Questionnaire

Sh SurveyMonkey

Where did you do most of your studying?

Response Response

Percent Count

\begin{tabular}{rrrr} 
UWE library & & $15.1 \%$ & 38 \\
\hline NHS library & & $7.1 \%$ & 18 \\
\hline Other library eg public & 7 & $1.2 \%$ & 3 \\
Home & Other (please specify) & 7
\end{tabular}

answered question

252

skipped question

0 
Question 10

\section{Placement Questionnaire}

\section{SurveyMonkey}

During your placement, from which locations did you access the following library resources? Tick all that apply.

\begin{tabular}{|c|c|c|c|c|}
\hline & UWE & NHS & Home & $\begin{array}{l}\text { Rating } \\
\text { Count }\end{array}$ \\
\hline Printing / photocopying & $35.9 \%(84)$ & $29.5 \%(69)$ & $64.5 \%(151)$ & 234 \\
\hline Books & $69.4 \%(163)$ & $20.4 \%(48)$ & $40.4 \%(95)$ & 235 \\
\hline Joumals & $51.6 \%(113)$ & $21.5 \%(47)$ & $57.1 \%(125)$ & 219 \\
\hline Ebooks & $45.1 \%(102)$ & $8.8 \%(20)$ & $71.2 \%(161)$ & 226 \\
\hline Ejournals & $44.7 \%(102)$ & $12.3 \%(28)$ & $73.2 \%(167)$ & 228 \\
\hline Databases & $45.3 \%(97)$ & $16.4 \%(35)$ & $68.2 \%(146)$ & 214 \\
\hline \multirow[t]{3}{*}{ Websites } & $31.5 \%(74)$ & $28.1 \%(66)$ & $84.7 \%$ (199) & 235 \\
\hline & & & answered question & 252 \\
\hline & & & skipped question & 0 \\
\hline
\end{tabular}

Question 11

Placement Questionnaire

\section{SurveyMonkey}

Do you have access to any of the following at home? Tick all that apply.

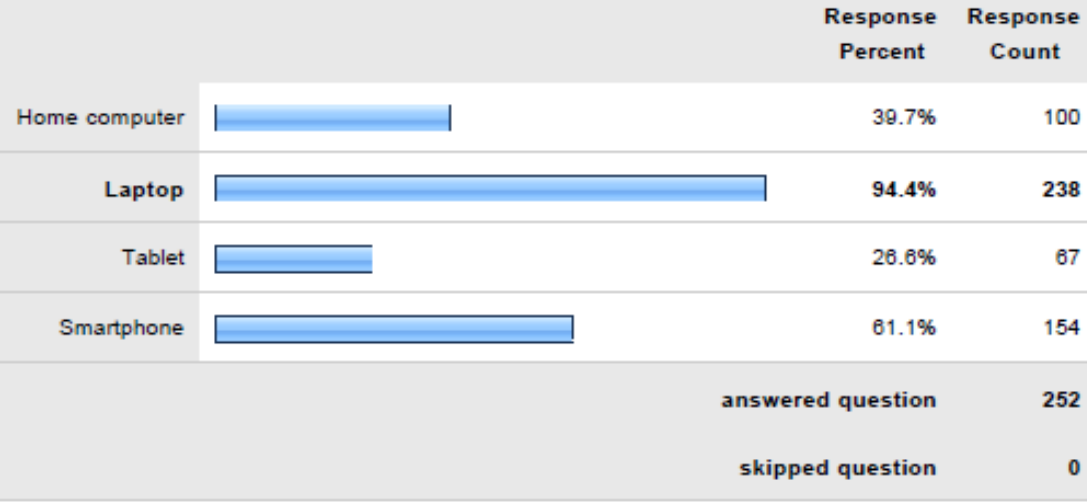


Before going on placement, do you feel you received enough information about how to access library resources from off campus?

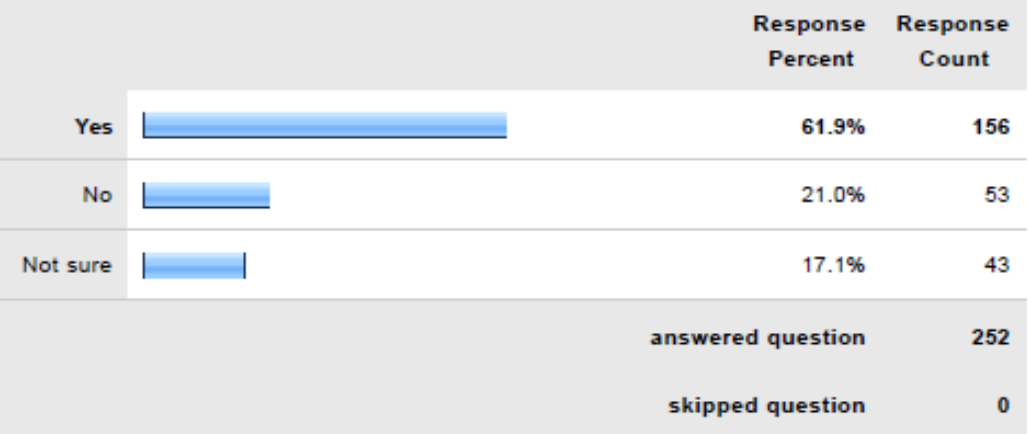

\section{Question 13}

\section{Placement Questionnaire}

\section{SurveyMonkey}

During your placement, how often did you contact any of the following for support in using library resources or facilities? Tick all that apply

\begin{tabular}{|c|c|c|c|c|}
\hline & Often & Sometimes & Never & $\begin{array}{l}\text { Rating } \\
\text { Count }\end{array}$ \\
\hline UWE librarian & $2.8 \%(7)$ & $37.2 \%(92)$ & $59.9 \%(148)$ & 247 \\
\hline NHS librarian & $2.9 \%(7)$ & $15.1 \%(36)$ & $81.9 \%(195)$ & 238 \\
\hline Mentor & $15.6 \%(38)$ & $26.3 \%(64)$ & $58.0 \%(141)$ & 243 \\
\hline Placement facilitator & $4.6 \%(11)$ & $18.9 \%(45)$ & $76.5 \%(182)$ & 238 \\
\hline Academic tutor & $3.3 \%(8)$ & $32.9 \%(79)$ & $63.8 \%(153)$ & 240 \\
\hline UWE IT support staff & $1.7 \%(4)$ & $21.2 \%(51)$ & $77.2 \%(186)$ & 241 \\
\hline Ask a Librarian / Chat & $3.4 \%(8)$ & $24.2 \%(57)$ & $72.5 \%(171)$ & 236 \\
\hline
\end{tabular}




\section{APPENDIX 16}

\section{NHS Librarian responses}

\section{NHS Library staff - research questions about UWE students on placement.}

1 - What types of queries do you receive from UWE students on placement?

How do I join the library?

How can I get hold of this book/article/report?

How do I reference this book, article, etc?

I need articles on a $X$ topic, how do I find them? (Database searching)

How do I log into the computers?

How do I print and what is the cost?

Can I photocopy?

Can I have some training on how to do a literature search?

Can I use the library when I am not on placement?

Can you borrow books from UWE for me?

Can you help me use the UWE resources?

How do I use/access Blackboard?

I need help with formatting my essay/report/dissertation? (tables, margins

etc.)

Difficulties with e-submission

General IT queries

Can I use the library out of hours?

Can you proof read my essay/dissertation etc. for me?

Questions re Athens

What is a primary resource and what is a secondary resource?

Mainly queries from students about how to register and use our library

facilities e.g. printing, inter-library loans etc.

We also get some queries with regard to literature searching, selecting appropriate resources and critical appraisal.

Library membership

Book loans

Access/use of computers

Requests for inter library loans (books \& journal articles)

24 hour access

Athens, book enquiries, subject enquiries, help with literature searching, how to access uwe email.

2 - On average, how many queries a week do you get from UWE students? 
We really could not say as it is not always easy to identify who is a UWE student unless they are in uniform. Very often they are not, especially if they come in for training or are not on placement or if they are a member of staff on a UWE course. If you would like us to do any monitoring activity then let us know.

We don't record this information but would estimate it to be around 5-10 queries per week.

Very few

10

3 - Please estimate how much time (hours/mins) that you spend dealing with queries from UWE students per week?

Again, this information is not recorded. Most enquires are answered within a couple of minutes but if we help someone with a literature search/critical appraisal then we may spend up to an hour with them.

Less than 30 mins

$11 / 2$ hours

4 - What information do NHS libraries offer to assist UWE students on placement?

20 minute Library Induction as part of their placement induction in their $1^{\text {st }}$ year

Student placement guide is also given to them.

We provide

- access to library webpages

- handouts and guides

- training (databases, referencing, evidence based resources, critical appraisal etc.),

- how to set up NHS Athens accounts

enquiry service

inter library loans

- 24 hour access

Photocopying

Printing

Scanning

book loans

support with using UWE Library Search

access to Trust policies

- support with IT

- supporting students when they are stressed

- availability of UWE guides e.g. Harvard Referencing 
- Student information noticeboards

Basically we provide everything we would as if they were a member of staff with the exception of doing a literature search for them, although we do provide database training and will help them with their specific topic.

We give UWE students a guide to our library with contact details and we always stress that they can come to use with any queries (including UWE resources) whilst on placement. We also have a $1 / 2$ slot on the student nurses induction where we tell them about the library and the students complete library registration forms.

We provide a UWE Student Guide to the Library, NHS Athens Guide, online access to e-books and online journals, all User Guides are held at the Library reception and are available electronically via the Intranet. The library homepage can be accessed via the Intranet \& Internet, similarly the SWIMS catalogue

Half hour induction slot on pre -placement day for student nurses which includes demonstrations of how to access $E$ resources.

Subject guides.

1 to 1 training.

They are also welcome to attend trust staff search skills training sessions which some do take up.

At Callington Road Hospital a weekly student support group is held which a librarian attends from time to time.

5 - If you are asked a question about UWE resources, which mechanisms do you use to resolve the query i.e. UWE CHAT, UWE Library webpages, NHS Liaison and Placement Support Librarian?

UWE single search

UWE web pages especially referencing

Ask NHS colleagues

Occasionally contact Placement Support Librarian, suggested students contact PSL, but they are reluctant

Suggested students contact UWE IT support, again they are reluctant

If a student has a question about how to use a specific UWE resource very often we are able to help. On the odd occasion that we are not able to help we would refer students back to the UWE library service.

Not asked but would refer them to the UWE Library website

Webpages and UWE CHAT 
6 - Do you think that you would benefit from more training on UWE library resources in order to help you support our students?

Possibly

No

Students deal with UWE library resources themselves but it would help if Trust Library staff had usernames \& passwords to access the site, so that if the students needed help, we would be more familiar with it's content

Yes - we would like to shadow a UWE librarian for a day (for example).

7 - Research has shown that students can have problems using and accessing library/learning resources on placement. Are you aware of any difficulties UWE students have?

Finding time to access the resources/computers

Sometimes they want us to do the work/searching for them, we provide support and lots of help so they continue to learn and hopefully become more self sufficient

They have problems when they cannot access e-journals - they think everything should be available

Using the native interfaces e.g. BNI, CINAHL etc., they find it confusing that each database looks different

The students who use our library seemed to be pleasantly surprised that we have resources specially aimed at them.

Students often comment that it is difficult to get to the UWE library, especially if they are working full time or are on placement in the city centre. I have also heard students comment that some of the loan times for UWE books are too short as it doesn't give them chance to read the book.

UWE students on placement have Trust logins to access computers using a username and password. Students are offered guest passwords if they do not have a Trust login. The library resources are on the Intranet \& Internet. We also provide Wi-Fi vouchers for one or five days.

Yes - students sometimes have difficulty because they don't have much time to devote to library resources. They need to improve literature search skills, are confused about Athens access - national/ local access, Athens while on placement.

Confusion over UWE single search.

Occasionally we have had experience of helping with literacy needs.

8 - In your opinion, what, if anything, needs improvement?

To find out about the students who we don't see and how to engage with them More training for students on UWE resources and more tailored support. 
None.

Prior to placement the university needs to ensure that students are aware of the Trust Library and its location and the services it provides to support students on placement

Trust Libraries need to be sure what services the students require from them on placement

Core reading textbooks (print) - not enough available.

More encouragement of students to use NHS libraries whilst on placement from UWE and NHS.

Encourage students to adopt a professional approach and respectful relationship whilst on placement.

9 - Are there any other comments or issues you would like to raise regarding students use of NHS library/learning resources whilst on placement?

They are distance learners and as well as online resources it is inevitable that they will need face to face support.

The more UWE librarian and NHS librarians know about each other's resources the better it will be for the students

Students often do not want to use UWE for ILLs, sometimes if this is suggested they would rather go without the resource

It would be very helpful if we could be provided with numbers, names and contact details of students who are on placement within the hospital.

We currently have a slot on the student nurses induction but do not provide library inductions for any other groups of UWE students.

If we had this information we may be able to adapt our service to better meet the needs of the students on placement.

The Library no longer has a slot at the UWE Student Induction at the start of their placement with the Trust 


\section{APPENDIX 17}

\section{Visiting and using other libraries while at UWE}

\section{Visiting other libraries}

Access arrangements to public and university libraries vary, and you are advised to check in advance of your visit.

\section{Search other library catalogues}

Almost all public and university libraries have a free-to-search catalogue. UWE library has compiled a list of recommended library catalogues.

\section{Other university libraries}

UWE students and staff can access most other UK university libraries through the SCONUL Access Scheme.

To join this scheme, you will need to apply onlinebefore visiting the library you wish to join. You will need to be in good standing with UWE Library at the time of your applicaton with no overdue books or fines.

\section{Eduroam}

UWE participates in the Eduroam service, so staff and students from UWE visiting other universities can access their wireless internet.

\section{NHS libraries}

Health and Social Care (HSC) students are eligible for full access to NHS libraries (including access to electronic resources through NHS Athens) if they are on an NHS commissioned education programme which involves practice and placement within NHS services.

To apply for library membership, contact the appropriate library. These include:

- $\quad$ Academy Library, Royal United Hospital, Bath. This library has UWE-networked PCs and printers

\section{O UWE guide to RUH Academy Library}

- Academy Library and Information Service (ALIS), Great Western Hospital (GWH), Swindon 
- $\quad$ ggether NHS Foundation Trust for Gloucestershire

(Wotton Lawn Library)

- Gloucestershire Hospitals NHS Foundation Trust Libraries

- $\quad$ North Bristol NHS Trust Libraries (Frenchay and Southmead)

- University Hospitals Bristol NHS Foundation Trust

\section{NHS Athens}

If you are an eligible HSC student, you will automatically receive a registration e-mail giving you your NHS Athens username and password to enable access to electronic databases and other resources used within the NHS.

For more information please refer to the logging in to databases via NHS Athens:

FAQS.

(You can also continue to use all UWE electronic resources whilst on placement using the NHS Academies - External Access service.)

\section{British Library (London)}

The British Library in London is a research Library, not a public reference library.

Admission is by reader's pass and access is only granted to those who can demonstrate that they need to consult material not available elsewhere. Registering for a BL Reader Pass. 


\section{APPENDIX 18}

Tweets to advertise survey

\begin{tabular}{|l|l|}
\hline UWE Glenside Library @uwelibglen \\
Anyone made use of technology or social media to support \\
students on placement e.g. mobile devices, apps, FB, Skype, etc? \\
Expand \\
\hline $\begin{array}{l}\text { UWE Glenside Library @uwelibglen } \\
\text { Level } 2 \text { or } 3 \text { HSC undergrad on placement? £30 prize up for } \\
\text { grabs: surveymonkey.com/S/P6DFKH5 } \\
\text { Expand }\end{array}$ \\
\hline
\end{tabular}




\section{JISC Mail Posting}

\section{APPENDIX 19}

UWE (Bristol) is currently reviewing the way Library Services support Health and Social Care (HSC) students on placement. Due to changes such as more varied placement locations and the increased use of electronic support services and resources, we plan to develop a new service which will better meet the library and information needs of our placement students.

We have obtained some funding from the HEA to carry out some primary research, but we would also love to hear from other academic libraries to find out what you do. We are particularly interested in any technological developments you may have implemented.

1. Do have a specific person who supports students on placement and/or liaises with NHS? What information do you give to students before they go out on placement?

2. What specific support do you offer students whilst on placement? (over and above placement loans or postal loans)

3. Have you made use of new technologies to support students on placement e.g. mobile devices, ipads, mobile apps, Skype, SMS messaging, etc.

4. Do you use social media for this purpose and if so, how? 